Volume 13 - Issue 1 January 2022

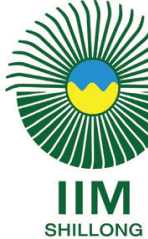

ims.spectrumjps.com

IIMS

JOURNAL OF

MANAGEMENT

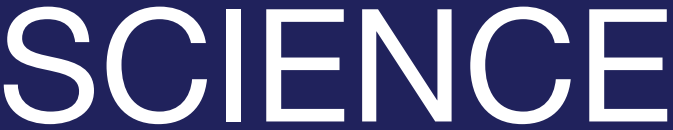

Special Section: Management in Response to COVID-19 Pandemic and Global Crisis Special Section Editor: Mousumi Bhattacharya

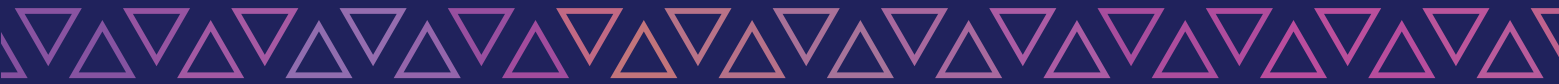
$7 \Delta \nabla \Delta \nabla \nabla \Delta \nabla \Delta \nabla \wedge \nabla \Delta \nabla \Delta \nabla \Delta \nabla \Delta \nabla \Delta \nabla \Delta \nabla \Delta \nabla \Delta \nabla$ $\nabla \wedge \nabla \wedge \nabla \Delta \nabla \Delta \nabla \Delta \nabla \Delta \nabla \Delta \nabla \Delta \nabla \Delta \nabla \Delta \nabla \Delta \nabla \Delta \nabla \wedge \nabla \wedge$

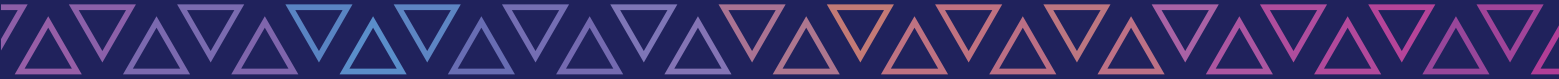
$\nabla \wedge \nabla \wedge \nabla \wedge \nabla \wedge \nabla \wedge \nabla \wedge \nabla \wedge \nabla \wedge \nabla \wedge \nabla \Delta \nabla \wedge \nabla \wedge \nabla \wedge \nabla \wedge$ $7 \wedge \nabla \wedge \nabla \Delta \nabla \Delta \nabla \wedge \nabla \wedge \nabla \wedge \nabla \wedge \nabla \wedge \nabla \Delta \nabla \Delta \nabla \wedge \nabla \wedge \nabla \Delta \nabla$ $\Delta \Delta \nabla \Delta \nabla \Delta \nabla \Delta \nabla \Delta \nabla \Delta \nabla \wedge \nabla \Delta \nabla \Delta \nabla \wedge \nabla \Delta \nabla \Delta \nabla \Delta \nabla \wedge$ $7 \Delta \nabla \Delta \nabla \Delta \nabla \Delta \nabla \Delta \nabla \Delta \nabla \Delta \nabla \Delta \nabla \Delta \nabla \Delta \nabla \Delta \nabla \Delta \nabla \Delta \nabla \Delta \nabla$ $\Delta \Delta \nabla \Delta \nabla \wedge \nabla \wedge \nabla \Delta \nabla \wedge \nabla \wedge \nabla \Delta \nabla \Delta \nabla \wedge \nabla \Delta \nabla \Delta \nabla \Delta \nabla \wedge$ $7 \Delta \nabla \Delta \nabla \Delta \nabla \Delta \nabla \Delta \nabla \Delta \nabla \Delta \nabla \Delta \nabla \Delta \nabla \Delta \nabla \Delta \nabla \Delta \nabla \wedge \nabla \Delta \nabla$ 
IIMS Journal of Management Science is published biannually in January and July by Indian Institute of Management Shillong.

Manuscripts must be submitted via email to journal@iimshillong.ac.in. Manuscripts should be prepared in accordance with the 7th edition of the Publication Manual of the American Psychological Association.

Copyright (C) 2022 Indian Institute of Management Shillong. All rights reserved. The views expressed in the articles and other material published in IIMS Journal of Management Science do not reflect the opinions of the Institute.

Annual Subscription: Individual rate (print only) ₹1,580; institutional rate (print only) ₹2,760. For orders from Pakistan, Bangladesh, Sri Lanka and Maldives, SAARC rates apply: individuals $\$ 35$; institutional rate $\$ 50$. Prices include postage. Print subscriptions are available for institutions at a discounted rate. For subscriptions, please write to: customerservicejournals@ sagepub.in

Change of Address: Four weeks' advance notice must be given when notifying change of address. Please send the old address label to ensure proper identification. Please specify the name of the journal and send change of address notification to customerservicejournals@ sagepub.in

Printed and published by Chief Administrative Officer, IIM Shillong, on behalf of Indian Institute of Management Shillong at Indian Institute of Management Shillong, Umsawli, Shillong 793018, East Khasi Hills District, Meghalaya, India. Printed at Sai Printo Pack Pvt Ltd, A 102/4 Phase II, Okhla Industrial Area, New Delhi, Delhi 110020.

Editor: Mousumi Bhattacharya 


\section{About the Journal}

IIMS Journal of Management Science is the scholarly journal of the Indian Institute of Management Shillong that publishes research contributions in all areas of management and its allied discipline since 2010. It follows a double blind peerreview process and publishes two issues a year. While submissions from all management domains and their allied disciplines are welcome, the journal encourages articles on cross-functional management domains with crossfunctional managerial or societal problems and implications.

The journal looks for original and insightful research articles that create differential research traditions to shed new evidence on contemporary challenges faced by management practitioners, policymakers, academicians, and others. The journal envisages publishing rigorous research output backed by qualitative or quantitative methods. The articles that establish the intuition, argument, and implications using clear and concise English and improve our understanding of the management theory and practice knowledge are preferred. All contributions should be well written in English and supported by either original/empirical data or a well-justified theoretical or mathematical model.

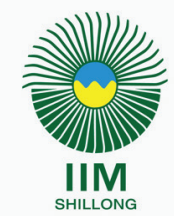




\section{Aims and Scope}

IIMS Journal of Management Science publishes original research and review articles that demonstrate theoretical and empirical research in management discipline through qualitative or quantitative methods. It follows a double-blind peer review policy.

The articles in all domains in management and its allied discipline, including but not limited to, Accounting, Analytics, Banking, Communications, Economics, Finance, Industrial-relations, Information Systems, Marketing, Operations and Supply Chain Management, Organisational Behaviour, Organisational Development, Human Resources Management, Strategy, Sustainability and Liberal Studies, Innovation, Entrepreneurship, Public Policy, and others are welcome.

Contributions with a rigorous analysis of economic, social, political, sustainability, and other factors relevant to management theory, practice, or policy are well received. Consistent with the journal policy, the journal invites articles on cross-functional research that provides new evidence on contemporary challenges faced by management practitioners, firms, societies, policymakers, academicians, and others. 


\section{Editor-in-Chief}

Mousumi Bhattacharya

IIM Shillong, Meghalaya, India

\section{Editorial Team}

\section{Ridhi Arora}

IIM Shillong, Meghalaya, India

Bidyut Jyoti Gogoi

IIM Shillong, Meghalaya, India

\section{Sanjita Jaipuria}

IIM Shillong, Meghalaya, India

\section{Gurpreet Kaur}

IIM Shillong, Meghalaya, India

\section{Debasisha Mishra}

IIM Shillong, Meghalaya, India

\section{Neelam Rani}

IIM Shillong, Meghalaya, India

\section{Advisory Board}

\section{Phani Tej Adidam}

University for Nebraska, Omaha, USA

\section{Harjeet S. Bhabra}

Concordia University, Montreal, Canada

\section{Robert Clift}

University of Pittsburgh, Pittsburgh, PA, USA

D. P. Goyal

IIM Shillong, Meghalaya, India

\section{Angappa Gunasekaran}

California State University, Bakersfield, USA

Mahesh Joshi

RMIT University, Melbourne, Australia 


\section{Madhu Kalimipalli}

Wilfrid Laurier University, Waterloo, Canada

\section{W. Jean Kwon}

St. John's University, USA

\section{Anil Mishra}

Western Sydney University, Sydney, Australia

\section{Prashant Mishra}

Indian Institute of Management Calcutta, Kolkata, India

\section{Jatin Pancholi}

Southampton Business School, University of Southampton, Southampton, UK

\section{Richard Ponarul}

California State University, California, USA

\section{Nripendra P. Rana}

School of Management, University of Bradford, UK

\section{Rakesh Sah}

Montana State University, Bozeman, MT, USA

\section{Paul Shrivastava}

Pennsylvania State University, State College, Pennsylvania, USA

\section{Satyendra Singh}

University of Winnipeg, Winnipeg, Canada

\section{S. K. Sinha}

IIM Ahmedabad, Gujarat, India

\section{Mohan Thite}

Griffith Business School, Nathan, Australia

\section{Sorin Tuluca}

Fairleigh Dickinson University, Teaneck, NJ, USA

\section{S.Viswanathan}

Nanyang Business School, Singapore 


\section{Contents}

Special Section: Management in Response to COVID- 19 Pandemic and Global Crisis

Special Section Editor: Mousumi Bhattacharya

\section{Introduction to the Special Section}

Management in Response to COVID-19 Pandemic and Global Crisis

Mousumi Bhattacharya

\section{Special Section Articles}

Lockdown Stringency and an Assessment of the Trajectory of COVID- 19 Pandemic in India

Padma Suresh Mandala

Impact of Virtual Try-On Technology on Customer's Mental Imagery During COVID- 19

Vijay Rathee and Sarita Kumari

Understanding Consumer Perception Toward Usage of Music Apps During COVID-19: A Study in West Bengal State

Samuel S. Mitra, A. Peter Arockiam, K. Joseph, Milton Costa and Payal Sharma

Effect of Communication Strategies for Implementation of IT-based Educational Innovation During COVID-19 Pandemic on Students' Motivation, Attitude, and Intent

Irum Alvi

Change in Consumer Behavior Due to Covid Crisis: An Exploratory Study Vikas Kumar Tyagi, Vikas Nain, Akhilesh Mishra and Saurabh Garg 


\section{Articles}

Are Fama-French Factors Relevant? A Sub-Sectorial Analysis

Vanita Tripathi, Ritu Sapra and Rishabh Gupta

Exploring the Influence of Emotional Intelligence on the Academic Performance of MBA Students

Abhishek Venkteshwar and Uma Warrier

\section{Book Review}

Ace V. Simpson, Leadership Lessons from the Bhagavad Gita

Sanjoy Mukherjee 


\section{Management in Response to COVID- 9 Pandemic and Global Crisis}

IIMS Journal of Management Science I3(I) 7-8, 2022

(C) The Author(s) 2022 DOI: $10.1177 / 0976030 \times 211066885$ ims.spectrumjps.com

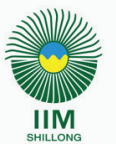

Due to its extensive impact, COVID-19 is expected to change the world of contemporary management functions, in terms of evolving thought and practices, both during the pandemic and in the future. The pandemic challenged the way we understand the role of society, government, and business across the globe. In this issue, a section has been dedicated to the special issue on management in response to the COVID-19 pandemic and Global Crisis.

In "Lockdown Stringency and an Assessment of the Trajectory of COVID-19 Pandemic in India," the author assesses how lockdown policies and stringency affected the spread of the pandemic in India. The author builds a composite measure of the pandemic to assess its correlation with the stringency index and identifies four phases in the trajectory of the pandemic. The author supports localized stringency measures rather than national level lockdowns to balance health and economy.

In "Impact of Virtual Try-on Technology on Customer's Mental Imagery During COVID-19," authors provide an insight about the mental imagery of customers towards the new developing technology virtual try-on. Using primary data, the authors show that virtual try-on technology positively influences vividness, quantity, and elaboration - the dimensions of mental imagery.

In "Understanding Consumer Perception Towards Usage of Music Apps During COVID-19: A Study in West Bengal State," the authors examine and analyze the attitudes and behavior of the consumers towards use of music apps in selected districts of West Bengal on the basis of "Technology Acceptance Model" (TAM). The authors conclude that consumers of West Bengal have positive perception towards music apps.

In "Effect of Communication Strategies for Implementation of IT-based Educational Innovation During COVID-19 Pandemic on Students' Motivation, Attitude, and Intent," the author measures the effect of rational persuasive strategy (utilizing legitimate contentions), assertive strategy (utilizing intimidation), consulting strategy (engaging in the act of giving expert advice), and inspirational (evoking feelings of appreciation) strategy for implementing IT-based educational innovations. The findings using PLS-SEM indicated strategies except assertive strategy have a positive and significant effect on student's motivation, attitude, and intent.

In "Change in Consumer Behaviour Due to COVID Crisis: An Exploratory Study," authors explore the consumer behavior (purchase pattern, volume, and frequency) and household expenditure alteration due to the COVID crisis using a 
mixed-method approach. They observed the changes in the purchase behavior, habits, and patterns due to COVID pandemic and noted that the such changes are more prominent in service industry compared to products.

I would like to take this opportunity to thank the members of the advisory and editorial board for their support and encouragement. I express my gratitude to all the anonymous reviewers who devoted much of their precious time reviewing all the papers submitted to this issue. I also thank all authors who contributed to this special issue. I hope you will enjoy reading the issue and find it informative and helpful.

Mousumi Bhattacharya, Editor-in-Chief IIM Shillong, Meghalaya, India Email:msb@iimshillong.ac.in 


\title{
Lockdown Stringency and an Assessment of the Trajectory of COVID-I 9 Pandemic in India*
}

IIMS Journal of Management Science I3(I) 9-26, 2022 (C) The Author(s) 2022 DOI: $10.1177 / 0976030 \times 211051064$ ims.spectrumjps.com

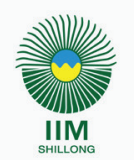

\section{Padma Suresh Mandala'}

\begin{abstract}
Since COVID-19 was declared a pandemic in March 2020, countries across the world have imposed lockdowns to curtail transmission of the disease.The objective of the present article is to use statistical tools to assess how lockdown policies and stringency affected the spread of the pandemic in India. The method of principal component analysis is used for dimensionality reduction and to track the trajectory of the pandemic in the two-dimensional space. The analysis identifies four phases in the trajectory of the pandemic. A composite measure of the pandemic is constructed to see how it correlates with the stringency index. While results show a negative and statistically significant relationship between the composite index of the pandemic and the stringency index over the entire period of the study, the phase-wise analysis gives useful insights. In particular, the phase in which the pandemic index declined even as stringency index declined and the phase of sudden onset of second wave with a consequent increase in stringency measures indicate the need for policies for better management of the pandemic. Tracking new epidemiological variants of the virus and geographically localized stringency measures rather than national level lockdowns are possible ways to balance health and economy.
\end{abstract}

\section{Keywords}

Health, economy, lockdown, composite pandemic index, principal component analysis

JEL Classification: | I5, II 8

\footnotetext{
* STATA I 3.0 was used for performing PCA and obtaining the rotated components and KMO statistic. For all other statistical analysis and figures, GRETL $202 \mathrm{lb}$ package was used.

' Department of Economics, Sri Venkateswara College, University of Delhi, New Delhi, India

Corresponding Author:

Padma Suresh Mandala, Department of Economics, SriVenkateswara College, University of Delhi, New Delhi II002I, India.

E-mail: padmasuresh@svc.ac.in
} 


\section{Introduction}

On March 11, 2020, the World Health Organization (WHO) declared COVID-19 to be a pandemic (WHO, 2020). Since then, the pandemic has spread worldwide disrupting economies and society. In order to control the spread of the virus, countries have imposed lockdowns that have restricted economic and social activities and movement of people. There is considerable divergence across countries in terms of the intensity and timing of stringency measures. For example, Sweden had a relaxed approach to stringency with minimal economic and social restrictions (Ferraresi et al., 2020a) while many other countries including India imposed a stringent lockdown early on in the pandemic. While lockdowns and stringency measures are intended to save lives by minimizing contact, these measures have a considerably harsh effect on the economy and livelihoods of people. One of the challenges of the COVID-19 pandemic has been to find ways to save lives and livelihoods. The question of how stringency measures affect the trajectory of the pandemic is therefore of interest.

The literature over the last year has investigated various aspects of the relation between lockdown stringency and the trajectory of the pandemic as well as its impact on the economy. Studies have examined determinants of stringency measures identifying variables such as political stability, level of development, and degree of decentralization (Ferraresi et al., 2020a). Other studies have examined the impact of alternative reopening strategies on economic recovery (Demirguc-Kunt et al., 2020). The issue of whether lockdown measures can contain the spread of the virus (Askitas et al., 2020; Mitra et al., 2020) and the degree to which they are effective have also been studied (Ferraresi et al., 2020b; Thayer et al., 2021). The objective of this article is to track the trajectory of the pandemic in India in the two-dimensional space, obtain a composite index of the pandemic and examine its relation to the stringency index.

A national-level lockdown was imposed in India on March 25, 2020. On the eve of the lockdown, India had 536 coronavirus cases and 10 deaths due to the disease. The Oxford COVID-19 Government Response Tracker (Hale et al., 2020) which calculates the Stringency Index, rated the lockdown as being the most stringent among countries and gave it a rating of 100 on 100 . The initial period of the lockdown was for 21 days which was extended in three phases until May 31, 2020. During this period, the relative spread of coronavirus was contained, but as restrictions began to be eased from June 2020 when the unlock phase began, the disease spread rapidly. By mid-September 2020, India had reached the peak of the first wave with nearly 100,000 new coronavirus cases daily and over 1,000 daily deaths. Subsequently, even as unlock measures continued, cases went down and by mid-February 2021, daily new cases were less than 10,000 and daily deaths were less than 100. But from mid-February 2021, a slow increase in cases was observed that ultimately led to an intense second wave of the pandemic in April 2021 with nearly 400,000 daily cases in April-May and over 3,000 daily deaths.

To examine the relationship between lockdown stringency and the trajectory of the pandemic in India, data on daily observations from March 25, 2020, to May 15,2021 , on six dimensions of the COVID-19 pandemic in India are obtained 
from Worldometer (Worldometers.info ${ }^{1}$ ). For the corresponding period, daily observations on the stringency index are obtained from the Oxford COVID-19 Government Response Tracker (Hale et al., 2020). Using the method of principal component analysis (PCA) for dimensionality reduction, we are able to construct a composite measure of the pandemic. The graphical representation of the score plot in the two-dimensional space enables us to clearly identify four phases in the trajectory of the pandemic. Correlations between the stringency index and the pandemic index are obtained corresponding to the grouping of observations of the trajectory into four phases. While a negative and statistically significant relationship is established between the pandemic index and the stringency index for the entire period of the study, the phase-wise analysis enables us to better understand the relation between the pandemic trajectory and stringency measures. In particular, the decline in the pandemic index even as the stringency index declined in the third phase and the sudden onset of the second wave with a sharp rise in the pandemic index and the corresponding rise in the stringency index in the fourth phase offer insights into managing the future trajectory of the pandemic as well as design of appropriate stringency measures. The understanding gained from the experience of the first two waves of the pandemic is crucial to the design of policies for containment and management of the pandemic. Tracking new epidemiological variants of the virus for their transmissibility has a vital role to play in managing the future trajectory of the pandemic while stringency measures imposed at a geographically localized level rather than a national level may be a more feasible way to balance lives and livelihoods.

The article is organized as follows. The second section contains a description of the data and methodology. In the third section, we discuss the results while section four presents an analytical discussion. The fifth section summarizes and concludes.

\section{Material and Method}

\section{Data}

During the course of the COVID-19 pandemic, data on different dimensions of the pandemic such as total number of cases, daily new cases, daily deaths, and positivity rate have been closely examined to get an understanding of the magnitude and scale of the pandemic. Some of these data relate to cumulative numbers while others are daily figures giving the changes in the scale of the pandemic from day to day. Given that these dimensions reveal different facets of the pandemic, one of the objectives of the study has been to use statistical techniques for dimensionality reduction using the data that are available on the many dimensions of the pandemic. The study is based on daily data from March 25, 2020, to May 15, 2021, on six such dimensions relating to the pandemic, that is, total number of coronavirus cases (total cv cases), total number of deaths (total cv deaths), active cases, daily new cases, daily deaths and daily recovered that are available from Worldometer website (Worldometers.info ${ }^{1}$ ). Data on stringency are obtained from the Oxford COVID-19 Government Response Tracker's Stringency Index (Hale et al., 2020). 


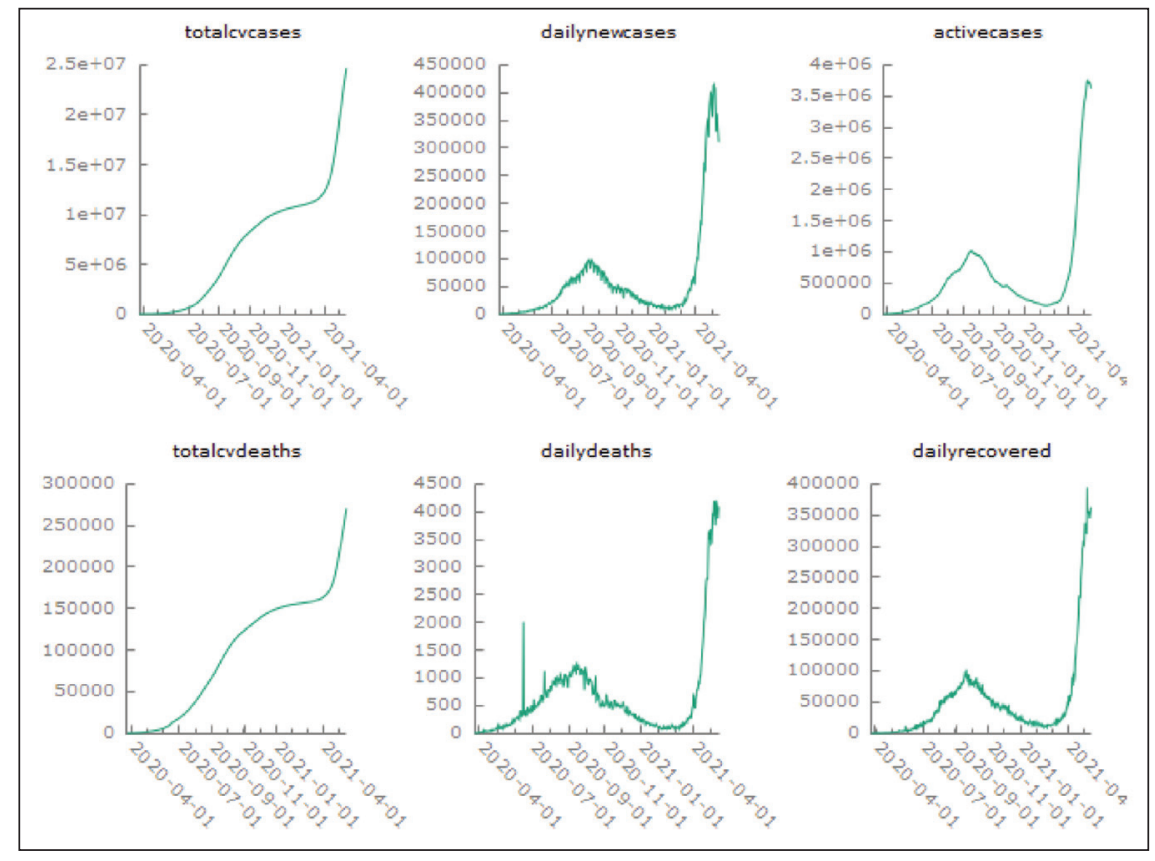

Figure I. Time Series Plot of Variables Using Observations from March 25, 2020, to May 15, 2021

Source: Authors' own (based on data obtained from Worldometer; Worldometers.info').

The time series plot of the variables is given in Figure 1. Total coronavirus cases and total deaths are cumulative figures and show an increase although the rate of increase slowed down after mid-September. The remaining four variables show a peak in mid-September and thereafter a decline. All the curves show a sharp vertical spike in April 2021 in the second wave of the pandemic. Due to misreporting and delays in reporting, estimates are sometimes revised when data are made available, leading to bunching of numbers that can be seen as outliers in the plot of variables in the data set.

\section{Principal Component Analysis}

PCA and factor analysis are multivariate statistical techniques that are used for the purpose of reducing dimensionality of a set of observed variables. However, the two techniques differ from each other in many ways and one of the main differences is that while factor analysis is based on an explicit model, PCA makes no such assumption (Jolliffe, 2002). The basic idea underlying the model in factor analysis is that there are latent factors or unobservable factors underlying the observed variables in the data set. In factor analysis, the model seeks to express the set of observed variables in terms of a smaller set of hypothetical variables that are called latent constructs or factors. The choice between the two techniques depends primarily on the purpose of the study. While both techniques are based on the correlations among the observed variables for dimensionality reduction, factor 
analysis is an appropriate technique if the aim is to specify a model in order to obtain latent constructs or factors that may be accounting for the variation in observed variables. But if the aim of the study is to reduce the set of correlated observed variables into a smaller set of dimensions with a minimum loss of information, then PCA is an appropriate technique. In this study, we use PCA since the objective is to reduce dimensionality to track the trajectory of the pandemic in a smaller subspace while accounting for as much of the variance in the data on the six dimensions relating to the spread of coronavirus.

If a data set has many dimensions, then PCA can be used to compress data into a smaller number of dimensions while retaining as much statistical information as possible (Anderson, 1958). This is done by obtaining summary measures called "principal components" which are linear combinations of the observed variables (Jolliffe, 2002; Jolliffe \& Cadima, 2016). These principal components (PCs) are ordered in terms of their variance and they are uncorrelated with each other.

Suppose the data set consists of $n$ observations on $p$ variables, $X_{1}, X_{2}, \ldots X_{p}$. The principal components are obtained as exact linear combinations of the observed variables as given in Equation (1).

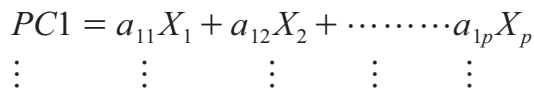

$$
\begin{aligned}
& P C p=a_{p 1} X_{1}+a_{p 2} X_{2}+\cdots \cdots \cdots a_{p p} X_{p}
\end{aligned}
$$

The linear combinations PC1, PC2, .. PCp are called the principal components. The $a_{i j}$ 's in Equation (1) represent the weights in the linear combinations of the variables and are given by the eigenvectors of the covariance matrix. Obtaining the linear combinations or principal components thus involves solving an eigenproblem for the covariance matrix of the data set. The covariance matrix for the data which are a $p \times p$ symmetric matrix has exactly $p$ real eigenvalues $\lambda_{1}, \lambda_{2}$, $\ldots \lambda_{p}$ and the corresponding eigenvectors form an orthonormal set of vectors. The eigenvalues $\lambda_{1}, \lambda_{2}, \ldots \lambda_{p}$ are sorted from largest to smallest and the corresponding eigenvectors sorted accordingly. The principal components are ordered so that the first principal component has largest variance given by the largest eigenvalue followed by the second principal component with the second largest eigenvalue and so on. The principal components successively maximize variance and have the property that they are uncorrelated with each other. The elements of the eigenvector are called loadings and represent the contribution made by each variable to a particular component.

The principal component scores are the values taken by each observation for any given principal component. The trace of the covariance matrix gives the sum of the variances of the $p$ variables in the data set. This equals the sum of the variances of all $p$ principal components $\sum_{j=1}^{p} \lambda_{j}$. The proportion of variance explained by the $j$ th PC is thus given by $\lambda_{j} / \sum_{j=1}^{p} \lambda_{j}$.

If the variables are standardized so that they have zero mean and unit variance, then the covariance matrix of the standardized variables is the correlation matrix of the original variables. The coefficients of the linear combinations are given by 
the eigenvectors of the correlation matrix. The trace of the correlation matrix equals the number of variables $p$ in the data set. For a correlation matrix PCA, the sum of the variances of all $p$ principal components equals $p$, that is, $\sum_{j=1}^{p} \lambda_{j}=p$ and the proportion of variance explained by $j$ th $\mathrm{PC}$ is $\lambda_{j} / p$.

If the original variables are highly correlated then PCA can be used successfully for dimensionality reduction. The decision on the number of principal components to be retained without an unacceptable loss of information is a subjective decision (Rea \& Rea, 2016). In general, the rule of thumb is to retain those components which cumulatively account for say $70 \%$ or $90 \%$ of the variation. Other methods include using a Scree plot (Cattell, 1966) which is a line graph that plots the eigenvalue of each component against the component. A steep fall in eigenvalue of a component that gives the graph an "elbow" shape is used to decide on the number of components to be retained. In correlation matrix PCA, the Kaiser rule is to retain only PCs that have an eigenvalue greater than one (Kaiser, 1960).

Many studies have used epidemiological and econometric models of the pandemic (Thayer et al., 2021; Thompson, 2020). The method of PCA can also be used to track the spread of COVID-19 disease (Mahmoudi et al., 2021). By tracking the relative clustering and spread of observations in a lower dimensional space, we can evaluate how the pandemic progressed in the different phases of lockdown and unlock in the economy during the last year.

\section{Results}

\section{Trajectory of the Pandemic in the Different Phases of Lockdown and Unlock}

Before performing PCA we did a preliminary examination of the data set and some tests to check the suitability of the variables for PCA. The Pearson's correlation coefficients between the six variables are given in Table 1. All the coefficients are high and statistically significant.

To check suitability of the data set for application of PCA, two tests were performed. The Kaiser-Meyer-Olkin (KMO) test is used to check whether

Table I. Correlation Coefficients Between Variables Using Observations from March 25, 2020, to May I5, 202I

\begin{tabular}{lcccccl}
\hline $\begin{array}{l}\text { Total cv } \\
\text { Cases }\end{array}$ & $\begin{array}{c}\text { Daily New } \\
\text { Cases }\end{array}$ & $\begin{array}{c}\text { Active } \\
\text { Cases }\end{array}$ & $\begin{array}{c}\text { Total cv } \\
\text { Deaths }\end{array}$ & $\begin{array}{c}\text { Daily } \\
\text { Deaths }\end{array}$ & $\begin{array}{c}\text { Daily } \\
\text { Recovered }\end{array}$ & \\
\hline 1.0000 & 0.6584 & 0.6595 & 0.9837 & $0.551 \mathrm{I}$ & 0.6649 & Total cv cases \\
& 1.0000 & 0.9810 & 0.5483 & 0.9468 & 0.9595 & Daily new cases \\
& & 1.0000 & 0.5553 & 0.9762 & 0.9927 & Active cases \\
& & & 1.0000 & $0.445 \mathrm{I}$ & 0.5625 & Total cv deaths \\
& & & & 1.0000 & 0.9745 & Daily deaths \\
& & & & & 1.0000 & Daily recovered
\end{tabular}

Source: Authors' own (based on data obtained from Worldometer;Worldometers.info').

Abbreviation: $\mathrm{cv}=$ coronavirus.

Note: $5 \%$ critical value (two-tailed) $=0.0960$ for $n=417$. 
Table 2. Estimates of Kaiser-Meyer-Olkin Measure of Sampling Adequacy

\begin{tabular}{lc}
\hline Variable & KMO \\
\hline Total coronavirus cases & 0.6395 \\
Daily new cases & 0.6987 \\
Active cases & 0.7005 \\
Total coronavirus deaths & 0.6026 \\
Daily deaths & 0.9349 \\
Daily recovered & 0.7172 \\
Overall & 0.7125 \\
\hline
\end{tabular}

Source: Authors' own (based on data obtained from Worldometer;Worldometers.info').

the data are suitable for structure detection (Kaiser, 1970; Kaiser \& Rice, 1974). The KMO statistic lies between 0 and 1 and if the KMO value is less than 0.50 then we cannot obtain a low dimensional representation of the data. The results are given in Table 2. All six variables have KMO values of more than 0.60 and the overall $\mathrm{KMO}$ value is 0.71 . Using Kaiser characterization the overall KMO value is in the "middling" range.

The squared multiple correlations of each of the six variables with all other variables were estimated to see if the variables have strong linear relations with each other. Table 3 gives these results and all these correlations are high and statistically significant and therefore all six variables in the data set can be retained.

The first step in performing PCA is to standardize the variables if the variables have different scales/units of measurement. Since we did not standardize the variables, we chose the correlation matrix option in STATA. PCA is performed using the correlation matrix to obtain the eigenvalues and their corresponding eigenvectors. Next, a decision regarding the number of components to be retained for further analysis needs to be made. Since correlation matrix PCA was performed, Kaiser's rule can be applied, and accordingly, we retain only the first two components that have eigenvalues greater than one (Kaiser, 1960). For further analysis, the component loadings on the retained principal components were examined to see if they gave a useful interpretation in the context of the study. Since this was not the case we rotated the first two components using varimax rotation with Kaiser normalization. In this rotation, while the total variance in the rotated twodimensional subspace remains the same, the variance is now distributed more evenly among the rotated components. The purpose of rotation is to make component

Table 3. Squared Multiple Correlations of Each Variable with All Other Variables

\begin{tabular}{|c|c|c|}
\hline Variable & Squared Multiple Correlation & $P$-value \\
\hline Total coronavirus cases & 0.9901 & .0000 \\
\hline Daily new cases & 0.9818 & .0000 \\
\hline Active cases & 0.9964 & .0000 \\
\hline Total coronavirus deaths & 0.9870 & .0000 \\
\hline Daily deaths & 0.9728 & .0000 \\
\hline Daily recovered & 0.9926 & .0000 \\
\hline
\end{tabular}

Source: Authors' own (based on data obtained from Worldometer;Worldometers.info'). 
loadings easier to interpret (Jolliffe, 2002). In the unrotated components, the four daily variables loaded with near equal weights and the two cumulative variables had low weights on the first component while the second component had large, small, and intermediate loadings making the task of interpretation difficult. Since we wanted to examine the score plot to track the trajectory of the pandemic in the two-dimensional space and interpret the first two components, rotation was applied to give a clearer interpretation of the components. After rotation, the first component loads high on the daily variables and low on the cumulative variables while for the second component the loadings for the variables are reversed, thus enabling easy interpretation. As the rotated components were found to have loadings with a simpler structure and a clearer interpretation than the original coefficients, we retained these results for further analysis. The results are given in Table 4.

The top half of Table 4 gives results for variance and proportion of variance and cumulative values of the variance accounted for by the rotated components. The first two components each explain over $65 \%$ and $33 \%$ of the variation in the data set respectively. Together they explain $98 \%$ of variability of the original variables in our data set. In general, the higher the degree of correlations among the observed variables, the fewer the number of components required to account for the variation in the data set (Jolliffe \& Cadima, 2016; Vyas \& Kumaranayake, 2006). The observed correlations are high among the six variables in the coronavirus data set, with high correlations among the variables that capture daily dimensions as well as between the two variables that capture the cumulative nature of the pandemic. Thus the first two principal components are able to account for a large part of the variation in the data set. From the original six correlated variables, we are therefore able to extract two uncorrelated principal components that explain a significant percentage of variation in the data set. The

Table 4. Results From Principal Component Analysis After Rotation Using Varimax Rotation with Kaiser Normalization

\begin{tabular}{|c|c|c|c|}
\hline \multicolumn{4}{|c|}{ Principal Component Analysis Using Correlation Matrix $n=417$} \\
\hline Component & Variance & Proportion & Cumulative \\
\hline I & 3.93212 & 0.6554 & 0.6554 \\
\hline 2 & $1.9893 \mid$ & 0.3316 & 0.9869 \\
\hline 3 & 0.0523795 & 0.0087 & 0.9956 \\
\hline 4 & 0.0175971 & 0.0029 & 0.9986 \\
\hline 5 & 0.00635187 & 0.0011 & 0.9996 \\
\hline 6 & 0.00224459 & 0.0004 & 1.0000 \\
\hline \multicolumn{4}{|c|}{ Rotated Components } \\
\hline Variable & $\mathrm{PCl}$ & \multicolumn{2}{|c|}{ PC2 } \\
\hline Total coronavirus cases & 0.0453 & \multicolumn{2}{|c|}{0.6687} \\
\hline Daily new cases & 0.4823 & \multicolumn{2}{|c|}{0.0312} \\
\hline Active cases & 0.4932 & \multicolumn{2}{|c|}{0.0244} \\
\hline Total coronavirus deaths & -0.0368 & \multicolumn{2}{|c|}{0.7365} \\
\hline Daily deaths & 0.5334 & \multicolumn{2}{|c|}{-0.0881} \\
\hline Daily recovered & 0.486 I & \multicolumn{2}{|c|}{0.0344} \\
\hline
\end{tabular}

Source: Authors' own (based on data obtained from Worldometer;Worldometers.info'). 
two-dimensional score plot using the first two components can therefore give a very good approximation of the original scatter plot of observations in the sixdimensional space.

The component loadings for the first two rotated principal components are given in the lower half of Table 4. Four of the variables load with high positive weights on the first principal component and the remaining two variables load with high positive weights on the second component (these weights are indicated in bold in Table 4). This allows for an easy interpretation of the first two components. The first principal component can therefore be regarded primarily as a weighted average of daily new cases, daily deaths, active cases, and daily recovered thus representing magnitude of the daily nature of coronavirus pandemic while the second component gives the magnitude of the pandemic in terms of cumulative picture, that is, total coronavirus cases and total deaths. Higher values on the first component (PC1) indicate greater severity of the pandemic from a daily perspective while higher values on the second component (PC2) indicate larger cumulative number of cases and deaths.

Using the score plot from the first two principal components we can track the progress of the pandemic in India. The score plot for the first two principal components is given in Figure 2. The phases of lockdown and unlock are indicated. We can determine the clustering of observations in the different phases of lockdown and unlock. The relative location of points indicates the course of the

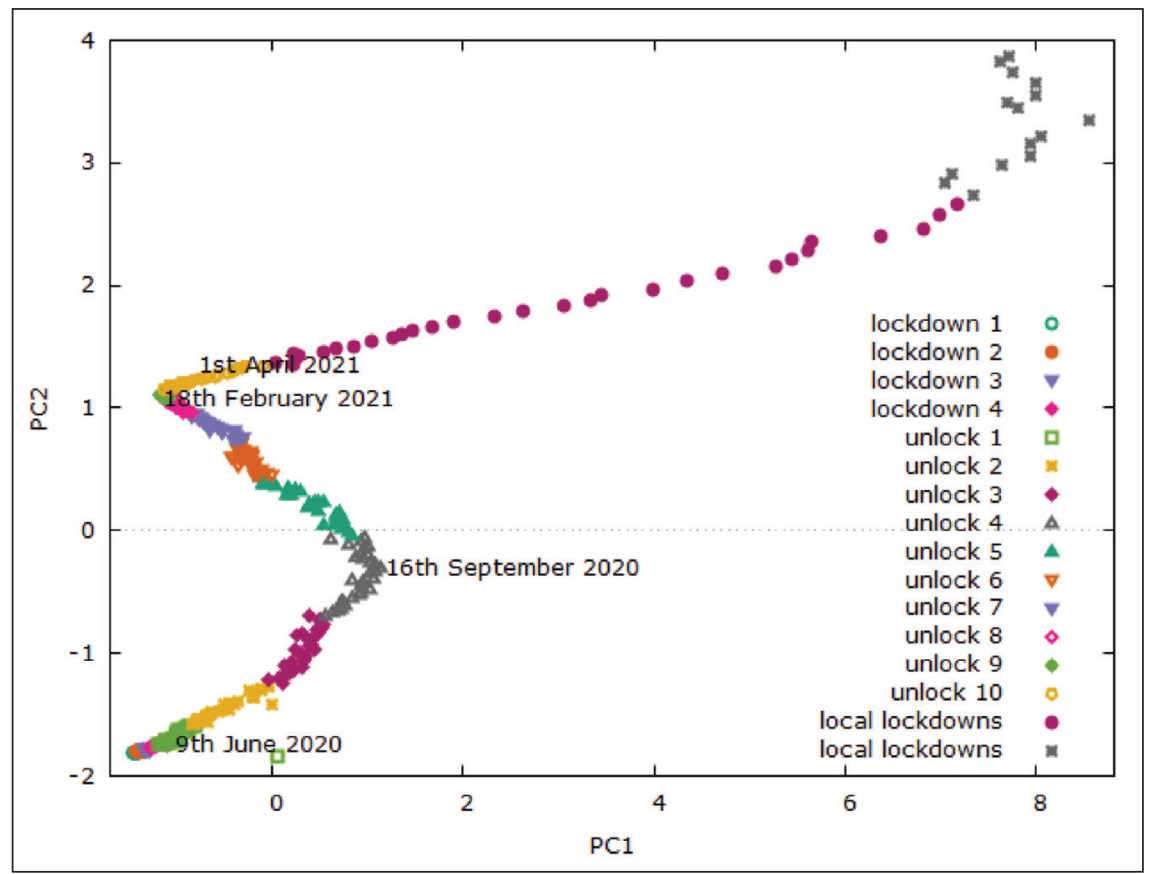

Figure 2. Trajectory of the Pandemic in the Lockdown and Unlock Phases Using Score Plot of the First Two Principal Components and Data from March 25, 2020, to May I5, 202 I

Source: Authors' own (based on data obtained from Worldometer;Worldometers.info'). 
pandemic. Closely bunched observations indicate that the pandemic is contained while a rapid rightward movement of observations on $\mathrm{PC} 1$ indicates that the situation is worsening from a daily perspective. A rapid upward movement on PC2 would indicate the situation worsening quickly in cumulative terms.

On March 25, 2020, a 40-day stringent lockdown was imposed in two phases from 25 March to 03 May. The lockdown was extended in two more phases till 31 May with some relaxation. The extremely compact clustering of observations seen in Figure 2 during the lockdown period between March 25, 2020, and May 31, 2020 (lockdown 1 to 4) indicates that the pandemic was largely contained. As the unlock phase began in June the score plot shows the wide dispersion of observations to the right on PC1 especially after June 9, 2020, indicating that the pandemic spread rapidly in the Unlock 1 to 4 phases between June and mid-September. This continued until a turning point is observed on September 16, 2020, in Unlock phase 4 when the inversion of the first component is seen and the scatter of observations moves leftward after that date. This indicates that the pandemic was reducing in severity from a daily viewpoint from the middle of Unlock 4 to middle of Unlock 9. The compact clustering of observations in Unlock phases 7 to 9 indicates that the overall spread of the pandemic from a daily perspective had come down significantly by the months of December, January and midFebruary and was largely stable.

After around February 18, 2021, the scatter plot shows the observations moving to the right and upward indicating the start of the second wave. The very rapid rightward and upward dispersion of observations in April 2021 shows the sudden snowballing nature of the situation from a daily as well as cumulative perspective.

Observing the clustering of observations from the score plot of the first two components in Figure 2, we can discern four phases in the trajectory of the pandemic. With a stringent lockdown from March 25, 2020, till around June 9, 2020, the pandemic was contained in the first phase given by the very close clustering of observations in this period. The second phase can be identified as the period between June 9, 2020, and September 16, 2020. This is when the unlock phase began on June 1, 2020, and continued in the coming months. As restrictions were eased in this phase, the pandemic situation worsened from a daily as well as a cumulative perspective given by the rapid rightward and upward movement of observations after June 9, 2020. This corresponds to the first wave of infections. From the clustering of observations, the third phase can be identified as being between September 17, 2020, and February 18, 2021. The observations show a leftward inversion during this phase indicating a decrease in the severity of the pandemic from a daily perspective. During this phase, India was placed in a comfortable yet puzzling situation with the pandemic situation improving as daily cases and deaths fell to low levels and the economy showing signs of recovery which was made possible by the easing of restrictions. In the fourth phase the pandemic situation started worsening from February 18, 2021, initially only gradually, and then followed by a sudden deterioration of the situation in April and May 2021 leading to the second wave of infections. This is evident in the rightward inversion of observations. We observe the initial clustering of observations in Unlock phases 9 and 10 in the months of February and March 
2021 and then the very rapid spread of observations in April until mid-May which is the date till which data have been obtained for the study.

\section{Relation Between Lockdown Stringency and Composite Measure of the Pandemic}

Using the two extracted principal components which account for over $98 \%$ of the variation observed in the original six variables in our data set, we constructed a composite index of the pandemic to establish its relation to the stringency index. A number of weighting schemes can be chosen to construct a composite index (OECD, 2008). In this study, the pandemic index is constructed as a weighted index using the scores of the principal components $\left(\mathrm{PC}_{i}\right)$ and the proportion of variance explained by each PC $\left(w_{i}\right)$ as weights as given in Equation (2).

$$
\text { Composite Pandemic Index }=\sum_{i=1}^{p} w_{i} \mathrm{PC}_{i}
$$

We use the scores of the first two extracted PCs and the weights are the proportion of variance accounted for by each PC as given in Table 4. For easy comparability with the stringency index, the composite measure of the pandemic is then calibrated on a scale of 0 to 100 . For each observation or data point, we obtain a value of the index. Larger values of the pandemic index signify greater severity of the pandemic. The time path of this index is related to the movement of the stringency index. The stringency index is obtained from the Oxford COVID-19 Government Response Tracker (Hale et al., 2020). This index gives the stringency index values for each day and we collected the data from March 25, 2020, to May 15,2021 . The stringency index is a composite measure on a scale of 0 to 100 with 100 indicating highest stringency. It is based on nine response indicators such as school closures, workplace restrictions, and travel restrictions. It measures how the strictness of lockdown policies restricts movement and activities of people. Figure 3 gives the time-series graph of the constructed pandemic index and the stringency index from March 25, 2020, to May 15, 2021.

In Table 5, the correlation coefficients between the pandemic index and the stringency index for the four different phases of the trajectory of the pandemic that are identified in the study are given. All the correlations coefficients are statistically significant. The overall estimated correlation coefficient for the entire period is -0.26385 indicating a negative relation between the pandemic and stringency index and this relation is statistically significant.

Figure 3 shows that when the stringency index (String. Index) value was high between March 25, 2020 (index was 100 on this date) and June 9, 2020, the pandemic index (Pand. Index) was initially zero and shows a very marginal increase in response to limited relaxations. The correlation coefficient is -0.73955 for this period. From June 10, 2020, till September 16, 2020, as the stringency index declined the pandemic index shows a quick increase and the correlation coefficient is -0.88047 for this period. Thus, until mid-September, we find a negative relationship between the two indices with the pandemic index increasing 


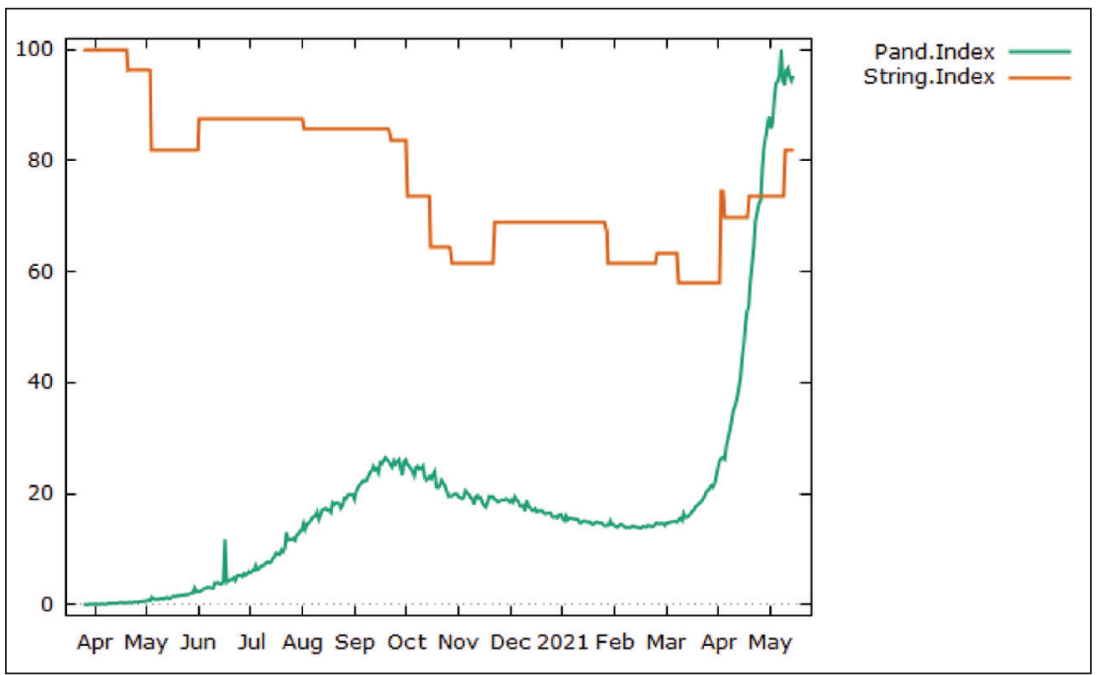

Figure 3. Time Series Plot of the Composite Pandemic Index and Stringency Index from March 25, 2020, to May I5, 2021

Source: Authors' own (based on data obtained from Worldometer, Worldometers.info'), and stringency index data obtained from Oxford COVID-19 Government Response Tracker (Hale et al., 2020).

Table 5. Correlation Coefficients Between the Pandemic Index and the Stringency Index by Sub-periods

\begin{tabular}{lccc}
\hline Time Period & $\begin{array}{c}\text { Number of } \\
\text { Observations }\end{array}$ & $\begin{array}{c}\text { Correlation Coefficient } \\
\text { Between Stringency Index } \\
\text { and Pandemic Index }\end{array}$ & P-value \\
\hline $\begin{array}{l}\text { March 25, 2020, to } \\
\text { June 9, 2021 }\end{array}$ & $N=77$ & -0.73955 & .0000 \\
$\begin{array}{l}\text { June 10, 2020, to } \\
\text { September 16, 2020 }\end{array}$ & $N=99$ & -0.88047 & .0000 \\
$\begin{array}{l}\text { September 17, 2020, } \\
\text { to February 18,2021 }\end{array}$ & $N=155$ & 0.62107 & .0000 \\
$\begin{array}{l}\text { February 19,2021, } \\
\text { to May 15, 2021 }\end{array}$ & $N=86$ & 0.85861 & .0000 \\
$\begin{array}{l}\text { March 25, 2020, to } \\
\text { May 15, 2021 }\end{array}$ & $N=417$ & -0.26385 & .0000 \\
\hline
\end{tabular}

Source: Authors' own (based on data obtained from Worldometer, Worldometers.info'), and stringency index data obtained from Oxford COVID-I9 Government Response Tracker (Hale et al., 2020).

as stringency declined. Figure 3 also shows the puzzling phenomenon between mid-September 2020 and mid-February 2021 when, even though the stringency index declined the pandemic index also declined slowly and leveled off. The correlation coefficient for this period is 0.62107 . Finally in the fourth phase, as the second wave of infections began, the pandemic index increased slowly in March 2021 and very rapidly in April 2021. In response, the stringency index also rose as 
many states imposed lockdowns and restrictions to curb transmission of the virus. The correlation coefficient is 0.85861 for this period. Thus in the last two phases, the correlation coefficient is positive with both indices moving in the same direction-either both declining or both increasing. The trend in the composite measure of the pandemic index also shows that the scale of the second wave of infections is significantly far more severe as compared to the first wave.

The analysis of the trajectory of the pandemic by the different phases helps us establish the relation between path of the pandemic and its relation to the stringency index. The stringent lockdown on March 25, 2020, with the stringency index value of 100 was an ex-ante measure designed to prevent transmission, save lives and give the country time to put in place health systems to cope with the pandemic. The rise in the stringency index during the second wave is more a response to the sudden severity of the second wave of infections.

\section{Discussion}

From the health perspective, India seemed to have reaped the "lockdown dividend" in terms of lives saved. The Economic Survey of 2020-2021 estimates that the lockdown restricted COVID-19 spread by 3.7 million cases and saved more than 100,000 lives (Government of India [GoI], 2021a).

Other statistical approaches to evaluating India's lockdown policies on incidence rate using time-series approach also show that lockdown policy in India reduced incidence rate and helped "flatten the curve" buying additional time for pandemic preparedness (Thayer et al., 2021).

The stringent lockdown saved lives but there was a cost in terms of loss of livelihoods. The economy contracted by a sharp $24.4 \%$ in the first quarter of fiscal year 2021 following the nationwide lockdown. This was the short-term pain that India was prepared to pay for saving human lives according to the Economic Survey (GoI, 2021a). The revival of the economy was planned through a number of sequenced policies to boost demand including a targeted stimulus program and complementary supply-side policies (GoI, 2021a; Goyal, 2020). Studies have shown that prompt and timely interventions can save lives with a not too significant cost in terms of foregone economic activity (Balmford et al., 2020). But for developing countries like India with a predominantly rural population, a large informal sector, and a high proportion of self-employed and casual labor, the stringent lockdown imposed a harsh and disproportionate burden on the most vulnerable sections of population pushing millions of people deeper into poverty (Biswas et al., 2020; International Labour Organization, 2020; Ray \& Subramanian, 2020). Deprived of work and a livelihood the lockdown stranded many millions of people in cities away from their homes leading to an unprecedented crisis (Nayyar, 2020).

Once the unlock phase began in June 2020, the economy showed signs of a recovery. With all key indicators improving, the Economic Survey of 2020-2021 (GoI, 2021a) pointed to a V-shaped recovery with a $7.5 \%$ contraction in second quarter as compared to a $24 \%$ contraction in first quarter of 2021, and real GDP was expected to grow by $11 \%$ in fiscal year 2021-2022. Also, the pandemic 
situation which initially worsened in the unlock phase began showing a turnaround after mid-September 2020. From mid-September 2020 to mid-February 2021 it seemed that India was in a fortunate situation with the economy picking up and the scale of the pandemic showing a remarkable easing. The leftward inversion of the scatter of points in Figure 2 after mid-September points to a puzzling decline in the scale of the pandemic even as unlock measures continued leading many to believe that the pandemic was coming to an end in India (Biswas, 2021). The relative easing of the pandemic situation led to relaxation of many stringency measures. The Oxford Severity Index which was 100 as of March 25, 2020, steadily fell to 63.53 on March 1, 2021. But with relaxations continuing, the index fell further to its lowest level of 57.87 on April 1, 2021, even as coronavirus cases steadily increased after mid-February 2021. Given the epidemiological characteristics of new variants of the virus which had greater transmissibility, the imminent threat of a second wave was dormant and when it erupted suddenly in April 2021 it led to a serious health crisis (The Lancet, 2021). The magnitude and severity of the second wave points to the vital role of genomic surveillance as an integral part of pandemic management (Chakraborty et al., 2021; Cyranoski, 2021).

Formulating and adopting policies to balance health and economy are crucial especially in the context of the second wave and possible future waves of infections. From the experience of the first wave, it would seem that rather than countrywide lockdowns, restrictions should instead be imposed at the state/local level where infections and positivity rates are high. The public health crisis in many cities in India during the second wave has led many states to impose restrictions in varying degrees of stringency (Sharma, 2021). The Oxford Stringency Index for India increased from 57.87 on April 1, 2021, to 73.61 on April 30, 2021, and increased further to 81.94 by May 10, 2021.

The current high levels of infection in the second wave and the restrictions imposed by states to contain the transmission of the virus are likely to have an adverse impact on the economy (S\&P Global Ratings, 2021). Although the Monthly Economic Review for April 2021 (GoI, 2021b) is optimistic that the effect on the economy may not be so severe as businesses have shown resilience in coping with COVID-19. Going forward, it may be useful to rely on datadriven policies that can identify at the state or local level as to which sectors or businesses need to have restrictions or shuttering. This can lead to informed decision-making so as to achieve public health goals and minimize social costs (Benzell et al., 2020).

The challenges to containing the pandemic are many (Ajmera et al., 2020). While the vaccination program has begun in India, the task of vaccinating a population of over 1.3 billion people in India will take time and in the meantime policies for pandemic containment and management are important. Comprehensive testing of people and epidemiological tracking of new variants of coronavirus need to take primacy in these policies. Widespread acceptance and adoption of COVID-19 protocols at the individual level are essential to contain the spread of the virus (Newbold et al., 2020). And swiftly adopted and implemented government policies including expanding health systems and strengthening social protection 
systems are needed to reduce mortality rates and lessen the social and economic burden on people (Bigiani et al., 2020; Martinez-Valle, 2021).

\section{Conclusion}

During the last year, the spread of the COVID-19 pandemic has been closely followed. Using data on six dimensions of the pandemic the study used PCA to assess the trajectory of the pandemic in India in the two-dimensional space. The analysis enables us to visualize the path of the pandemic and identify four phases in the trajectory corresponding to the lockdown and unlock periods.

Using the two extracted principal components, a composite pandemic index is constructed and its relation to the stringency index is examined. Overall the relation between the composite index of the pandemic and the stringency index was found to be negative and statistically significant. But the phase-wise analysis is significant for understanding the trajectory of the pandemic and lockdown policy. It reveals that the early stringent lockdown did help to save lives and push back the peak of the pandemic. But the puzzling and unexplained easing of the pandemic situation even as restrictions were eased between mid-September 2020 and mid-February 2021 and the suddenness and severity of the second wave of infections points to the need to track new variants of the virus for their transmissibility. Such epidemiological surveillance is vital for informed public health policy response to keep transmission levels low and save lives.

The present study examines the relation between stringency measures and the path of the pandemic at an aggregative level but further research into the causal factors in the relation is needed. While the study covers a long duration of the pandemic and offers insights into the trajectory, it is clear from the second wave that managing the pandemic at local level is crucial. The significant variation in the spread of the pandemic across states in India indicates that further research using state or district level data needs to focus on the determinants of the spread of the pandemic, stringency measures adopted at the local level, and impact on mobility and local economy and business. Such district-level and state-level analysis can give insights into mitigation strategies for curtailment and management of possible future waves of infections.

\section{Declaration of Conflicting Interests}

The author declared the following potential conflicts of interest with respect to the research, authorship, and/or publication of this article: This research work has not been published elsewhere in the same form nor has it been sent for consideration for publication elsewhere.

\section{Funding}

The author received no financial support for the research, authorship, and/or publication of this article. 


\section{Note}

1. https://www.worldometers.info/coronavirus/country/india/

\section{References}

Ajmera, P., Majeed, J., Goyal, R. K., Yadav, S., \& Mukhopadhyay, D. (2020). Overcoming the pandemic: Analysing the ongoing challenges in the prevention of COVID-19 in India. Journal of Health Management, 22(4), 630-652. https://doi. org/10.1177/0972063420983076

Anderson, T. W. (1958). An introduction to multivariate statistical analysis. John Wiley \& Sons.

Askitas, N., Tatsiramos, K., \& Verheyden, B. (2020). Lockdown strategies, mobility patterns and COVID-19 [IZA DP No. 13293]. IZA Institute of Labor Economics. http://ftp.iza.org/dp13293.pdf

Balmford, B., Annan, J. D., Hargreaves, J. C., Altoè, M., \& Bateman, I. J. (2020). Crosscountry comparisons of Covid-19: Policy, politics and the price of life. Environmental and Resource Economics, 76(4), 525-551. https://doi.org/10.1007/s10640-020-00466-5

Benzell, S. G., Collis, A., \& Nicolaides, C. (2020). Rationing social contact during the COVID-19 pandemic: Transmission risk and social benefits of US locations. Proceedings of the National Academy of Sciences, 117(26), 14642-14644. https://doi. org/10.1073/pnas.2008025117

Bigiani, L., Bigiani, S., \& Bigiani, A. (2020). How to minimize the impact of pandemic events: Lessons from the COVID-19 crisis. International Journal of Health Policy and Management, 9(11), 469-474. https://doi.org/10.34172/ijhpm.2020.115

Biswas, R. K., Huq, S., \& Afiaz, A. (2020). Relaxed lockdown in Bangladesh during COVID-19: Should economy outweigh health? International Journal of Health Policy and Management, 9(11), 488-490. https://doi.org/10.34172/ijhpm.2020.98

Biswas, S. (2021, February 15). Coronavirus: Is the epidemic finally coming to an end in India? https://www.bbc.com/news/world-asia-india-56037565

Cattell, R. B. (1966). The scree test for the number of factors. Multivariate Behavioral Research, 1(2), 245-276. https://doi.org/10.1207/s15327906mbr0102_10

Chakraborty, D., Agrawal, A., \& Maiti, S. (2021). Rapid identification and tracking of SARS-CoV-2 variants of concern. The Lancet, 397(10282), 1346-1347. https://doi. org/https://doi.org/10.1016/S0140-6736(21)00470-0

Cyranoski, D. (2021). Alarming COVID variants show vital role of genomic surveillance. Nature, 589(7842), 337-338. https://doi.org/10.1038/d41586-021-00065-4

Demirguc-Kunt, A., Lokshin, M., \& Torre, I. (2020). Opening-up trajectories and economic recovery: Lessons after the first wave of the COVID-19 pandemic [Policy Research Working Paper No. 9480]. World Bank. https://openknowledge.worldbank. org/handle/10986/34835

Ferraresi,M.,Kotsogiannis,L., Rizzo,L., \& Secomandi,R.(2020a).The "greatlockdown" and itsdeterminants.EconomicsLetters, 197,109628.https://doi.org/10.1016/j.econlet.2020. 109628

Ferraresi, M., Kotsogiannis, L., Rizzo, L., \& Secomandi, R. (2020b). COVID-19: "Lockdown" and institutions [SIEP Working Paper No. 755]. http://www.siepweb.it/ siep/images/joomd/1590426906Ferraresi_et_al_WP_SIEP_755.pdf

Government of India (GoI). (2021a). Economic Survey. 2020-21. Ministry of Finance. https://www.indiabudget.gov.in/economicsurvey/

GoI. (2021b). Monthly economic review. April 2021. Department of Economic Affairs. https://dea.gov.in/sites/default/files/MER\%20April\%202021.pdf 
Goyal, A. (2020). Post Covid-19: Recovering and sustaining India's growth. Indian Economic Review, 55, 161-181. https://doi.org/10.1007/s41775-020-00089-z

Hale, T., Webster, S., Petherick, A., Phillips, T., \& Kira, B. (2020). Oxford COVID-19 Government Response Tracker. Blavatnik School of Government. https://covidtracker. bsg.ox.ac.uk/

International Labour Organization. (2020). COVID-19 and the world of work, impact and policy responses. https://www.ilo.org/wcmsp5/groups/public/---dgreports/---dcomm/ documents/briefingnote/wcms_738753.pdf

Jolliffe, I. T. (2002). Principal component analysis (2nd ed.). Springer-Verlag. https://doi. org $/ 10.1007 / \mathrm{b} 98835$

Jolliffe, I. T., \& Cadima, J. (2016). Principal component analysis: A review and recent developments. https://doi.org/10.1098/rsta.2015.0202

Kaiser, H. F. (1960). The application of electronic computers to factor analysis. Educational and Psychological Measurement, 20, 141-151. https://doi.org/10.1177/0013164460 02000116

Kaiser, H. F. (1970). A second generation little jiffy. Psychometrika, 35(4), 401-415. https://doi.org/10.1007/BF02291817

Kaiser, H. F., \& Rice, J. (1974). Little Jiffy, Mark Iv. Educational and Psychological Measurement, 34(1), 111-117. https://doi.org/10.1177/001316447403400115

Mahmoudi, M. R., Heydari, M. H., Qasem, S. N., Mosavi, A., \& Band, S. S. (2021). Principal component analysis to study the relations between the spread rates of COVID-19 in high risks countries. Alexandria Engineering Journal, 60(1), 457-464. https://doi.org/https://doi.org/10.1016/j.aej.2020.09.013

Martinez-Valle, A. (2021). Public health matters: Why is Latin America struggling in addressing the pandemic? Journal of Public Health Policy, 42(1), 27-40. https://doi. org/10.1057/s41271-020-00269-4

Mitra, A., Pakhare, A. P., Roy, A., \& Joshi, A. (2020). Impact of COVID-19 epidemic curtailment strategies in selected Indian states: An analysis by reproduction number and doubling time with incidence modelling. PLOS ONE, 15(9), e0239026. https://doi. org/10.1371/journal.pone.0239026

Nayyar, D. (2020). Lives, livelihoods and the economy: India in pandemic times. The Indian Journal of Labour Economics, 63(1), 53-59. https://doi.org/10.1007/s41027020-00256-Z

Newbold, S. C., Finnoff, D., Thunström, L., Ashworth, M., \& Shogren, J. F. (2020). Effects of physical distancing to control COVID-19 on public health, the economy, and the environment. Environmental \& Resource Economics, 1-25. https://doi.org/10.1007/ s10640-020-00440-1

OECD. (2008). Handbook on constructing composite indicators. Methodology and user guide. OECD Publications. https://www.oecd.org/sdd/42495745.pdf

Ray, D., \& Subramanian, S. (2020). India's lockdown: An interim report. Indian Economic Review, 55(1), 31-79. https://doi.org/10.1007/s41775-020-00094-2

Rea, A., \& Rea, W. (2016). How many components should be retained from a multivariate time series PCA? http://arxiv.org/abs/1610.03588

S\&P Global Ratings. (2021, May). Second COVID wave may derail India's budding recovery. S\&P Global. https:/www.spglobal.com/ratings/en/research/articles/210505second-covid-wave-may-derail-india-s-budding-recovery-11942315 
Sharma, S. (2021, May 9). National lockdown, just not in name: Almost 98\% of India is under some form of lockdown. India Today. https:/www.indiatoday.in/diu/story/26states-uts-under-some-lockdown-india-s-score-on-global-stringency-index-jumps-to74-1800507-2021-05-09

Thayer, W. M., Hasan, M. Z., Sankhla, P., \& Gupta, S. (2021). An interrupted time series analysis of the lockdown policies in India: A national-level analysis of COVID-19 incidence. Health Policy and Planning. https://doi.org/10.1093/heapol/czab027

The Lancet. (2021). India's COVID-19 emergency. The Lancet, 397(10286), 1683. https:// doi.org/https://doi.org/10.1016/S0140-6736(21)01052-7

Thompson, R. N. (2020). Epidemiological models are important tools for guiding COVID-19 interventions. BMC Medicine, 18(1), 152. https://doi.org/10.1186/s12916020-01628-4

Vyas, S., \& Kumaranayake, L. (2006). Constructing socio-economic status indices: How to use principal components analysis. Health Policy and Planning, 21(6), 459-468. https:// doi.org/10.1093/heapol/czl029

WHO. (2020). WHO Director-General's opening remarks at the media briefing on COVID-19-11 March 2020. https://www.who.int/director-general/speeches/detail/ who-director-general-s-opening-remarks-at-the-media-briefing-on-covid-19---11march-2020 


\title{
Impact of Virtual Try-On Technology on Customer's Mental Imagery During COVID-I 9
}

IIMS Journal of Management Science

I3(I) 27-42, 2022

(C) The Author(s) 2022 DOI: 10.1 177/0976030X21 1051095 ims.spectrumjps.com

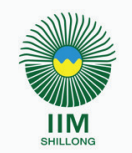

\section{Vijay Rathee' and Sarita Kumari}

\begin{abstract}
During the lockdown period of this pandemic, online retailing is getting the place of offline retail. This study provides an insight about the mental imagery of customers toward the new developing technology: virtual try-on. This descriptive study provides empirical evidence that virtual try-on technology influences the customer's mental imagery toward the product presented on an online platform. Primary data were collected from 142 online customers of the Delhi NCR region. Various journals, websites, and reports were used to collect secondary data. Mean, standard deviation, and one sample t-test were used to study the significance of different dimensions on mental imagery toward virtual try-on technology in this pandemic period. Three dimensions of mental imagery have been studied, namely "vividness, quantity, and elaboration." The findings of this study show that virtual try-on technology positively influences all the dimensions of mental imagery. E-tailers might get help from these findings and frame their strategies accordingly to attract more traffic on their website, increase sales outcomes, and get competitive advantages during and after this pandemic.
\end{abstract}

\section{Keywords}

Augmented reality, virtual try-on, mental imagery, vividness, elaboration

JEL Classification: $\mathrm{M} 3 \mathrm{I}, \mathrm{O} 33, \mathrm{O} 3 \mathrm{I}, \mathrm{O} 32$

\footnotetext{
' MDU-CPAS, Gurugram, Haryana, India

${ }^{2}$ Institute of Management Studies and Research, Maharshi Dayanand University, Rohtak, Haryana, India

Corresponding Author:

Vijay Rathee, MDU-CPAS, Gurugram, Haryana I2200I, India.

E-mail: vijayratheel@yahoo.com
} 


\section{Introduction}

As social creatures, people not only come out to shop but for socialization also. This pandemic restricts them to stay at home which raises their anxiety level and change in behavior. COVID-19 pandemic provides an opportunity to develop and increase the use of new emerging technology such as augmented reality (AR), virtual reality (VR), and mixed reality. These technologies enable people to talk, shop, and socialize virtually, and this happened due to more usage of smartphones and high internet connectivity (cio.economictimes.indiatimes.com). Various innovative technological means provide an interactive shopping environment in online retail. Retailers are adopting new visualization means such as try-on, 3D, video, and zoom to provide more experiential values and sensory experience. In e-tailing, where direct interactivity with the product is not possible, new emerging visualization technologies not only lead to more traffic on the website but also enhance the decision-making of customers (Park \& Yoo, 2020; Yoo \& Kim, 2014). Retailers should put more effort and find solution to how an online product can lead to a better virtual experience (Yoo \& Kim, 2014). A product presented in a good manner on an online platform evokes better cognitive and affective customer response, which influences outcome and customer's experience. Experiential values include "sensory, emotional, cognitive, and satisfaction." Products which require higher need to touch, like apparel shoppers, prefer to buy these from offline stores, and products which require low need to touch before buying attracts more customers to purchase it from e-tail platform (Yoo \& Kim, 2014). New product presentation technologies provide more interactivity (Park \& Yoo, 2020; Yoo \& Kim, 2014) and vividness to the customer than the static picture of the product. Lack of sensory experience is a major problem in e-tail (Yoo \& Kim, 2014).

Like other technologies such as laptops and smartphones, AR is a fully developed technology that was not widespread earlier. But this COVID-19 pandemic and lockdown period increased its adoption and use. As per experts, in the last few months, this worldwide pandemic created more interest toward AR through smartphones to engage more customers and enhance their unique digital experience during this COVID-19 pandemic. Jewelry retailer (Tanishq) recently launched "phygital features" that depicted both physical as well as digital features. It promotes contactless selling by adopting AR such as "video calling, live assisted chats, and virtual try-on" to increase customer's experience and safety during this COVID-19 pandemic. Virtual try-on enables the customer to try products (necklaces, earrings, and pendants) virtually (indianexpress.com). A mismatch between the customer expectation and the product provides reason for purchase return. Virtual try-on technology provides more personalized shopping and prevents product return which is $25 \%-40 \%$ for most retailers (indiaai.gov.in). AR provides customize shopping experiences and virtual try-on for jewelry, eyewear, and apparel of different brands with 3D model creation and increase immersion in this pandemic period. COVID-19 increases the possibility for advancement in AR technology, touch-free shopping, and try-on of product in the virtual platform. In the COVID-19 period, the growth of fashion industry witnessed a decrease from $3 \%$ to $4 \%$ (MGFI). ${ }^{1}$ Virtual try-on provides an integrated 
view of virtual mirror and color try-on that helps the customer get a good shopping experience; it reduces the problem of match and fit. Customer's ways to shop the product are changing due to COVID-19 because they avoid direct interaction and tester of products. Hence, customers would like to use virtual try-on both at online platform and store environment.

After studying different articles and previous studies, the research gap is to find whether virtual try-on technology provides clear, sharp, and more number of mental images to the customers which will help them to elaborate product information. The objective of this study is to empirically examine whether virtual try-on activates the mental imagery by affecting the different dimensions of mental imagery. As per previous literature, mental imagery is a latent construct that includes "vividness, quantity, and elaboration." Research questions of this study are as follows: (a) Does virtual try-on provide more vivid product images? (b) Does virtual try-on provide a number of product images? (c) Does virtual try-on help imagine herself/himself as part of the image? This study contributes to the field of marketing and helps to understand the consumers' response toward this new emerging technology in terms of their mental imagination.

The rest part of this article is organized as follows. The first section is "Conceptual Development and Literature Review." The next section is the "Hypothesis Development" followed by "Research Methodology" section. The fifth section is "Discussion and Conclusion" that includes theoretical and managerial implications also.

\section{Conceptual Development and Literature Review}

\section{Augmented Reality}

AR is defined as "a technology which allows computer-generated virtual imagery to exactly overlay physical objects in real-time" (Zhou et al., 2008). "Augmented reality (AR) refers to the integration of the actual world with digital information about it" (Farshid et al., 2018). AR is also described as an immersive technology. Immersive technology is defined as "technology that blurs the boundary between the physical and virtual world and enables the user to experience a sense of immersion" (Suh \& Prophet, 2018). It is a virtual-reality continuum and available easily on smartphones. AR technology is widely emerging in different sectors such as engineering, health care, education, real estate, military, video games, and retail industry (Park \& Yoo, 2020).

Nowadays adoption of AR technology is increasing by the marketers as a means to display products. Like a screen displays both the product and customer's images wearing that product with physical surroundings through a virtual fitting room. It enables to display product with real surroundings wherever the customer is through AR apps (Sun et al., 2019). Customers can try a product online before buying it with real surroundings wherever the customer is through AR "virtual try-on" app on smart devices. Different studies describe the different features of AR such as "virtuality, mobility, synchronization and location-specificity" (Sun et al., 2019). Bonetti et al. (2018) stated that AR mixes the online and physical worlds. A digital camera such as webcam and mobile devices enable AR to blend 
the real data with the online information and get customer attention because now customers can interact with online products which enhance their experiential values and buying intention. In retailing, AR technology is used at different touch points, namely "physical, mobile, and online." AR facilitates more interactivity, immersion, enjoyment, and fun experience. Face-to-face interaction is not possible in an online environment. Without visiting an offline store, AR technology provides more understanding and reliability. Interactivity and funny experience in the purchase process leads to more customer involvement, and this makes the customer feel that they are in an offline store (Park \& Yoo, 2020).

\section{Mental Imagery}

"Mental activity that visualizes a concept or relationship" is called mental imagery. It is a quasi-perceptual experience (Choi \& Taylor, 2014; Ha et al., 2019; Park \& Yoo, 2020) that evokes sensory information in the customer's mind because stimulus activates the mental imagery (Park \& Yoo, 2020). It is a stimulation in the customer's imagination, and people have a feel of experience in a given milieu without any other external stimuli (Ha et al., 2019). Mental imagery is defined as "mental invention or recreation of an experience that in at least some respect resembles the experience of actually perceiving an object or an event, either in conjunction with, or, in the absence of direct sensory stimulation" (Neck \& Manz, 1992).

Mental imagery evokes when information stored in the mind is processed and creates an experience such as "seeing with the mind's eye" and "hearing with mind's ear." Mental imagery makes an individual able to elicit sensory stimulus when it is not present in actual. Mental imagery activates the imagination in the brain. As per mental imagery theory, people combine present perceptual information with past experiences. It does not mean that mental imagery is related only with past perceived actions or stimuli, but it is evoked by modifying perceptual information in new innovative ways. Customer combines new information available in the present with past similar product experience and imagines a product which is never seen by them in actual. The way of product presentation also has an impact on mental imagery (Overmars \& Poels, 2015).

In mobile advertisement, mental imagery affects cognitive and affective behavioral dimensions of customer response such as "ad recall, attitude toward the brand, attitude toward the ad, attention, brand belief and brand recall, intention, their duration and feelings also" (Gavilan et al., 2014). Mental imagery evokes pre-experiencing also; it means people can imagine what they did not experience in the past. In the context of online retailing, mental imagery evokes different images in the mind of the customer which acts as an information source, and they can predict future experience and make a purchase decision.

Dimensions of Mental Imagery. Mental imagery has different dimensions. As a multidimensional concept, it consists of elaboration, quality (Ha et al., 2019; Park \& Yoo, 2020; Yoo \& Kim, 2014) "vividness, quantity and elaboration" (Gavilan et al., 2014). Elaboration means the number of images that comes into a customer's 
mind when they process the available information (Park \& Yoo, 2020). Quality means clarity and vividness of these images in their mind (Park \& Yoo, 2020).

Initially, Bone and Ellen (1992) identified only two dimensions of mental imagery: vividness and quantity. Later, another dimension called "elaboration" was added to this model (Babin \& Burns, 1998). Vividness means "clarity with which a consumer evokes an image. It means capturing the qualitative facet of mental imagery" (Bone \& Ellen, 1992). Quantity means "the number of images that a consumer generates from a stimulus while processing information" (Bone \& Ellen, 1992). Later researchers consider quantity as a part of elaboration. Elaboration refers to "the activation of stored information in the production of mental images beyond what is provided by the stimuli" (Babin \& Burns, 1998). Walters et al. (2007) stated that two dimensions of mental imagery were quality and elaboration. Quality means "vividness, intensity, and clarity of the images," and elaboration means "the degree to which one develops images in his/her mind after viewing an object” (Ha et al., 2019).

\section{Literature Review}

According to $\mathrm{Wu}$ and $\mathrm{Li}$ (2021), retailers need to pay attention on the online presentation of a product to introduce, provide information related to it, and to show its features. They stated that good quality images play key role in purchase decision and make it easy for the e-shoppers to process information. They depicted mental imagery as a "sensory and sometimes, a multisensory process" (which includes different senses such as sound, touch, smell, taste, and sight). They argued that concrete image provides clear, sharp, vivid, intense, and visual appeal. They proposed that mental imagery is high in concrete background as compared to solid background because concrete background provides more concrete and vivid information which draws attention, increases imagination, and evokes "consumer sensory experience" which results mental imagery.

Huang and Ha (2021) argued that visual content is the core for online environment. They stated that mental imagery is a "primary concept that explains the processes through which consumer perceptions of information content affect subsequent responses." They highlighted the role of social media as a tool of communication which provides visual information in such a way that engages consumers and increases their interactivity that immersed them. This visual information and images evoke imagery for the content. Mental imagery increases the cognitive value like perceived usefulness. So, the marketer should provide content in such a way that increases mental imagery, like picture of a product with real life experience along with a text message.

Skard et al. (2021) showed that the vividness and interactivity of virtual world objects form the mental imagery. Destination picture with VR increases the telepresence (as they are present in the real environment) and mental imagery. They stated that telepresence is a psychological state and mental imagery as information processing which occurs immediately while interacting with the online world. Skard et al. (2021) argued that the results support the notion that mental imagery "offers a sensory and emotional surrogate of consumption 
experience, it stands to reason that (it) may influence attitude strength enough affective response."

Lao et al. (2021) examined the effects of "sensorial, pragmatic, cognitive, and social" dimensions of customer experience on "shopping value, self-mental imagery, and behavioral intention." They also studied the mediating role of shopping values (hedonic, utilitarian, and social) and self-mental imagery between the customer experience and behavioral intentions (word of mouth and purchase intention). They found that all the dimensions of customer experience have favorable influence on the self-mental imagery. They stated that except social dimension, all other dimensions of customer experience influence utilitarian values significantly. All the dimensions of shopping value are significantly influenced by the sensorial experience. They highlighted that social and sensorial dimensions have significant positive influence on social and hedonic values. Self-mental imagery has positive influence on behavioral intentions. Except the influence of cognitive dimension on purchase intention, mental imagery worked as a mediator between other dimensions of customer experience and "behavioral intentions."

Cheng and Toung (2021) defined mental imagery fluency as "the subjective ease with which one can imagine hypothetical scenarios that have not yet occurred." They stated it as a thinking fluency of consumers and the sensations derived while thinking. Mental imagery fluency is meta-cognitive experience that evokes consumers' opinion, their attitude. They can consider and process the information easily. Easiness of imagination leads to subjective probability that evokes consumer's purchase intention. Way of product presentation, vividness, consumers' ability to explore, and their cognitive ability influence the mental imagery fluency. Consumers' preference can be strengthened by providing more vivid and imaginative appeals of product description. Imaginative appeals lead to favorable attitude and purchase intention.

Ha et al. (2019) conducted two studies to find the effect of mental imagery on "brand SNS attitude." They collected data from a web-based survey design. "Positive affect" works as a mediator between the dimensions of mental imagery and brand SNS attitude, and transportability works as a moderator between dimensions of mental imagery and "brand SNS attitude and positive affect." They stated that the activation of visionary and imaginary mental images is elaboration, vividness, sharpness, clarity, and intensity of mental images are quality. They argued that if stimuli have more mental imagery, then the attitudes, behavioral intentions, and beliefs are also more. They recommended that the content provided by the "social networking sites" should be filled with quality and elaboration, which develops mental imagery so the users can perceive themselves as a part of that content.

Khrouf and Frikha (2016) explored that different stimuli of the website influence the behavior of web-surfers that increases the website vividness. These stimuli are layout, color, and space. They stated mental imagery as multisensory (which includes taste, hearing, sight, smell, and touch) and multidimensional. Mental imagery affects reactions of users in a given milieu, like color used on website influences web-surfers. They studied the effect of "website dominant hue on mental imagery." They found that mental imagery plays mediating role between "dominant website's hue and web-surfers conative response." They stated that congruency between content and website hue leads to activation of mental 
imagery. Mental images activated through congruency influence the conative response of web-surfers the most.

\section{Hypothesis Development}

Skard et al. (2021) showed the influence of VR on the travel intentions. They conducted an experiment and studied that VR leads more mental imagery when the level of telepresence is high. They also studied that VR influence predicted happiness through the telepresence and mental imagery. They found that VR leads to more telepresence, stronger mental imagery, and the predicted happiness was also stronger in the VR environment. They stated that VR has a significant effect on mental imagery when telepresence works as a mediator. Predicted happiness was also high when the relation was mediated by mental imagery and telepresence. VR also has a positive influence on the behavioral intention. Mediating role of "telepresence, mental imagery, and predicted happiness" leads to positive influence of VR on the "behavioral intention and actual purchase."

Wu et al. (2020) studied the effect of product presentation on purchase intention in online retailing. They conducted an experimental study and found that the way (video and text) influences mental imagery. They also highlighted the indirect influence of mental imagery on purchase intention. Further mental imagery has an indirect influence on purchase intention which is mediated by perceived social risk and positive emotions. They stated that the presentation of product features through video, and pictures have more influence on mental imagery than the features presented only in the text forms. Hence, concrete picture presentation influences mental imagery more than textual information.

Park and Yoo (2020) studied the relationship between "mental imagery and consumer response" in the context of mobile shopping. They took two dimensions of mental imagery "elaboration and quality" and "customer attitude and behavioral intention" as consumer response. They conduct a survey in South Korea on female consumers and studied the impact of AR interactivity on consumer response through mental imagery. Structural equation modeling (SEM) results indicate that the two dimensions of interactivity, "controllability and playfulness," have a positive effect on both the dimensions of mental imagery, "elaboration and quality." The attitude of customers toward the product is significantly affected by both the dimensions of mental imagery, and this attitude further influences the behavioral intention.

Ha et al. (2019) took two dimensions of mental imagery, "elaboration and quality," in their study. They conducted a web-based survey and analyzed that whether mental imagery influences attitude toward brand SNS. SEM was conducted by them, and it was found that quality has a significant influence on the attitude of brand SNS, but elaboration does not have this significant relationship. "Positive effect" works as a mediator between dimensions of mental imagery and the brand SNS attitude. Both dimensions have a significant positive effect on brand SNS attitude when this relationship is mediated by "positive effect."

Choi and Taylor (2014) argued that 3D virtual advertising has more positive influence than 2D advertising for both the high need for touch as well as the low 
need for touch. They conducted an experimental study and took only one dimension of mental imagery - "vividness." They studied the mediating effect of mental imagery on attitude and intentions. They found that "site type" has a significant impact on mental imagery. When both site type and mental imagery regressed simultaneously, it reduced the effect of site type. Hence, mental imagery has a significant mediating effect on all the dependent variables "site attitude, brand attitude, purchase intention, and revisiting intention."

Yoo and Kim (2014) investigated how consumer responses are affected by the online product presentation through mental imagery perspective. They took a sample of college women and experimented. They took two dimensions, that is, "elaboration and quality," of mental imagery in the study. They found out that relevant consumption background helps to evoke mental imagery which increases customer's behavioral intention by producing more emotional responses positively. They also revealed that both the dimensions of mental imagery have a significant direct influence on behavioral intention. Positive emotions act as a partial mediator between them.

Gavilan et al. (2014) conducted experiment research and studied the mediating effect of mental imagery on "ad trust and purchase intention" in mobile advertising. They took three dimensions of mental imagery, that is, "vividness, quantity, and elaboration," as mediators. The results showed that MMS ads evoke more vivid and elaborated mental images than SMS ads. SMS evokes more quantity of mental images than MMS. According to the results shown by the regression model, on the one hand, independent variables_-vividness and elaboration-have a positive effect on the dependent variable "purchase intention", however, on the other hand, the effect of quantity is not significant.

Lao (2013) highlighted that product presentation stimuli used in online retail have a significant impact on mental imagery. They found out that when "selfmental imagery" developed by the users is high, there will be a positive user response and the purchase intention toward the product which is presented. Selfmental imagery influences both "hedonic and self-conscious emotions" positively. These emotions further have an impact on user's "impulse purchase" and their purchase intentions.

Schlosser (2003) stated that medium helps the shoppers in interaction with the product which increases immersion and vividness in mental images. They found out that mental imagery acts as a mediator between interactivity and purchase intention. Mental imagery information processing system has an important role in influencing the customer's purchase intention. They also found out that cognitive elaboration works as a mediator and has an interaction effect between "site and goal" and "attitude."

Dahl et al. (1999) experimented and studied whether visual mental imagery affects new product design. They found out that visual mental imagery, that is, "imagination imagery and memory imagery," impacts different aspects of new product design. They highlighted that visual mental imagery plays a vital role in the pre-product design and during the design stages, which increases usefulness. They stated that imagination imagery provides a wide and conducive environment for designing creative designs. 
Based on the literature review, the following hypotheses were developed.

$H_{1}$ : Virtual try-on technology has positive effect on the vividness dimension of mental imagery.

$H_{2}$ : Virtual try-on technology has positive effect on the elaboration dimension of mental imagery.

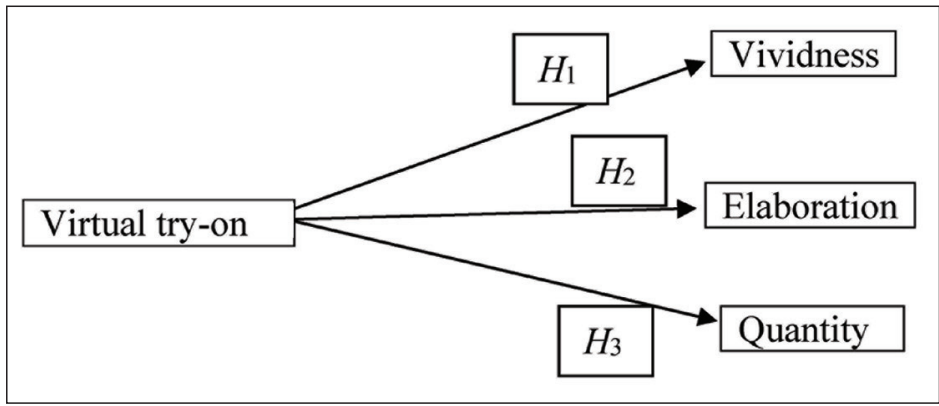

$H_{3}$ : Virtual try-on technology has positive effect on the quantity dimension of mental imagery.

\section{Research Methodology}

The descriptive research design along with convenience sampling technique was used in this study to measure the influence of virtual try-on on the mental imagery of customers. Three dimensions of mental imagery, namely "vividness, elaboration, and quantity" were taken from the previous studies. This study included 142 participants of the Delhi NCR region to measure the effect of virtual try-on on their mental imagery. To give an insight about Lenskart try-on, steps to try glasses over the Lenskart website and app were explained along with an online questionnaire that helps participants who have not tried it earlier try it now and record their level of agreement.

Questionnaire designing and data analysis procedure: In the first part of the questionnaire, demographic information was collected such as their age, gender, educational level, and online shopping experience (years). In the second part of the questionnaire, 10 statements were used to measure three constructs, "vividness, elaboration, and quantity." These statements were taken from the previous studies. The statements of vividness and elaboration are taken from Walters et al., (2007), and the statements of quantity are adapted from Babin and Burns (1998). A 5-point Likert scale was used to measure participant's level of agreement and disagreement. All the hypotheses $H_{1}, H_{2}$, and $H_{3}$ were analyzed by descriptive statistics and one-sample $t$-test in SPSS 21.

\section{Analysis and Interpretation}

As per the assumption of the $t$-test, the variables are continuous, and all the observations are independent of each other. There is no outlier in the data set. A 
sample size of 142 respondents is taken. "In fact, for a large sample of 120 or more, the $t$ distribution and the normal distribution are virtually indistinguishable" (Malhotra et al., 2017).

Table 1 shows the different variables of mental imagery grouped in three factors known as "vividness, quantity, and elaboration." The mean value and standard deviation of different items are shown in Table 1. The mean value shows the average level of agreement, and the variability of responses is shown by the standard deviation. For the first factor (vividness), the mean value of "very sharp images of glasses come in my mind" has the highest mean value $(\bar{X}=4.41)$ followed by the "provide me very vivid product information" and "very intense images of glasses come in my mind" with a mean value $(\bar{X}=4.27)$. The variable "very clear and specific images of glasses come in my mind" has the highest variability in response $(\sigma=0.711)$. In the second factor (quantity), only two variables are there, and both have the same mean value $(\bar{X}=4.32)$, but the variability of response in the second item "I can imagine many things during virtual try-on" is high $(\sigma=0.728)$. In the third factor (elaboration), four variables are there. "Easy to imagine wearing glasses" has the highest mean value $(\bar{X}=4.39)$ and variations in response with a standard deviation $(\sigma=0.742)$. The second highest mean value $(\bar{X}=4.31)$ is of item "virtual try-on imagination helps me to construct story about myself and the product." The variable "it seems that I am actually trying the glasses" has the lowest contribution in the factor "elaboration" with a mean value $(\bar{X}=4.26)$. Hence, it is supposed that the variable having the highest mean value influences the mental imagery the most, and those that are having the lowest mean value are the low influencer of mental imagery; same as the variable having the high standard deviation means to have high variability in responses.

Table 2 depicts the various factors of mental imagery with their mean value and standard deviations. Quantity and elaboration dimensions have approximately equal means $(\bar{X}=4.316)$ and $(\bar{X}=4.315)$, respectively. Hence, these evoke more mental imagery than the vividness which has a mean value $(\bar{X}=4.297)$. Table 2 shows that elaboration has the highest variability in responses with a standard deviation $(\sigma=0.614)$ followed by quantity $(\sigma=0.585)$ and vividness $(\sigma=0.519)$. It means vividness has the highest consistency in responses. All the dimensions of mental imagery are significant and provide insight to the retailer that these should be taken into account while deciding the way of product presentation in the online environment.

Table 3 represents an analysis of mental imagery dimensions based on the $t$-test. A one-sample $t$-test has been run to check whether "vividness" is different from the normal score or not, defined as "vividness" score 3. The mean score of "vividness" $(M=4.297)$ is higher than the normal "vividness" score of 3 , a statistically mean difference of $1.297,95 \% \mathrm{CI}, t(141)=29.787, p=.000$. Hence, "vividness" is positively affected by "virtual try-on." Again one-sample $t$-test is used in $\mathrm{H}_{2}$ to check whether "quantity" is different from the normal score or not, defined as a "quantity" score 3 . The mean "quantity" score $(M=4.316)$ is higher than the normal "quantity" score of 3, a statistically mean difference of 1.316 , $95 \% \mathrm{CI}, t(141)=26.829, p=.000$. Hence, "quantity" is positively affected by 
Table I. Dimensions of Mental Imagery

\begin{tabular}{lcc}
\hline Scale Items & M & SD \\
\hline $\begin{array}{l}\text { Vividness } \\
\text { Very clear and specific images of glasses come in my } \\
\text { mind, when I try Lenskart try-on. }\end{array}$ & 4.23 & 0.7 II \\
$\begin{array}{l}\text { Very intense images of glasses come in my mind when I } \\
\text { try Lenskart try-on. }\end{array}$ & 4.27 & 0.621 \\
$\begin{array}{l}\text { Lenskart try-on provide me very vivid product } \\
\text { information. }\end{array}$ & 4.27 & 0.654 \\
$\begin{array}{l}\text { Very sharp images of glasses come in my mind, when I } \\
\text { try Lenskart try-on. }\end{array}$ & 4.4 I & 0.665 \\
$\begin{array}{l}\text { Quantity } \\
\text { During virtual try-on many images of product and myself } \\
\text { come in my mind. }\end{array}$ & 4.32 & 0.678 \\
I can imagine many things during virtual try-on. & 4.32 & 0.728 \\
$\begin{array}{l}\text { Elaboration } \\
\text { While using Lenskart try-on, it seems that I am actually } \\
\text { trying the glasses. }\end{array}$ & 4.26 & 0.73 I \\
$\begin{array}{l}\text { While using Lenskart try-on, it is easy to imagine } \\
\text { wearing glasses. }\end{array}$ & 4.39 & 0.742 \\
$\begin{array}{l}\text { While using Lenskart try-on, it seems that I am a part of } \\
\text { that image which come in my mind. } \\
\text { Virtual try-on imagination helps me to construct story } \\
\text { about myself and the product. }\end{array}$ & 4.30 & 0.714 \\
\hline
\end{tabular}

Source: Primary data.

Note: I = strongly disagree, 2 = disagree, 3 = neutral, 4 = agree, 5 = strongly agree.

virtual try-on. In $\mathrm{H}_{3}$ also, one-sample $t$-test is used to check whether "elaboration" is different from the normal score or not, defined as a "elaboration" score 3 . The mean "elaboration" score $(M=4.315)$ is higher than the normal "elaboration" score of 3 , a statistically mean difference of $1.315,95 \%$ CI, $t(141)=25.541$, $p=.000$. Hence, "elaboration" is positively affected by virtual try-on. Table 3 depicts that all the hypotheses are accepted and at a $95 \%$ confidence interval all the factors are significant. This implies that all the factors, "vividness, quantity, and elaboration," have a significant contribution in evoking mental imagery toward the product presented through this new developing technology. This means that virtual try-on technology will be beneficial during the pandemic period and after this period also.

\section{Discussion and Conclusion}

\section{Discussion}

This study highlighted the different variables and dimensions which evoke mental imagery. To attract and engage the customers for a longer time to browse and learn about virtual products, retailers need to provide vivid, clear product images, and 
Table 2. Analysis of Mental Imagery Dimension on the Basis of Mean Score: One-Sample Statistics

\begin{tabular}{lcccc}
\hline & $N$ & $M$ & $S D$ & $\begin{array}{c}\text { Std. Error } \\
\text { Mean }\end{array}$ \\
\hline Vividness & 142 & 4.2975 & 0.51908 & 0.04356 \\
Quantity & 142 & 4.3169 & 0.58491 & 0.04908 \\
Elaboration & 142 & 4.3151 & 0.61359 & 0.05149 \\
\hline
\end{tabular}

Source: Primary data.

Note: $\mathrm{I}$ = strongly disagree, 2 = disagree, 3 = neutral, 4 = agree, 5 = strongly agree.

quality information that helps customers to imagine the product. This study found out that virtual try-on technology of product presentation has positive influence on all the dimensions of mental imagery which leads to the activation of more mental images. Results of our study are consistent with the results of following different studies. Skard et al. (2021) showed that VR induces mental imagery. Lao (2013) and $\mathrm{Wu}$ annd $\mathrm{Li}$ (2021) found out that the way of product presentation influences mental imagery. Choi and Taylor (2014) showed that "site type" has significant impact on metal imagery. Yoo and Kim (2014) resulted that relevant consumption backgrounds evoke more mental imagery. Gavilan et al. (2014) showed that MMS ads evoke more vivid and elaborated images, but the quantity of images are more in SMS ads. Schlosser (2003) stated that a medium helps to induce more vividness in mental images. Lao et al. (2021) found out that customer experience dimensions, that is, "sensorial, pragmatic, cognitive, and social," also have positive influence on the mental imagery. Huang and Ha (2021) found out that fluency in processing information and images enhances mental imagery. Khrouf and Frikha (2016) found out that congruency between content and website hue causes activation of mental imagery.

Retailers should adopt strategies that increase interactivity with the product (Choi \& Taylor, 2014) because interactivity increases imagery of product which leads to a positive attitude toward retailers and the product. In an e-tail environment, mental imagery acts as a key contributor in persuading customers to buy. Gavilan et al. (2014) stated that mental imagery affects cognitive and affective behavior such as "ad recall, attitude toward the brand, attitude toward the ad, attention, brand belief and brand recall, intention, their duration, and feelings." It has a direct effect on consumer's attitudes and their behavioral intention

Table 3. Analysis of Mental Imagery Dimensions on the Basis of $t$-Test One-Sample Test

\begin{tabular}{lcccccc}
\hline \multicolumn{7}{c}{ Test Value $=3$} \\
\hline & & & & & \multicolumn{2}{c}{$\begin{array}{c}\text { 95\% Confidence Interval of } \\
\text { the Difference }\end{array}$} \\
\hline Vividness & 29.787 & 141 & 0.000 & 1.29754 & 1.2114 & 1.3837 \\
Quantity & 26.829 & 141 & 0.000 & 1.31690 & 1.2199 & 1.4139 \\
Elaboration & 25.541 & 141 & 0.000 & 1.31514 & 1.2133 & 1.4169 \\
\hline
\end{tabular}

Source: Primary data.

Note: $\mathrm{I}$ = strongly disagree, 2 = disagree, 3 = neutral, 4 = agree, 5 = strongly agree. 
(Choi \& Taylor, 2014). Mental imagery is a key mediator between technology and the consumer's attitude. The customer's attitude toward the product is significantly affected by both the dimensions of mental imagery (Park \& Yoo, 2020). Attitude enhances the behavioral intentions of customers (Rathee \& Kumari, 2020). Dimensions of mental imagery, that is, "elaboration and quality," have a significant direct influence on behavioral intention (Yoo \& Kim, 2014). Vividness and elaboration dimensions have a significant influence on purchase intention (Gavilan et al., 2014). Self-mental imagery enhances "hedonic and self-conscious emotions" which leads to "impulse purchase" and positive purchase intentions (Lao, 2013). If customers feel that a particular technology provides a clear and quality information which is required during the purchase process, they can immerse and engage more with it. Product visualization with clear and quality images changes the abstract mindset into concrete (Choi \& Taylor, 2014). Concrete picture presentation influences mental imagery more than textual information (Wu et al., 2020).

\section{Theoretical and Managerial Implications}

The findings provide insight about the mental imagery to retailers as well as researchers to understand the importance of product presentation in the e-tail environment during this COVID-19 pandemic. Results of our study may help to provide empirical evidence to the e-tailer to create better e-tail environment. E-tailers might get help from these findings and frame their strategies accordingly to attract more traffic on their website, increase sales outcomes, and get competitive advantages during and after this pandemic. It also provides theoretical and practical insights to researchers: How virtual try-on technology influences the mental imagery? This study contributes to the literature of marketing to study the mental imagery of customers toward the new developing technologies.

\section{Conclusion}

The objective of this study is to empirically examine whether virtual try-on activates the mental imagery by affecting the different dimensions of mental imagery. The results show that virtual try-on technology enhances the mental imagery of customers toward the glasses. All the dimensions of mental imagery have a positive mean value (above 4). Based on the results and discussion, it is concluded that the e-tailers can increase the customer's mental imagery and virtual experiences by adopting new product visualization technology (virtual try-on) during this pandemic because it not only enhances mental imagery but also leads mental imagery to positive customer attitude toward product, technology, and retailer's website. Mental imagery also influences the behavioral intention of customers. Hence, mental imagery plays a crucial role in this online retail environment so the retailers can widen their business and get a competitive advantage.

Few limitations were confronted by the researchers while conducting this study. First, this study is conducted in the Delhi NCR region, so the results may not be 
generalized all over India and other countries. Second, while collecting data, the questionnaire was sent to respondents via the internet. No face-to-face interaction was there with the respondents. Third, the study was conducted through the internet survey method; its results might have been different if it was an experiment and conducted in controlled conditions. Future studies can be conducted in other regions with specific product categories and with face-to-face interactions.

\section{Declaration of Conflicting Interests}

The authors declare that there is no conflict of interest.

\section{Funding}

The authors received no financial support for the research, authorship, and/or publication of this article.

\section{Note}

1. Revolutionary virtual try-on technology in fashion retail will boost economic recovery. Retrieved June 21, 2021, from https://inc42.com/resources/revolutionaryvirtual-try-ontechnology-vto-in-fashion-retail-will-boost-global-economic-recovery/

\section{References}

Babin, L. A., \& Burns, A. C. (1998). A modified scale for the measurement of communication-evoked mental imagery. Psychology and Marketing, 15(3), 261-278.

Bone, P. F., \& Ellen, P. S. (1992). The generation and consequences of communication-evoked imagery. Journal of Consumer Research, 19(1), 93. https://doi.org/10.1086/209289

Bonetti, F., Warnaby, G., \& Quinn, L. (2018). Augmented reality and virtual reality. In T. Jung \& M. C. Tom Dieck (Eds.), Augmented reality and virtual reality: Empowering human, place and business. https://doi.org/10.1007/978-3-319-64027-3

Cheng, L.-K., \& Toung, C.-L. (2021). More fluency of the mental imagery, more effective? Journal of Social Marketing, 11(1), 1-24. https://doi.org/10.1108/JSOCM-03-20200031

Choi, Y. K., \& Taylor, C. R. (2014). How do 3-dimensional images promote products on the Internet? Journal of Business Research, 67(10), 2164-2170. https://doi.org/10.1016/j. jbusres.2014.04.026

Dahl, D. W., Chattopadhyay, A., \& Gorn, G. J. (1999). The use of visual mental imagery in new product design. Journal of Marketing Research, 36(1), 18. https://doi. org $/ 10.2307 / 3151912$

Farshid, M., Paschen, J., Eriksson, T., \& Kietzmann, J. (2018). Go boldly! Business Horizons, 61(5), 657-663. https://doi.org/10.1016/j.bushor.2018.05.009

Gavilan, D., Avello, M., \& Abril, C. (2014). The mediating role of mental imagery in mobile advertising. International Journal of Information Management, 34(4), 457-464. https://doi.org/10.1016/j.ijinfomgt.2014.04.004

Ha, S., Huang, R., \& Park, J.-S. (2019). Persuasive brand messages in social media: A mental imagery processing perspective. Journal of Retailing and Consumer Services, 48, 41-49. https://doi.org/10.1016/j.jretconser.2019.01.006

Huang, R., \& Ha, S. (2021). The role of need for cognition in consumers' mental imagery: A study of retail brand's Instagram. International Journal of Retail \& Distribution Management, 49(2), 242-262. https://doi.org/10.1108/IJRDM-04-2020-0146 
Khrouf, L., \& Frikha, A. (2016). Web-surfers' conative reactions to the website's dominant hue: Mental imagery's role. Internet Research, 26(5), 1249-1268. https://doi. org/10.1108/IntR-01-2014-0015

Lao, A. (2013). Mental imagery and its determinants as factors of consumers emotional and behavioural responses: Situation analysis in online shopping. Recherche et Applications En Marketing (English Edition), 28(3), 58-81. https://doi.org/ $10.1177 / 2051570713505479$

Lao, A., Vlad, M., \& Martin, A. (2021). Exploring how digital kiosk customer experience enhances shopping value, self-mental imagery and behavioral responses. International Journal of Retail \& Distribution Management, 49(7), 817-845. https://doi.org/10.1108/ IJRDM-09-2020-0357

Malhotra, N. K., Nunan, D., \& Birks, D. F. (2017). Marketing research: An applied approach (5th ed.). Pearson Education Limited.

Neck, C. P., \& Manz, C. C. (1992). Thought self-leadership: The influence of self-talk and mental imagery on performance. Journal of Organizational Behavior, 13(7), 681-699. https://doi.org/10.1002/job.4030130705

Overmars, S., \& Poels, K. (2015). How product representation shapes virtual experiences and re-patronage intentions: the role of mental imagery processing and experiential value. The International Review of Retail, Distribution and Consumer Research, 25(3), 236-259. https://doi.org/10.1080/09593969.2014.988279

Park, M., \& Yoo, J. (2020, January). Effects of perceived interactivity of augmented reality on consumer responses: A mental imagery perspective. Journal of Retailing and Consumer Services, 52, 101912. https://doi.org/10.1016/j.jretconser.2019.101912

Rathee, V., \& Kumari, S. (2020). Impact of 3D technology on consumer buying behavior: A review of literature approach. Wesleyan Journal of Research, 13(4), 64-75.

Schlosser, A. E. (2003). Experiencing products in the virtual world: The role of goal and imagery in influencing attitudes versus purchase intentions. Journal of Consumer Research, 30(2), 184-198. https://doi.org/10.1086/376807

Skard, S., Knudsen, E. S., Sjåstad, H., \& Thorbjørnsen, H. (2021, June). How virtual reality influences travel intentions: The role of mental imagery and happiness forecasting. Tourism Management, 87, 104360. https://doi.org/10.1016/j.tourman.2021.104360

Suh, A., \& Prophet, J. (2018). The state of immersive technology research: A literature analysis. Computers in Human Behavior, 86, 77-90. https://doi.org/10.1016/j.chb. 2018.04.019

Sun, D., Xu, L., Zhang, L., \& Cui, N. (2019). How augmented reality affects people's perceptions: Adoption of AR in product display improves consumers' product attitude. Journal of Physics: Conference Series, 1288(1), 012037. https://doi.org/10.1088/17426596/1288/1/012037

Walters, G., Sparks, B., \& Herington, C. (2007). The effectiveness of print advertising stimuli in evoking elaborate consumption visions for potential travelers. Journal of Travel Research, 46(1), 24-34. https://doi.org/10.1177/0047287507302376

Wu, J., Wang, F., Liu, L., \& Shin, D. (2020, February). Effect of online product presentation on the purchase intention of wearable devices: The role of mental imagery and individualism-collectivism. Frontiers in Psychology, 11, 1-14. https://doi.org/10.3389/ fpsyg.2020.00056

Wu, R., \& Li, Y. (2021). The effect of human model image backgrounds on consumer responses: Empirical evidence from a Chinese apparel e-retailer. Asia Pacific Journal of Marketing and Logistics, 33(8), 1844-1860. https://doi.org/10.1108/APJML-052020-0343 
Yoo, J., \& Kim, M. (2014). The effects of online product presentation on consumer responses: A mental imagery perspective. Journal of Business Research, 67(11), 2464-2472. https://doi.org/10.1016/j.jbusres.2014.03.006

Zhou, F., Duh, H. B.-L., \& Billinghurst, M. (2008, September). Trends in augmented reality tracking, interaction and display: A review of ten years of ISMAR. In 2008 7th IEEE/ ACM International Symposium on Mixed and Augmented Reality (pp. 193-202). IEEE. https://doi.org/10.1109/ISMAR.2008.4637362 


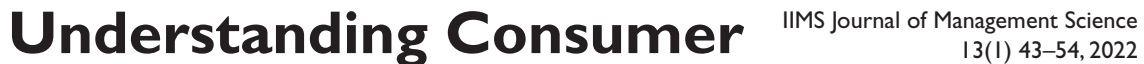 Perception Toward Usage of Music Apps During COVID-19: A Study in West Bengal State

\author{
Samuel S. Mitra', A. Peter Arockiam², \\ K. Joseph ${ }^{3}$, Milton Costa ${ }^{4}$ and Payal Sharma ${ }^{3}$
}

\begin{abstract}
The astounding proliferation of mobile internet and technological innovations is one of the revelations of the 2 Ist-century modern world. Electronic gadgets such as smartphones and tablets possess bewildering and alluring features which when blended with internet gives the modus vivendi of the consumers a completely different meaning. It has been observed that consumers have shown a strong penchant toward such technological vantages and innovative gadgets. In this context, the rise in the usage of music apps has been driven largely by the skyrocketing in the production and use of smartphones, coupled with the landscape of fast-paced internet. There are large number of consumers who have been adopting and using music apps, especially during the boring and monotonous period of COVID-19. The current research study is attempted at examining and analyzing the attitudes and behavior of the consumers toward the use of such music apps. For this purpose, a survey has been conducted in selected districts of West Bengal on the basis of "technology acceptance model". The results reveal that consumers of West Bengal have positive perception toward music apps.
\end{abstract}

\section{Keywords}

COVID-19 pandemic, mobile commerce, music apps, attitudes and behavior, technology acceptance model (TAM)

\footnotetext{
' St. Xavier's College (Autonomous), Kolkata,West Bengal, India

${ }^{2}$ Department of Commerce (Evening), St. Xavier's College (Autonomous), Kolkata, West Bengal, India ${ }^{3}$ Department of Commerce (Morning), St. Xavier's College (Autonomous), Kolkata, West Bengal, India

${ }^{4}$ Deparment of Commerce and Management, St. Xavier's University, Kolkata, West Bengal, India
}

\section{Corresponding Author:}

Samuel S. Mitra, Staff and Researcher, St. Xavier's College (Autonomous), Kolkata, West Bengal 700016, India.

E-mail: samuelmitra18@gmail.com 
JEL Classification: M3I, O33, O3 I

\section{Background Reflections}

The growth and upsurge in the milieu of technological applications has been largely triggered by the dramatic escalation in the usage of internet, smartphones, and persistent percolation of technologies in the ambit of e-commerce. The eyetwitching technologies coupled with the consumers' proclivity toward a more luxurious modus operandi has been a nifty driving force for the emergence of such alluring transitions in the landscape of consumers' modus vivendi. In the past few years in a developing country like India, the spontaneous proliferation in the domain of e-commerce and mobile commerce has facilitated a plethora of hasslefree online applications such as mobile apps, food apps, shopping apps, taxi hailing apps, and so on that has been embraced by a huge proportion of Indian customers, thereby, bringing a change in their behavioral trajectories. The implementation of $4 \mathrm{G}$ network, low data cost, the juggernaut of technological innovations, the splendid metamorphosis in the features of latest smartphones, blended with penchant of Indian consumers in the quest for a more luxurious lifestyle has propelled the demand in the usage of various music apps such as Gaana, Wynk, JioSaavn, Spotify, Google Play Music, and so on. With the advent of music apps, a major clod of Indian consumers have been instantaneously willing to use such expedient services that are offered at free or minimal cost. The objective of current research endeavor is to investigate the intrinsic motivations, perceptions, and adoption mechanisms of users of music apps in the era of COVID-19.

\section{Introductory Observations}

Greater access to internet during COVID-19 has been an opportunistic tenet, increasing the consumers' reliance of digital platforms. By capitalizing on the latest technological vantage points in the context of music apps, consumers are enjoying the benefits of high-quality audio streaming services at no cost. It can be safely asserted that consumers are done with the traditional modes of listening to music in the form of CDs, cassettes, and MP3 player which came with substantial cost and durability issues. The present age of digital revolution has created an impeccable aura which the consumers are quick to respond and usher into. Moreover, music apps serve the twin purpose of a low storage space and easy access to audio streaming which includes innumerable number and variety of songs which otherwise would have been impossible to store in a smartphone or tablet given the storage capacity of the devices, thus, proving to be a win-win situation. Thus, with such prolific amelioration in technology, customers are unshackled of the traditional stranglehold of music listening. According to the data published by Statista Research Department on April 23, 2021, there are five biggest players of music streaming app in India's audio streaming market: Gaana, JioSaavn, Wynk, Spotify, and Google Play Music, followed by others. Gaana was perched with a whopping proportion of $30 \%$ in the country's audio streaming market share, followed by JioSaavn which accounted for $24 \%$ while Wynk and 
Spotify reserved $15 \%$ each. Google Play was at the fourth place with $10 \%$ and the rest making up for the available $6 \%$. Truth to be told, the Indian online audio streaming sector is said to be growing in leaps and bounds in the forthcoming years. However, music is unmonetized in India and thus, there lies a chink in the armor for all such music streaming companies to experiment with advertisement supported as well as paid streaming options (Srivastava, 2020). In 2020, Gaana showed that $85 \%$ of its users listened to Indian pop music while Spotify showed that even a bigger chunk of listeners stream international acts (Pavez, 2021).

One of the arduous tasks for any academic researcher exists in augmenting the current cognizant level of multiple factors which influences the adoption and usage of music apps, in light of "technology acceptance model" (TAM), where the crux objective is to probe into the motivations, preferences, attitudes, and behavioral intentions (BIs) of consumers toward such technology or apps. In the current research study, TAM has been modified to rejig the domains of "subjective norm" (SN) and "COVID-19 exigency." Albeit few researches that have shown the blending of key components like "attitude-intention-behavior," here in the present research study, the emphasis should be on conventional TAM with minor modifications.

\section{Objectives of the Study}

1. To develop an integrated framework of user acceptance and intention toward music apps pillared on traditional TAM constructs and contemporaneous components.

2. To examine and analyze the attitudes and behavior of consumers toward music apps amidst COVID-19 pandemic.

\section{Review of Associated Literature}

Research in the domain of technology and consumer behavior is not new, but probing into the perceptions of consumers toward music apps in the context of 'new normal' is a novel endeavor. Over the years, there have been massive pioneering and development of myriad theories and models for the purpose of explaining and prognosticating the behavior toward technologically driven acts. TAM is considered to be among the most influential models of technological acceptance, "an extension of the theory of reasoned action (TRA)."

Here, in the current research study, we are attempting to measure the attitudes and behavior of consumers in the state of West Bengal toward adoption and usage of music apps and hence it is almost imperative to discuss about TAM and use it for bolstering the worth of the study. "TAM is one of the most influential extensions of Theory of Reasoned Action (TRA)," which was brought into existence by Ajzen and Fishbein (1980). TAM is an amelioration over TRA since it was pillared on independent variables such as "perceived usefulness" (PU) and "perceived ease of use" (PEOU) as well as dependent variables like "attitude toward usage" (ATU).

Fred Davis first coined the term "perceived usefulness" which refers to the extent of a belief held by a person that the usage of a particular system would 
result in the enhancement of his/her job performance. Davis (1989) also defined the term "perceived ease of use" as the extent of a belief held by a person regarding the usage of a system which would be effortless. In further addition to the existing theory, Davis (1993) opined that the usage of the actual information system was a determination of a concept called "behavioral intention" which was a result of the combined force of ATU and PU. He defined it as "the subjective probability that an individual will perform a specified behavior." ATU is a crux dependent variable in the TAM, and, in the words of Ajzen and Fishbein (2000), ATU is the evaluative effect of positive and negative emotions among individuals toward the usage of a particular system.

TAM is being continuously studied and expanded. Luam and Lin (2004) emphasized on the application of TAM, where their crux objective was the corroboration of the influence of mobile trust, PU and PEOU on services over wireless devices categorizing these crux components as independent variables having an inexorable impact on the customer adoption of SMS technology. It is noteworthy that the traditional model of TAM has also proven to be quite flexible to include independent constructs, most notably SN, as first introduced by Taylor and Todd (1995), who defined it as "the influence gained from social circle on whether or not to use a particular system." The two crux upgrades include TAM2 (Venkatesh \& Davis, 2000) and "unified theory of acceptance and use of technology" (Venkatesh et al., 2003). There has also been a proposition of TAM3 in the ambit of e-commerce, inclusive of trust effects and perceived risk on system usage (Venkatesh \& Bala, 2008).

Roy (2017), in his study, incorporated a similar model blending the domain of SN with keywords of PU, PEOU, ATU and BI. The study focused on the consumer acceptance and adoption toward the use of taxi-hailing apps.

The motivation for developing a similar research model for the present study has been largely taken from Davis et al. (1989) and Roy (2017).

Any exigencies or unforeseen emergencies triggers abnormal behavior among consumers. The attitude and behavior of consumers also change in times of exigencies, and COVID-19 is no exception. The attitudinal display witnessed by the consumers during the time of this ongoing pandemic is quite astounding where consumers have become more cost conscious and alert toward health and safety. In this light, they are currently restricting their outdoor activities and trying to stay at home to the best possible extent, thus, adhering to the norms of COVID-19 protocols. However, the harsh isolations at home and traditional methods of music listening has become a burden on the consumers which they are looking forward to unshackle. As a result, consumers are seen adopting and using music apps and listening to variety of songs, even international songs, after a comfy and hasslefree access. This phenomenon is also having a prodigious impact on the attitudes and behavior of the consumers.

Albeit, past researches that have been conducted taking into consideration the concept of SN in the context of TAM are very rare. In addition to this, we find it extremely arduous to come across the domain of COVID-19 exigency used as a construct in TAM, by further introspection of existent literature. This in fact is the essence of our present research study. 


\section{Research Gap}

An intricate analysis of further literature would reveal that there are hardly any research papers that emphasize to measure the perception of consumers toward the adoption and usage of music apps. Past few researches have rather focused on consumer behavior toward online music services, and, as a result, there lies an extensive domain of unexplored research that could be undertaken to examine and analyze the consumer preferences and attitudes toward music apps.

\section{Theoretical Framework}

The existent literature in the domain of consumer behavior and TAM is vast. But a major innovation in contributing to the existing associated literature would be to blend the keywords of SN and "exigency" (COVID-19). The present research study is a novel effort, where the grueling task involved has been blending such key constructs to unfurl the underlying motivations, attitudes, BIs, and perception of consumers, which is the very essence of our purported endeavor.

The current research study is an endeavor, attempted in developing a conceptual framework of the user adoption and usage of music apps, pillared on marginally modified TAM. The below model is a re-modified TAM. The constructs namely SN and "exigencies" (COVID-19)" have been incorporated to cater to the influence of peer groups and urgent unforeseen needs, respectively. Therefore, our research model comprises of 6 constructs, which have been developed and presented below. For this purpose, the following hypotheses have been developed and substantiated through the research model represented above.

$H_{1}$ : PU has a positive influence on ATU.

$\mathrm{H}_{2}$ : PU has a positive influence on BI of consumers.

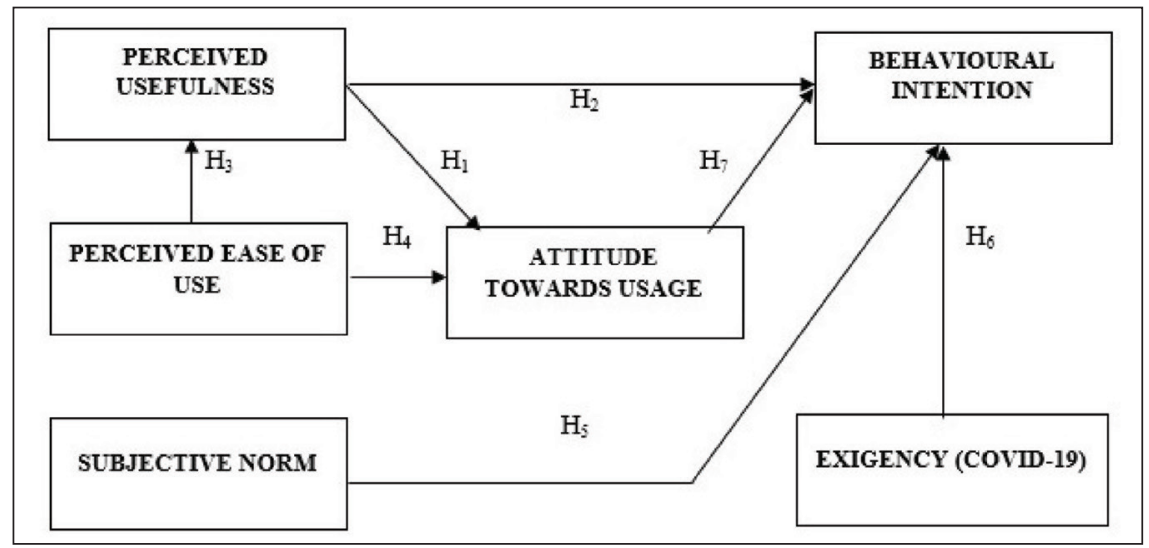

Figure I. Research Model

Source: The authors. 
$H_{3}$ : PEOU has a positive influence on PU.

$H_{4}$ : PEOU has a positive influence on ATU.

$H_{5}$ : $\mathrm{SN}$ has a positive influence on BI of consumers.

$H_{6}$ : Exigency (COVID-19) has a positive influence on BI of consumers.

$H_{7}$ : ATU has a positive influence on BI of consumers.

\section{Data and Methodology}

A rigorous research was conducted including both primary and secondary data. Secondary data was used to create a robust foundation of conceptual framework of the present research study. For this purpose, several research papers have been acquired from various authentic and reliable e-resource websites such as SAGE, JSTOR, BASE, Google Scholar, and so on. The process of primary data collection includes a survey which has been conducted on a total sample size of 500 respondents in different districts of West Bengal such as Kolkata, Howrah, Hooghly, Burdwan, and Birbhum, belonging to the age group of 18-55 years, engaged in various occupations, all of them using music apps. To this end, a closeended questionnaire was developed. Most of the questionnaires were mailed while others were randomly doled out to the respondents. The questions in the questionnaire were mostly self-developed albeit few questions have been adopted from previous researches. The questionnaire contained 23 questions under 6 segments, namely, PU, PEOU, SN, “exigencies" (COVID-19), ATU, and BI. A five-point Likert scale ( $5=$ strongly agree and $1=$ strongly disagree) has been used to measure the concepts. There were few responses that were erroneous and some were not returned, hence, those responses had to be rejected. After the rejection of such responses, the final valid responses stood at 462 .

As observed in Table 1, the number of male respondents $(n=244)$ exceeds the female respondents $(n=218)$. Most of the respondents belong to a young age group in the category of 26-35 years and 36-45 years. Majority of the respondents are either students or servicemen. We also see that most of the respondents having a moderately strong level of income perched in the range of $25.1 \mathrm{~K}-50 \mathrm{~K}$.

\section{Reliability Analysis}

For the purpose of testing whether the variables are consistent or not a Cronbach's Alpha has been run which would help to examine the scale reliability of the constructs. All the "Cronbach's Alpha" values as evidenced in the above table exceed the ideal value of 0.7 , while "Correlations of Corrected Items" are all above the ideal value of 0.5 (see Table 2).

\section{Convergent and Divergent Validity Test}

A convergent validity test has been conducted to check for the convergence of items. According to Fornell and Larcker (1981), "The convergent validity of scale items are determined by their respective factor loadings, composite reliability and 
Table I. Representation of Descriptive Statistics

\begin{tabular}{llcc}
\hline $\begin{array}{llc}\text { Demographic } \\
\text { Construct }\end{array}$ & Classification & $\begin{array}{c}\text { Population } \\
\text { Statistics }\end{array}$ & Percentage \\
\hline Gender & Male & 244 & 0.53 \\
& Female & 218 & 0.47 \\
Age & Total & 462 & 1.00 \\
& $18-25$ & 189 & 0.41 \\
& $26-35$ & 192 & 0.42 \\
Current occupation & 56 & 0.12 \\
& $36-45$ & 25 & 0.05 \\
& $46-55$ & 462 & 1.00 \\
& Total & 166 & 0.36 \\
& Student & 151 & 0.33 \\
& Service & 108 & 0.23 \\
Monthly income & Business & 37 & 0.08 \\
& Others & 462 & 1.00 \\
& Total & 12 & 0.03 \\
& Less than 10,000 & 124 & 0.27 \\
& I0,00I-25,000 & 182 & 0.39 \\
& 25,00I-50,000 & 105 & 0.23 \\
& $50,001-100,000$ & 39 & 0.08 \\
& Above I00,000 & 462 & 1.00 \\
\hline
\end{tabular}

Source: The authors.

average variance extracted." The loadings of "confirmatory factor analysis" (CFA) and composite reliabilities of all factors report figures of above required level of 0.7, while average variance explained (AVE) report figures above required level of 0.5 (see Table 3 ).

The usage of "square root of ACE" and the "correlation coefficient matrix" is important for testing the divergent validity of constructs. As per Fornell and Larcker (1981), "Discriminant validity was obtained by comparing the shared variance between factors with the AVE from the individual factors." The below matrix shows that maximum shared variance and average shared variance between factors are less compared to AVE and also the square root of AVE is higher compared to the correlations of inter-constructs, hence, satisfying the discriminant validity test (see Table 4).

\section{Test for Structural Equation Modelling}

Structural equation modelling (SEM) has been performed to delve into the relationships existing between 6 variables, namely, PEU, PU, ATU, SN, BI, and EXC. The rationality exist in testing the fit between the model and the obtained data. The first stage of making inference about the results of SEM encompasses a review of "fit indices." All the fit indices when juxtaposed with their corresponded values which has been suggested will give a good model fit "ratio of chi-square to its degrees of freedom" $(\chi 2 / d f)=1.977$, "goodness-of-fit index" $(\mathrm{GFI})=0.958$, "Adjusted GFI" 
Table 2. Reliability Statistics

\begin{tabular}{|c|c|c|c|c|}
\hline Construct & Cronbach's Alpha & Items & $\begin{array}{l}\text { Total Correlation } \\
\text { Value of } \\
\text { Corrected ltem }\end{array}$ & $\begin{array}{l}\text { Cronbach's } \\
\text { Alpha When } \\
\text { Item Removec }\end{array}$ \\
\hline Total & 0.994 & 23 & - & - \\
\hline \multirow[t]{3}{*}{ PEOU } & 0.988 & PEUI & 0.987 & 0.982 \\
\hline & & PEU2 & 0.985 & 0.980 \\
\hline & & PEU3 & 0.985 & 0.978 \\
\hline \multirow[t]{6}{*}{ PU } & 0.989 & PUI & 0.975 & 0.986 \\
\hline & & PU2 & 0.974 & 0.985 \\
\hline & & PU3 & 0.978 & 0.985 \\
\hline & & PU4 & 0.979 & 0.985 \\
\hline & & PU5 & 0.977 & 0.985 \\
\hline & & PU6 & 0.917 & 0.983 \\
\hline \multirow[t]{4}{*}{ ATU } & 0.990 & ATUI & 0.980 & 0.985 \\
\hline & & ATU2 & 0.978 & 0.986 \\
\hline & & ATU3 & 0.971 & 0.988 \\
\hline & & ATU4 & 0.969 & 0.988 \\
\hline \multirow[t]{4}{*}{ SN } & 0.962 & SNI & 0.872 & 0.957 \\
\hline & & SN2 & 0.935 & 0.943 \\
\hline & & SN3 & 0.950 & 0.940 \\
\hline & & SN4 & 0.938 & 0.945 \\
\hline \multirow[t]{3}{*}{$\mathrm{BI}$} & 0.981 & BII & 0.977 & 0.961 \\
\hline & & $\mathrm{B} 12$ & 0.941 & 0.984 \\
\hline & & $\mathrm{BI} 3$ & 0.974 & 0.962 \\
\hline & 0.975 & $\mathrm{EXCl}$ & 0.972 & 0.989 \\
\hline \multirow[t]{2}{*}{ (COVID-19) } & & EXC2 & 0.930 & 0.912 \\
\hline & & EXC3 & 0.974 & 0.962 \\
\hline
\end{tabular}

Source: The authors.

$(\mathrm{AGFI})=0.936$, "relative fit index" $(\mathrm{RFI})=0.967$, "comparative fit index" $(\mathrm{CFI})=$ 0.983 and "Root Mean Square Error of Approximation" (RMSEA) = 0.042 (see Table 5).

To this end, the results of hypothesis testing have been obtained. The Table 6 clearly represents the validation of all the hypotheses through the path analysis. It can be concluded that PU and PEOU favorably impact attitudes toward usage with each reporting figures of $(\beta=0.192, p<.05)$ and $(\beta=0.402, p<.05)$, respectively, thereby supporting $\mathrm{H}_{1}$ and $\mathrm{H}_{4}$. The same could be safely asserted for the relationship between PU, SN, ATU, and exigency (COVID-19), which are all significantly associated with BI of consumers toward music apps, with each reporting figures of $\beta=0.198, p<.05 ; \beta=0.405, p<.05 ; \beta=0.443, p<.05$; and $\beta=0.402, p<.05$ respectively substantiating $\mathrm{H}_{2}, \mathrm{H}_{5}, \mathrm{H}_{6}$ and $\mathrm{H}_{7}$. The relationship between PEOU and PU is also linked with figure reporting $(\beta=0.609, p<.05)$, thus, substantiating $\mathrm{H}_{2}$.

\section{Deliberation of Research Findings}

The present research study was a pioneering effort in delving into the consumer attitude and behavior toward music apps by applying TAM. On the basis of our 
Table 3. Convergent Validity Results

\begin{tabular}{|c|c|c|c|c|}
\hline Construct & Items & Factor Loading & AVE & C.R. \\
\hline \multirow[t]{3}{*}{ PEOU } & PEUI & 0.972 & 0.977 & 0.968 \\
\hline & PEU2 & 0.972 & & \\
\hline & PEU3 & 0.977 & & \\
\hline \multirow[t]{6}{*}{ PU } & PUI & 0.978 & 0.947 & 0.992 \\
\hline & PU2 & 0.977 & & \\
\hline & PU3 & 0.980 & & \\
\hline & PU4 & 0.981 & & \\
\hline & PU5 & 0.980 & & \\
\hline & PU6 & 0.942 & & \\
\hline \multirow[t]{4}{*}{ ATU } & ATUI & 0.978 & 0.961 & 0.991 \\
\hline & & 0.977 & & \\
\hline & ATU3 & 0.979 & & \\
\hline & ATU4 & 0.977 & & \\
\hline \multirow[t]{4}{*}{ SN } & SNI & 0.925 & 0.885 & 0.990 \\
\hline & SN2 & 0.846 & & \\
\hline & SN3 & 0.889 & & \\
\hline & SN4 & 0.857 & & \\
\hline \multirow[t]{3}{*}{$\mathrm{BI}$} & BII & 0.979 & 0.960 & 0.986 \\
\hline & $\mathrm{BI} 2$ & 0.977 & & \\
\hline & $\mathrm{BI} 3$ & 0.976 & & \\
\hline Exigency & $\mathrm{EXCl}$ & 0.980 & 0.947 & 0.992 \\
\hline \multirow[t]{2}{*}{ (COVID-19) } & EXC2 & 0.942 & & \\
\hline & EXC3 & 0.978 & & \\
\hline
\end{tabular}

Source: The authors.

Table 4. Divergent Validity Results

\begin{tabular}{lcccccc}
\hline & \multicolumn{7}{c}{ Inter-construct Correlations } \\
\cline { 2 - 7 } Construct & PEU & PU & ATU & SN & BI & EXC \\
\hline PEU & 0.989 & & & & & \\
PU & 0.985 & 0.973 & & & & \\
ATU & 0.982 & 0.954 & 0.980 & & & \\
SN & 0.805 & 0.827 & 0.817 & 0.941 & & \\
BI & 0.963 & 0.969 & 0.974 & 0.934 & 0.942 & \\
EXC & 0.975 & 0.982 & 0.989 & 0.958 & 0.966 & 0.980 \\
\hline
\end{tabular}

Source: The authors.

proposed research model, we explored the liaisons among the traditional TAM components and contemporaneous components such as SN and exigency (COVID-19). The findings of the data analysis of the survey have been examined and proved to have positive and significant relationships with each other as per the hypothetical statements. The current research study is highly relevant in the context of recent proliferation in the milieu of technological innovations and advancements, resulting in the upsurge of e-commerce, m-commerce, smartphones, online audio streaming services, and music apps. According to the first hypothesis, PU had a positive relationship with ATU as the extent to which the importance 
Table 5. Indices for Measure of "Goodness-of-Fit"

\begin{tabular}{lccc}
\hline $\begin{array}{l}\text { Goodness of Fit } \\
\text { Measure }\end{array}$ & $\begin{array}{c}\text { Recommended } \\
\text { Value }\end{array}$ & $\begin{array}{c}\text { Actual Value of } \\
\text { Measures }\end{array}$ & Result of Model Fit \\
\hline CMIN/DF & $\leq 3.00$ & 1.977 & Good \\
GFI & $\geq 0.90$ & 0.958 & Good \\
AGFI & $\geq 0.90$ & 0.936 & Good \\
RFI & $\geq 0.90$ & 0.967 & Good \\
CFI & $\geq 0.90$ & 0.983 & Good \\
RMSEA & $\leq 0.05$ & 0.042 & Good \\
\hline
\end{tabular}

Source: The authors.

Table 6. Results of Path Validation (Hypothesis Testing)

\begin{tabular}{llcll}
\hline Hypotheses & Path & Coefficient & Direction & Results \\
\hline $\mathrm{H}_{1}$ & $\mathrm{PU} \longrightarrow \mathrm{ATU}$ & 0.192 & Positive & Supported \\
$\mathrm{H}_{2}$ & $\mathrm{PU} \longrightarrow \mathrm{BI}$ & 0.198 & Positive & Supported \\
$\mathrm{H}_{3}$ & $\mathrm{PEU} \longrightarrow \mathrm{PU}$ & 0.609 & Positive & Supported \\
$\mathrm{H}_{4}$ & $\mathrm{PEU} \longrightarrow \mathrm{ATU}$ & 0.408 & Positive & Supported \\
$\mathrm{H}_{5}$ & $\mathrm{SN} \longrightarrow \mathrm{BI}$ & 0.405 & Positive & Supported \\
$\mathrm{H}_{6}$ & $\mathrm{ATU} \longrightarrow \mathrm{BI}$ & 0.443 & Positive & Supported \\
$\mathrm{H}_{7}$ & $\mathrm{EXC} \longrightarrow \mathrm{BI}$ & 0.402 & Positive & Supported \\
\hline
\end{tabular}

Source: The authors.

of usefulness will be psychologically casted would have a bearing on the attitude of the consumers. As per the second hypothesis, it was also observed that PU was related to BI. An explanation for this would be that the consumers are always in the quest for using a beneficial application which would make their lives more convenient. We evidence, in the third hypothesis testing, that PU was strongly influenced by PEOU. This hints that providing appropriate user training is essential for bolstering the consumers' perception of the usefulness of a technology. Besides, PEOU was also positively related to ATU, validating our fourth hypothesis. The fifth hypothesis was attempted at examining the relationship between SN and BIs. The impact cast by social circle had a significant impact on the BI of consumers toward adoption and usage of music apps. This is a crucial finding as local clubs, colleagues, or opinion leaders shape the perceptions and attitudes of people toward a technology. As observed by the sixth hypothesis, we have comprehended that the attitude of consumers toward music apps has been instrumental in shaping the BI of such consumers, as both mental as well as physical faculties are a nifty driving force in developing the perceived likelihood of consumers. Finally, the seventh hypothesis analyzed the relationship between exigency (COVID-19) and BIs. Any unforeseen exigencies would trigger an abnormal behavior among people. An example would be any war which can bring a stunning change in the consumption trajectories of the consumers as they would hoard food grains, spend less on luxury items, cut costs, focus on health and safety, and so on. The current situation of this ongoing COVID-19 pandemic is also similar, where people are relinquishing old ways of doing things for the ravishing new ones. The adoption and usage of 
music apps during COVID-19 has also been easy and convenient largely due to the skyrocketing of internet usage and penetration. Such prolonged attitudes observed among the consumers during this "new normal" has brought a bewildering change in their behavior as well.

\section{Research Limitations}

1. Albeit the study emphasizes on West Bengal, sample has been collected from five selected districts of West Bengal only.

2. Owing to the paucity of time and ongoing COVID-19 situations, the sample size has been restricted to only 462 respondents.

\section{Conclusive Statements}

The breathtaking metamorphosis in the landscape of technology has triggered a bewildering growth in e-commerce and m-commerce. The smartphones and tablets of today exhibit qualities like never, hence, making the modus operandi of people rather luxurious. The modern technologies have pulled off a stunning heist by intriguing the customers' frame of mind. Taking into consideration the proclivity of consumers in the contemporaneous panorama, these amelioration in the circa of technology, particularly e-commerce and m-commerce, was a muchneeded tonic. The current research study highlighted certain crux elements under TAM constructs which shall be highly relevant in guiding future researches. People in West Bengal prodigiously valuing the services of online audio streaming especially during these times of pandemic is a manifestation in the sudden escalation in the adoption and usage of music apps and other sources of online audio streaming. Truth to be told, the framework of TAM has been criticized because of its debatable heuristic value, constrained explanatory, and predictive power and triviality. Despite such shortcomings, it is by far, the most popular theoretical model used in academia. The present research study is robust enough to provide valuable conclusions concerning consumer behavior displayed toward adoption and usage of music apps.

\section{Declaration of Conflicting Interests}

The authors declared no potential conflicts of interest with respect to the research, authorship, and/or publication of this article.

\section{Funding}

The authors received no financial support for the research, authorship, and/or publication of this article.

\section{References}

Ajzen, I., \& Fishbein, M. (1980). Understanding attitudes and predicting social behaviour. Prentice Hall. 
Ajzen, I., \& Fishbein, M. (2000). Attitudes and the attitude-behavior relation: Reasoned and automatic processes. European Review of Social Psychology, 11(1), 1-33. https:// doi.org/10.1080/14792779943000116

Davis, F. D. (1989). Perceived usefulness, perceived ease of use, and user acceptance of Information Technology. MIS Quarterly, 13(3), 319-340. https://doi.org/10.2307/249008

Davis, F. D. (1993). User acceptance of information technology: System characteristics, user perceptions and behavioural impacts. International Journal of Man-Machine Studies, 38(3), 475-487. https://doi.org/10.1006/imms.1993.1022

Davis, F. D., Bagozzi, R. P., \& Warshaw, P. R. (1989). User acceptance of computer technology: A comparison of two theoretical models. Management Science, 35(8), 982-1003. https://doi.org/10.1287/mnsc.35.8.982

Fornell, C., \& Larcker, D. F. (1981). Structural equation models with unobservable variables and measurement error: Algebra and statistics. Journal of Marketing Research, 18(3), 382-388. https://doi.org/10.1177/002224378101800313

Luam, P., \& Lin, H. H. (2004). Towards an understanding of the behavioral intention to use mobile banking. Computers in Human Behavior, 21(6), 340-348.

Pavez, T. (2021). Music streaming trends and music services in India: An overview. SonoSuite. http://www.sonosuite.com/blog/music-streaming-trends-in-india/

Roy, S. (2017). Scrutinizing the factors influencing customer adoption of app-based cab services: An application of the technology acceptance model. IUP Journal of Marketing Management, 16(4), 54-69.

Srivastava, A. (2020). Market share of music streaming apps in India. AS. http://www. arpitsrivastava.com/market-share-of-music-streaming-apps-in-india/

Taylor, S., \& Todd, P. A. (1995). Understanding Information Technology usage: A test of competing models. Information Systems Research, 6(2), 144-176. https://doi. org/10.1287/isre.6.2.144

Venkatesh, V., \& Bala, H. (2008). Technology acceptance Model 3 and a research agenda on interventions. Decision Sciences, 39(2), 273-315.

Venkatesh, V., \& Davis, F. D. (2000). A theoretical extension of the technology acceptance model: Four longitudinal field studies. Management Science, 46(2), 186-204. https:// doi.org/10.1287/mnsc.46.2.186.11926

Venkatesh, V., Morris, M. G., Davis, G. B., \& Davis, F. D. (2003). User acceptance of Information Technology: Toward a unified view. MIS Quarterly, 27(3), 425-478. https://doi.org/10.2307/30036540 


\title{
Effect of Communication Strategies for Implementation of IT-based Educational Innovation During COVID-I 9 Pandemic on Students' Motivation, Attitude, and Intent
}

IIMS Journal of Management Science I3(I) 55-73, 2022

(c) The Author(s) 2022 DOI: $10.1177 / 0976030 \times 211051096$ ims.spectrumjps.com

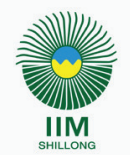

\author{
Irum Alvi'
}

\begin{abstract}
The COVID-19 pandemic made the world come to a halt, but the number and pace of innovation responses became faster than ever. However, there is a paucity of studies concentrating on the management/implementation of innovation in educational institutes. Moreover, no in-depth study has been conducted on the effect of communication strategies adopted for educational innovation implementation on the students' motivation, attitude, and intent to use, particularly in India, to the best of the writer's information.Accordingly, the present study aims to address the research gaps by measuring the effect of select communication strategies used for implementing IT-based educational innovations. Grounded on prior research, the study scrutinizes the effect of rational persuasive strategy (utilizing legitimate contentions), assertive strategy (utilizing intimidation), and consulting strategy (engaging in the act of giving expert advice), and inspirational (evoking feelings of appreciation) strategy. To address the hypotheses framed, the
\end{abstract}

\footnotetext{
' Department of Humanities, English and Applied Sciences (HEAS), Rajasthan Technical University, Kota, Rajasthan, India

\section{Corresponding Author:}

Irum Alvi, Department of Humanities, English and Applied Sciences (HEAS), Rajasthan Technical University, Kota, Rajasthan 3240 I0, India.

E-mail: irumalvi@gmail.com
} 
data for the cross-sectional quantitative study was collected from engineering students using an e-questionnaire from Rajasthan, India. The sample comprised 305 (84.3\% male and $15.7 \%$ female) students, with a mean age of 18.16 years. The findings of PLS-SEM using SmartPLS 3.2.9 confirmed that all strategies except assertive strategy had a positive and significant effect on motivation, attitude, and intent, thereby confirming the role of communication strategies. The study adds to the extant studies on communication strategies, innovation implementation, and adoption of Information Technology for education. The managerial implications include assisting institutes, faculty, and administration in providing insight into appropriate tactics to encourage the implementation of educational innovations among students. The study will also be useful for the administrators/policymakers, for better comprehension of issues and finding solutions for innovation implementation.

\section{Keywords}

Survey of practices, higher education, communication strategies, innovation management/implementation

JEL Classification: 123, 128, 129

\section{Introduction}

The pandemic caused by COVID-19 made the world come to a halt. The number and pace of innovation responses have been bewildering (Woolllinscroft, 2020) as indeed, the innovations have emerged at a very fast pace during the pandemic. The innovations in the field of education were a response to the disruptions to educational institutes, the chaos caused by the lockdown imposed on schools and colleges, and so on. Implementation of educational innovation involves preparing the institute and its stakeholders, especially the students, for using and accepting the innovation, and for its sustained use. Innovation management is the procedure of finding suitable and dedicated usage (Klein \& Sorra, 1996), which depends on the users' choice to accept and to use it (Baradarani \& Kilic, 2018; Dube, 2018), combined with its continuous use (Maroulis \& Wilensky, 2015; Somech \& DrachZahavy, 2013), across different levels (Baek et al., 2018; Tian et al., 2019), until it becomes almost a routine for them (Baradarani \& Kilic, 2018; Dube, 2018; Lapiedra et al., 2011).

Innovation has been the focus of research in recent times as an instrument essential for advancement, improvement, and competitiveness (Chen et al., 2013; Choi et al., 2011). It is characterized as novel thoughts, information, or tasks, and refers to the introduction of new things/methods (Brewer \& Tierney, 2012). The success, financial or otherwise, of any organization/institute is based on its capacity to create and adopt an innovation (Singh et al., 2020). The realization of innovation management is based on mutual adjustment and cooperation between individual/groups with different or contradictory concerns (Cohen et al., 2004); this requires the resolution of the preliminary tensions between innovation and implementation entities (Chung \& Choi, 2018; González-Blanco et al., 2019). 
Educational innovation, in the context of the present study, refers to actions intended to accomplish instructive and educational objectives. The choices for innovation in education during the pandemic were vast and wide-ranging from the instructive framework, structure, ideas, strategies, to educational programs. The innovations endeavors may not always yield the positive results envisioned. This may be ascribed to failure in implementation rather than the failure of innovation (Kim \& Chung, 2017). Moreover, in the context of educational innovation implementation, research has found varied results regarding its success or failure, for example, classroom response system was regarded as good, meticulously trailed by e-lectures, classroom chat, and then mobile virtual reality (Sprenger \& Schwaninger, 2021); other studies have also found inconsistent and contradictory results for the implementation and acceptance of educational innovations from time to time.

Thus, there is a paucity of literature on the implementation of innovation (Kirillova et al., 2020), especially in the context of educational institutes. Although several studies have examined how motivation influences the students' intention, and attitude for the utilization of innovations, no in-depth study has been conducted on the effect of communication strategies used for educational innovation management/implementation, to the best of the writer's information, especially in India. Accordingly, the study aims to address the research gaps by assessing the effectiveness of communication strategies on the students' motivation and their attitude and intent to use because the role played by these strategies is important (Klein et al., 2001). The Technology Acceptance Model (TAM) (Enu-Kwesi \& Opoku, 2020; Zaineldeen \& Koffi, 2020) and Diffusion of Innovation Theory (DIT) (Dearing \& Cox, 2018; Murray, 2020) have established the students' perceptions play an important part in the formation of attitudes and intentions of the students towards any innovation.

\section{Literature Review}

Communication strategy refers to the strategy that imbues communication efforts with a plan/agenda (Christensen, 2014). For the management of any educational innovation, the administration utilizes different communication strategies to deal with and convince the students to acknowledge and utilize the innovation. The strategies include communication, influence, cooperation, or pressure (Burke, 2014; Huy et al., 2014). The administration may use diverse communication strategies to influence the students to achieve the desired objective. The communication strategies are of particular concern for the current examination since they positively or negatively affect the users' motivation, attitudes, or even performance (Al-Asfour \& Lettau, 2014). Based on prior studies, rational persuasive strategy (utilizing legitimate contentions for influencing students attitude and usage of the innovation), assertive strategy (utilizing intimidation for influencing students attitude and usage of the innovation), and relationship-based strategy (alluding to the individual relations for influencing students attitude and usage of the innovation) (Chong, 2014; Chong et al., 2013, 2015), which play an important part in innovation implementation, were selected. However, the relationship-based 
strategy does not apply to the current research because it is not usually implemented in present scenarios (FuPeng et al., 2004).

\section{Assertive Strategies AS}

Illustrations of assertive strategies which administration may adopt for innovation implementation include demanding or even threatening users or incessantly scrutinizing them (Chong, 2014), reiterating the demands again and again until it is fulfilled (Fu et al., 2004) or resorting to the use of the educational institute policies, rules, and regulations for ensuring that the students follow them. It is usually observed that when the institute resorts to the use of assertiveness, the students comply, though they may also resort to resistance at times. The following hypotheses are proposed:

$H_{1 \mathrm{a}}$ : Assertive strategies (AS) positively and significantly affect the students' motivation towards IT-based educational innovation.

$H_{1 \mathrm{~b}}$ : Assertive strategies (AS) positively and significantly affect the students' attitude towards IT-based educational innovation.

$H_{1 \mathrm{c}}$ : Assertive strategies (AS) positively and significantly affect the students' intent to use IT-based educational innovation.

\section{Consulting Strategies CS}

"Consulting" means to engage in the act of giving expert advice to others often about a professional or technical issue, or the business of giving expert advice to others, as such the administration may advise the students about the utility of the IT-based innovation for educational purposes. The consulting strategies may help in solving problems and moving from the current state to the desired state. To scrutinize the effect of consulting strategies on the students, the following hypotheses were formulated:

$H_{2 \mathrm{a}}$ : Consulting Strategies (CS) positively and significantly affect the students' motivation towards IT-based educational innovation.

$H_{2 \mathrm{~b}}$ : Consulting Strategies (CS) positively and significantly affect the students' attitude towards IT-based educational innovation.

$H_{2 \mathrm{c}}$ : Consulting Strategies (CS) positively and significantly affect the students' intent to use IT-based educational innovation.

\section{Inspirational Strategies IS}

Inspiration, a psychological concept (Thrash \& Elliot, 2003) is frequently used interchangeably with several other terms (Oleynick et al., 2014), for example, motivation, encouragement, and so on. Educational administration may utilize inspirational strategies to convince the students why certain practices are better liked, using inspiration to influence the students' behaviors and attitudes. In the innovation implantation phase, the administration/staff/faculty may evoke feelings 
of appreciation for new and novel ideas, things that "fire" the soul (Harding, 1948). The tripartite concept (Thrash \& Elliot, 2003) stipulates three core features of inspiration, namely, elicitation, transcendence, and approach. The hypotheses formulated are as follows:

$H_{3 \mathrm{a}}$ : Inspirational Strategies (IS) positively and significantly affect the students' motivation towards IT-based educational innovation.

$H_{3 \mathrm{~b}}$ : Inspirational Strategies (IS) positively and significantly affect the students' attitude towards IT-based educational innovation.

$H_{3 \mathrm{c}}$ : Inspirational Strategies (IS) positively and significantly affect the students' intent to use IT-based educational innovation.

\section{Rational Persuasion Strategies}

The educational institutes may resort to the use of persuasion strategies to convince the students, giving them logical and rational arguments for elucidating the innovation's harmonious aspects with the users' beliefs and values (Chong et al., 2013, 2015). They may discuss how the educational institute could provide training, deliver advantage (Yukl et al., 2005), ask for input/feedback, and involve them in the process of implementation (Chong, 2014), thus making the users commit to the use (Yukl et al., 2005). It is assumed that if the users are aware of the positive aspects of the innovation being implemented and if they are provided with the requisite assistance in its use, they would be more like to accept it (Sharma \& Yetton, 2007). It is anticipated that the communication strategy lowers the perceived complexity of the IT-based educational innovation. The hypotheses proposed are as follows:

$H_{4 a}$ : Rational Persuasion Strategies (RPS) positively and significantly affect the students' motivation towards IT-based educational innovation.

$H_{4 \mathrm{~b}}$ : Rational Persuasion Strategies (RPS) positively and significantly affect the students' attitude towards IT-based educational innovation.

$H_{4 \mathrm{c}}$ : Rational Persuasion Strategies (RPS) positively and significantly affect the students' intent to use IT-based educational innovation.

\section{Motivation}

Motivation is a psychological feature that clarifies why individuals behave differently (Nahavandi et al., 2015); it is a source of conviction (Gopalan et al., 2020). The students' motivation influences how they respond to any educational innovation implemented by the institutes. In light of self-determination theory (SDT), a student may be argued to possess three fundamental psychological requirements: autonomy, ability, and relatedness (Aryee et al., 2015; Haivas et al., 2013). Motivation is pertinent to the management of innovation as it shows the primacies that the individual seeks (Loscocco, 1989), which may bring about various results for implementing innovation. Thus, the following hypotheses were framed: 
$H_{5}$ : Motivation (M) positively and significantly affects the students' attitude towards IT-based educational innovation.

$H_{6}$ : Motivation (M) positively and significantly affects the students' intent to use IT-based educational innovation.

\section{Innovation in the Context of the Current Study}

Innovation refers to any new products/processes/procedures which are new for the students, irrespective of the fact of how long they have been accessible (Rogers, 2003). The study mainly focuses on ICT-based educational innovations, which have been recently introduced by the Department of Higher Education, Government of Rajasthan, for achieving vision goals of 2022 and are being used extensively during the pandemic, for example, "Massive open online courses (MOOCs), spoken tutorials for FOSS courses, digital classrooms, online test for students to access skill and aptitude on regular basis, ... etc.” (digitalLearning Network, 2017).

The term "administration" alludes to institute administration/staff/faculty entrusted with the responsibility of implementing the innovation. The students' attitudes and intentions are measured as results of innovation implementation and as dependent variables, and the various communication strategies are used as independent variables. Figure 1 displays the hypothesized model for the present study.

\section{Methodology}

The research design utilized for the investigation was cross-sectional, using a quantitative approach to get reactions from the students for measuring and

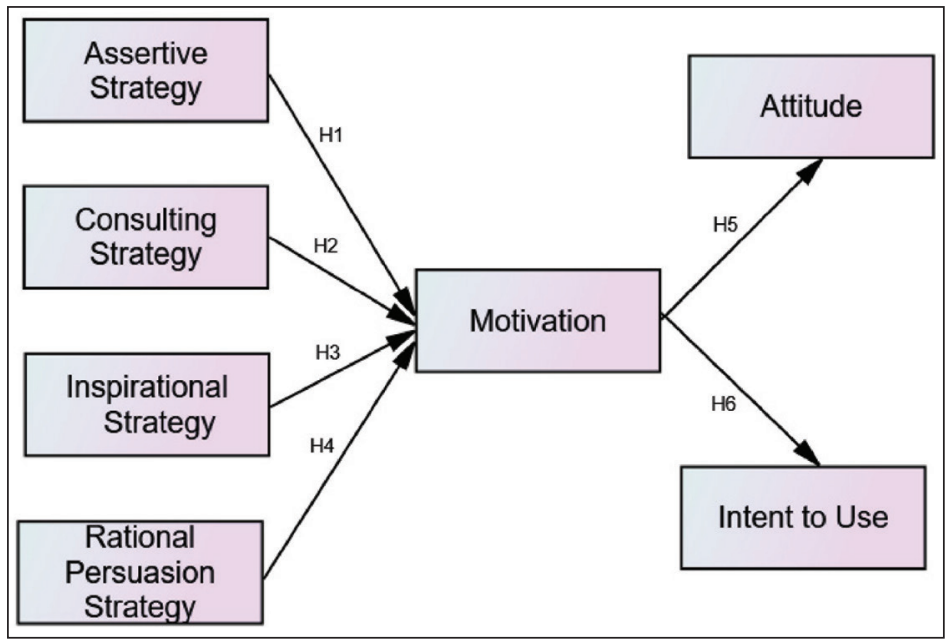

Figure I. Research Model Showing the Hypothesized Paths

Source: The author. 
evaluating the effectiveness of communication strategies for the management/ implementation of educational IT Innovations on the students' motivation, attitudes, and intention. The data was collected in January 2021 from students from the State of Rajasthan, India. The State of Rajasthan was chosen as the target area for the survey, as the "Government of Rajasthan introduced innovations into the State's educational landscape" ... "realizing the growing importance of higher education for youngsters as one of the important prerequisites for grabbing good jobs and achieve a decent living standard." (digitalLearning Network, 2017). As no detailed study has been done in this context, the present study aimed to bridge the research gap by investigating the role of communication strategies on educational innovation implementation.

The sample was chosen using the random sampling method for the validation of the hypotheses framed. Random sampling gave all the students in the populace equivalent opportunities to partake in the investigation. A total of 305 students were selected from different engineering institutes. As the background of the student, educational level and the stream of education may have an impact on the results of the study, hence, data were collected only from engineering students. It is pertinent to mention that the background of the students is crucial to embracing any kind of tech-based innovation, for example, engineering graduates may easily adapt to technology-based innovations in the classroom, whereas literature or philosophy students, for instance, may not embrace it in the same way. The author took care of this aspect in the research design, by limiting the scope of the study to engineering students only. Moreover, the level of education and age may also have a comparable effect, so data was collected only from first-year students with an average age of 18.16 years standard deviation of 0.94 . The sample comprised of 305 students, 257 males $(84.3 \%)$ and 48 females (15.7\%) with a mean age of 18.16 years.

\section{Instrument and Constructs}

The information for this examination was collected using an e-questionnaire. All the items were based on measures from extant scholarly work. The constructs for the examination were estimated utilizing different items anchored on the fivepoint Likert scale - where, 1 is "emphatically disagree" and 5 is "emphatically agree"-for securing the students" perceptions about the select constructs. The constructs for select communication strategies were based on the influence strategy Behavior questionnaire (Chiu, 2017; Yukl et al., 2005; Yukl et al., 2008). Each construct consisted of four items; however, few items were deleted, based on their poor loadings, to ensure the construct's reliability. The construct of motivations was estimated utilizing three items based on extant studies (Loscocco, 1989). The procedure of data management involved the corroboration of the filled e-questionnaires received from the students, information authentication, and inspection for errors, discovering mistakes in the data document, and remedying the current mistakes in the data set (Field, 2005; Hair et al., 2010; Pallant, 2005). The sample size was calculated using the ten times rule as well as the power investigation technique (Hair et al., 2017). 


\section{Data Analysis}

Scrutinizing common method variance (CMV) is important in cases where dependent and independent factors are based on the responses acquired through a self-administrated questionnaire for the collection of data (Podsakoff et al., 2003). To ensure honest responses were given by the students, anonymity and privacy measures were taken. Second, Harman's single factor test was used to ensure the data was clean and unbiased. Common method bias is caused when one factor embodies a main portion of variances after factor analysis (Podsakoff et al., 2003). The sums of squared loading extracted indicated $38.383 \%$ of the variance, which is much below the threshold of $50 \%$, demonstrating method bias is not an issue (Podsakoff et al., 2003). For analyzing the data, structural equation modeling (SEM) was considered since the study utilized a designed questionnaire for gathering data employing latent constructs (Usakli \& Kucukergin, 2018). The values for KMO and Bartlett's Test of Sphericity were 0.890 and 3126.822 significant at $<0.000$.

\section{Hypothesis Testing}

Using SmartPLS, SEM was used for testing the Hypotheses framed in the hypothetical model. Comparable to SEM (CB-SEM), the selected application helps validate direct and indirect effects. Moreover, it does not necessitate data normality, which is important for CB-SEM (Hair et al., 2011). It can satisfactorily assess models despite a moderate sample size (Hair et al., 2017). As such, PLS-SEM was used, due to the moderate sample size, and its lack of normal distribution. The study adopted a two-stage approach, the measurement model, and the structural model (Ali et al., 2018).

\section{Results}

\section{Measurement Model}

The model developed was tested for composite, convergent, and discriminant validities. Reliability was estimated utilizing Cronbach's alpha coefficient. The general guideline is that it ought to have values above 0.70 (Bagozzi \& Yi, 1988; Cronbach, 1971; Nunnally, 1978). Composite reliability (CR) is an alternative measure for calculating reliability. For demonstrating suitability in exploratory and advanced research, estimations ranging from 0.60 to 0.90 are considered satisfactory. The average variance extracted (AVE) was utilized to establish validity, which was above 0.5 (Table 1 ).

For testing of discriminant validity, the Fornell-Larcker criterion was used (Fornell \& Larcker, 1981; Henseler et al., 2016); as indicated in Table 2 all values in diagonal shown in bold were found to be higher than the correlations between the other items. The cross-loadings were checked and found satisfactory, as indicated in bold fonts for each construct. The outcomes are shown in Tables 2 and 3.

Heterotrait-Monotrait (HTMT) ratio, an alternative gauge for measuring discriminant validity, is considered as more vigorous in identifying validity issues; HTMT values were below the threshold of 0.90 (Henseler et al., 2015). Table 4 shows the HTMT ratio. Subsequently, the structural model was constructed after convergent reliability and discriminant validity were established. 
Table I. Construct Validity and Reliability

\begin{tabular}{|c|c|c|c|c|c|c|c|}
\hline Constructs & Indicators & Loadings & CA & Rho A & $\mathrm{CR}$ & (AVE) & Results \\
\hline \multirow{4}{*}{$\begin{array}{l}\text { Inspirational } \\
\text { strategy }\end{array}$} & ISI & 0.692 & & & & & \\
\hline & IS2 & 0.718 & & & & & \\
\hline & IS3 & 0.829 & & & & & \\
\hline & IS4 & 0.749 & 0.835 & 0.840 & 0.836 & $0.56 \mathrm{I}$ & Valid \\
\hline \multirow{2}{*}{$\begin{array}{l}\text { Assertive } \\
\text { strategy }\end{array}$} & AS2 & 0.887 & & & & & \\
\hline & AS3 & 0.780 & 0.818 & 0.828 & 0.821 & 0.698 & Valid \\
\hline \multirow{3}{*}{$\begin{array}{l}\text { Consulting } \\
\text { strategy }\end{array}$} & CS2 & 0.765 & & & & & \\
\hline & CS3 & 0.806 & & & & & \\
\hline & CS4 & 0.791 & 0.829 & 0.831 & 0.830 & 0.620 & Valid \\
\hline \multirow[t]{2}{*}{ Attitude } & ATI & 0.832 & & & & & \\
\hline & AT2 & 0.731 & 0.756 & 0.765 & 0.760 & 0.613 & Valid \\
\hline \multirow[t]{4}{*}{ Motivation } & IMI & 0.824 & & & & & \\
\hline & IM2 & 0.625 & & & & & \\
\hline & IM3 & 0.792 & & & & & \\
\hline & IM4 & 0.769 & 0.835 & 0.849 & $0.84 I$ & 0.572 & Valid \\
\hline \multirow[t]{2}{*}{ Intent to use } & IU2 & 0.746 & & & & & \\
\hline & IU3 & 0.815 & 0.756 & 0.760 & 0.757 & 0.610 & Valid \\
\hline \multirow{4}{*}{$\begin{array}{l}\text { Rational } \\
\text { persuasion } \\
\text { strategy }\end{array}$} & RPSI & 0.829 & & & & & \\
\hline & RPS2 & 0.957 & & & & & \\
\hline & RPS3 & 0.814 & & & & & \\
\hline & RPS4 & 0.868 & 0.900 & 0.928 & 0.904 & 0.754 & Valid \\
\hline
\end{tabular}

Source: The author.

Table 2. Fornell and Larker Criteria using SmartPLS

\begin{tabular}{|c|c|c|c|c|c|c|c|c|}
\hline & AS & AT & CS & IS & $\begin{array}{l}\text { Intent } \\
\text { to Use }\end{array}$ & M & RPS & Results \\
\hline $\begin{array}{l}\text { Assertive } \\
\text { strategy }\end{array}$ & 0.835 & & & & & & & Valid \\
\hline Attitude & 0.401 & 0.783 & & & & & & Valid \\
\hline $\begin{array}{l}\text { Consulting } \\
\text { strategy }\end{array}$ & 0.778 & 0.392 & 0.787 & & & & & Valid \\
\hline $\begin{array}{l}\text { Inspirational } \\
\text { strategy }\end{array}$ & 0.488 & 0.531 & 0.470 & 0.749 & & & & Valid \\
\hline Intent to use & 0.328 & 0.255 & 0.360 & 0.316 & $0.78 I$ & & & Valid \\
\hline Motivation & 0.492 & 0.349 & 0.533 & 0.477 & 0.499 & 0.756 & & Valid \\
\hline $\begin{array}{l}\text { Rational } \\
\text { persuasion } \\
\text { strategy }\end{array}$ & 0.496 & 0.268 & 0.459 & 0.438 & 0.615 & 0.744 & 0.869 & Valid \\
\hline
\end{tabular}

Source: The author. 
Table 3. Cross Loadings

\begin{tabular}{|c|c|c|c|c|c|c|c|c|c|}
\hline Construct & Indicators & AS & AT & CS & IS & $\begin{array}{l}\text { Intent } \\
\text { to } \\
\text { Use }\end{array}$ & $M$ & RPS & Results \\
\hline \multirow{4}{*}{$\begin{array}{l}\text { Inspirational } \\
\text { strategy }\end{array}$} & ISI & 0.273 & 0.296 & 0.243 & 0.692 & 0.199 & 0.330 & 0.260 & \\
\hline & IS2 & 0.392 & 0.403 & 0.386 & 0.718 & 0.196 & 0.342 & 0.298 & \\
\hline & IS3 & 0.380 & $0.38 I$ & 0.358 & 0.829 & 0.273 & 0.395 & 0.380 & \\
\hline & IS4 & 0.413 & 0.509 & 0.416 & 0.749 & 0.273 & 0.357 & 0.367 & Valid \\
\hline \multirow{2}{*}{$\begin{array}{l}\text { Assertive } \\
\text { strategy }\end{array}$} & AS2 & 0.887 & 0.317 & 0.630 & 0.371 & 0.254 & 0.436 & 0.431 & \\
\hline & AS3 & 0.780 & 0.356 & 0.676 & 0.451 & 0.298 & 0.383 & 0.397 & Valid \\
\hline \multirow{3}{*}{$\begin{array}{l}\text { Consulting } \\
\text { strategy }\end{array}$} & $\mathrm{CS} 2$ & 0.543 & 0.294 & 0.765 & 0.412 & 0.243 & 0.408 & 0.316 & \\
\hline & CS3 & 0.595 & 0.292 & 0.806 & 0.282 & 0.361 & 0.430 & 0.416 & \\
\hline & CS4 & 0.699 & 0.340 & 0.791 & 0.419 & 0.243 & 0.422 & 0.349 & Valid \\
\hline \multirow[t]{2}{*}{ Attitude } & ATI & 0.274 & 0.832 & 0.275 & 0.367 & 0.189 & 0.290 & 0.198 & \\
\hline & AT2 & 0.361 & 0.731 & 0.346 & 0.473 & 0.213 & 0.255 & 0.224 & Valid \\
\hline \multirow[t]{4}{*}{ Motivation } & IMI & 0.381 & 0.274 & 0.419 & 0.386 & 0.437 & 0.824 & 0.635 & \\
\hline & IM2 & 0.336 & 0.186 & 0.359 & 0.345 & 0.275 & 0.625 & 0.437 & \\
\hline & IM3 & 0.397 & 0.304 & 0.422 & 0.358 & 0.376 & 0.792 & 0.596 & \\
\hline & IM4 & 0.373 & $0.28 I$ & 0.412 & 0.355 & 0.405 & 0.769 & 0.565 & Valid \\
\hline \multirow[t]{2}{*}{ Intent to use } & IU2 & 0.270 & 0.234 & 0.336 & 0.256 & 0.746 & 0.372 & 0.493 & \\
\hline & IU3 & 0.244 & 0.167 & 0.231 & 0.239 & 0.815 & 0.406 & 0.469 & Valid \\
\hline \multirow{4}{*}{$\begin{array}{l}\text { Rational } \\
\text { persuasion } \\
\text { strategy }\end{array}$} & RPSI & 0.423 & 0.216 & 0.337 & 0.387 & 0.532 & 0.616 & 0.829 & \\
\hline & RPS2 & 0.420 & 0.296 & 0.439 & 0.395 & 0.593 & 0.712 & 0.957 & \\
\hline & RPS3 & 0.473 & 0.167 & 0.423 & 0.365 & 0.466 & 0.606 & 0.814 & \\
\hline & RPS4 & 0.413 & 0.242 & 0.392 & 0.377 & 0.538 & 0.646 & 0.868 & Valid \\
\hline
\end{tabular}

Source: The author.

Table 4. HTMT Ratio/Henseler Criterion Using SmartPLS

\begin{tabular}{|c|c|c|c|c|c|c|c|c|}
\hline & AS & AT & CS & IS & $\begin{array}{l}\text { Intent } \\
\text { to Use }\end{array}$ & $M$ & RPS & Results \\
\hline \multicolumn{9}{|l|}{$\begin{array}{l}\text { Assertive } \\
\text { strategy }\end{array}$} \\
\hline Attitude & $0.4 \mathrm{II}$ & & & & & & & Valid \\
\hline $\begin{array}{l}\text { Consulting } \\
\text { strategy }\end{array}$ & 0.785 & 0.398 & & & & & & Valid \\
\hline $\begin{array}{l}\text { Inspirational } \\
\text { strategy }\end{array}$ & 0.494 & 0.540 & $0.47 I$ & & & & & Valid \\
\hline Intent to use & 0.333 & 0.260 & 0.363 & 0.317 & & & & Valid \\
\hline Motivation & 0.498 & 0.350 & 0.539 & 0.483 & 0.499 & & & Valid \\
\hline $\begin{array}{l}\text { Rational } \\
\text { persuasion } \\
\text { strategy }\end{array}$ & 0.499 & 0.268 & 0.457 & 0.437 & 0.615 & 0.745 & - & Valid \\
\hline
\end{tabular}

Source: The author. 


\section{Structural Model}

SEM model was constructed to find the effect of select communication strategies on the students' motivation, attitude, and intent in a single model. Furthermore, the predictive relevance and impact size are measured after developing the structural model (Hair et al., 2016). A model using PLS-SEM bootstrap was used to validate the effect of the select variables on motivation, attitude, and intent. The structural model was also scrutinized for collinearity issues (Ali et al., 2018), through variance inflation factor (VIF) values which were below the threshold of 5 (Hair et al., 2011). The $R^{2}$ and path coefficients $(\beta)$, and $t$-statistics, and $p$-values were observed for assessing the model, using 5,000 resamplings for bootstrapping (Hair et al., 2011) using SmartPLS v 3.2.9. The foremost criteria (Hair et al., 2017) for assessing the structural model are to check path coefficient $(\beta)$, coefficient of Determination $\left(R^{2}\right)$, and Predictive Relevance $\left(Q^{2}\right) . R^{2}$ values indicated the influence of exogenous variables on endogenous ones, thereby showing the accuracy of the proposed model. The values under $0.25,0.50$, and 0.75 are regarded as small, medium, and large respectively, for ascertaining the predictive accurateness (Merli et al., 2019). The values for the present model were Attitude 0.122, Intent to Use 0.250, and Motivation 0.611, which were considered as small, medium, and large respectively (Henseler et al., 2009). The $f^{2}$ effect size was used for assessing adjustment in $R^{2}$ estimation in case a predefined exogenous construct was excluded from the proposed model. These values ranged from small (assertive strategy) to moderate (motivation) to high (RPS) (according to criteria presented by Cohen (1988). The predictive accurateness of the model was evaluated using Stone-Geisser $Q^{2}$ (Hair et al., 2017; Stone, 1974) through blindfolding. SRMR is a model fit measure (Hair et al., 2017; Henseler et al., 2014). The SRMR value for the proposed model was 0.048 which is acceptable (Hair et al., 2011).

\section{Hypothesis Testing}

The hypotheses formulated were tested using bootstrapping process. First, the direct effect of the four select communication strategies $\left(H_{1 \mathrm{a}}, H_{2 \mathrm{a}}, H_{3 \mathrm{a}}\right.$, and $\left.H_{4 \mathrm{a}}\right)$, and motivation $H_{4}$ and $H_{5}$ were tested, next the specific indirect and total effects were evaluated. Figure 2 SEM shows the path coefficients and indicator loadings using SmartPLS.

Direct Effect. The process of bootstrapping yielded the results shown in Table 5 . All communication strategies except the assertive strategy had a positive effect on motivation; however, the effect of the inspirational strategy was not statistically significant, although it was positive. Therefore, $H_{2 \mathrm{a}}$ and $H_{4 \mathrm{a}}$ were supported, while $H_{3 a}$ was partially supported. A glance at the path coefficients shows that the effect of Rational persuasion strategy $\longrightarrow$ Motivation (0.607) is greater than both Consulting (0.240) and Inspirational strategy (0.124). The results also indicated the effect of motivation on attitude and intent is positive and statistically significant, as such $H_{5}$ and $H_{6}$ were both accepted. 


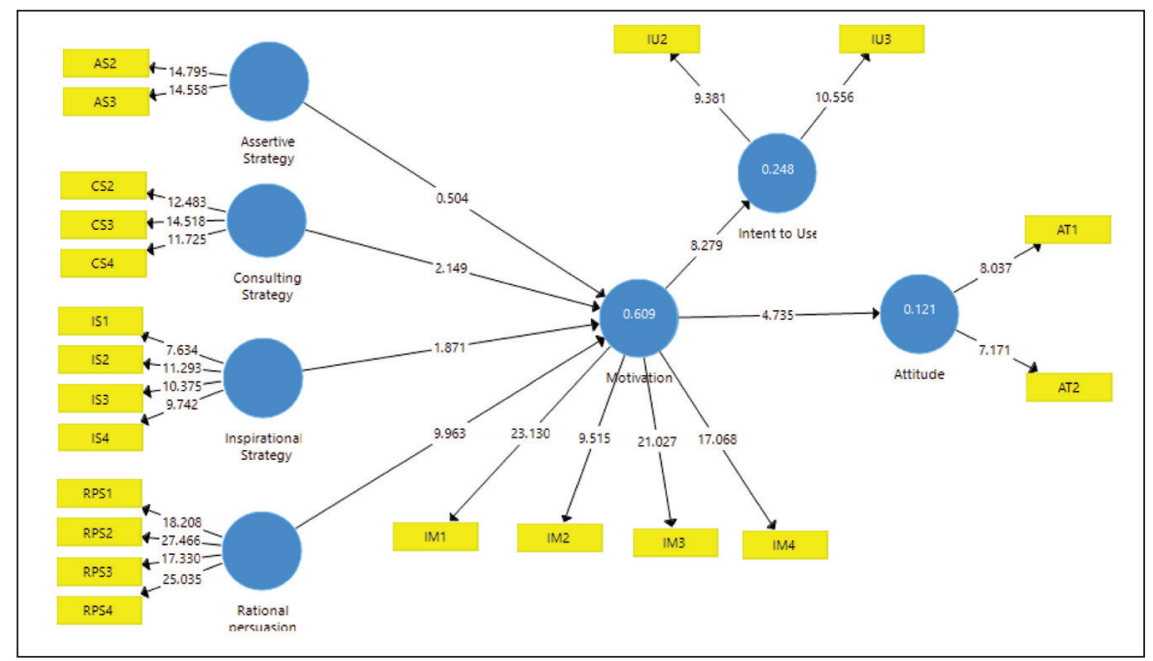

Figure 2. SEM Showing Path Coefficients and Indicator Loadings

Source: The author.

Indirect Effects. Bootstrapping test was conducted using SmartPLS which showed specific indirect effects, as indicated in Table 6. The effects of Consulting strategy $\longrightarrow$ Motivation $\longrightarrow$ Intent to use, Rational persuasion strategy $\longrightarrow$ Motivation $\longrightarrow$ Attitude, Rational persuasion strategy $\longrightarrow$ Motivation $\longrightarrow$ Intent to use were found to be significant, as the confidence interval did not contain zero. The indirect effect of Consulting strategy $\longrightarrow$ Motivation $\longrightarrow$ Attitude did not contain zero but the $T$-value was slightly lower than 1.96 , which is considered as the threshold. The indirect effects of Assertive_strategy $\longrightarrow$ Motivation $\longrightarrow$ Attitude, Assertive_strategy $\longrightarrow$ Motivation $\longrightarrow$ Intent to use, and Inspirational_strategy $\longrightarrow$ Motivation $\longrightarrow$ Attitude, and Inspirational_strategy $\longrightarrow$ Motivation $\longrightarrow$ Intent to use were insignificant. Based on the findings, the hypotheses $H_{1 \mathrm{~b}}$, and $H_{1 \mathrm{c}}$ were rejected, while $H_{2 \mathrm{c}}, H_{4 \mathrm{~b}}$, and $H_{4 \mathrm{c}}$ were accepted and $H_{2 \mathrm{~b}}, H_{3 \mathrm{~b}}$, and $H_{3 \mathrm{c}}$ were partially accepted as the effect was positive but small.

\section{Discussion}

Efficient implementation of educational IT-based innovations requires making circumstances favorable by improving the process of management/implementation (Wilcox \& Lawson, 2018) for improved execution, loyalty, and steadfastness (Falter \& Hadwich, 2020). As such, the result of the process of implementation depends on the strategies adopted by the institute administration. The process increases the insight and information for the management of the innovation (Dhir et al., 2019), which may make the institutes more successful. As such, the present study confirmed the significant role played by communication strategies in IT-based educational innovation management/implementation. Assertiveness, as the results indicate, did not have any statistically significant effect on the students' motivation, attitude, and intent. It may be assumed that the students desired 

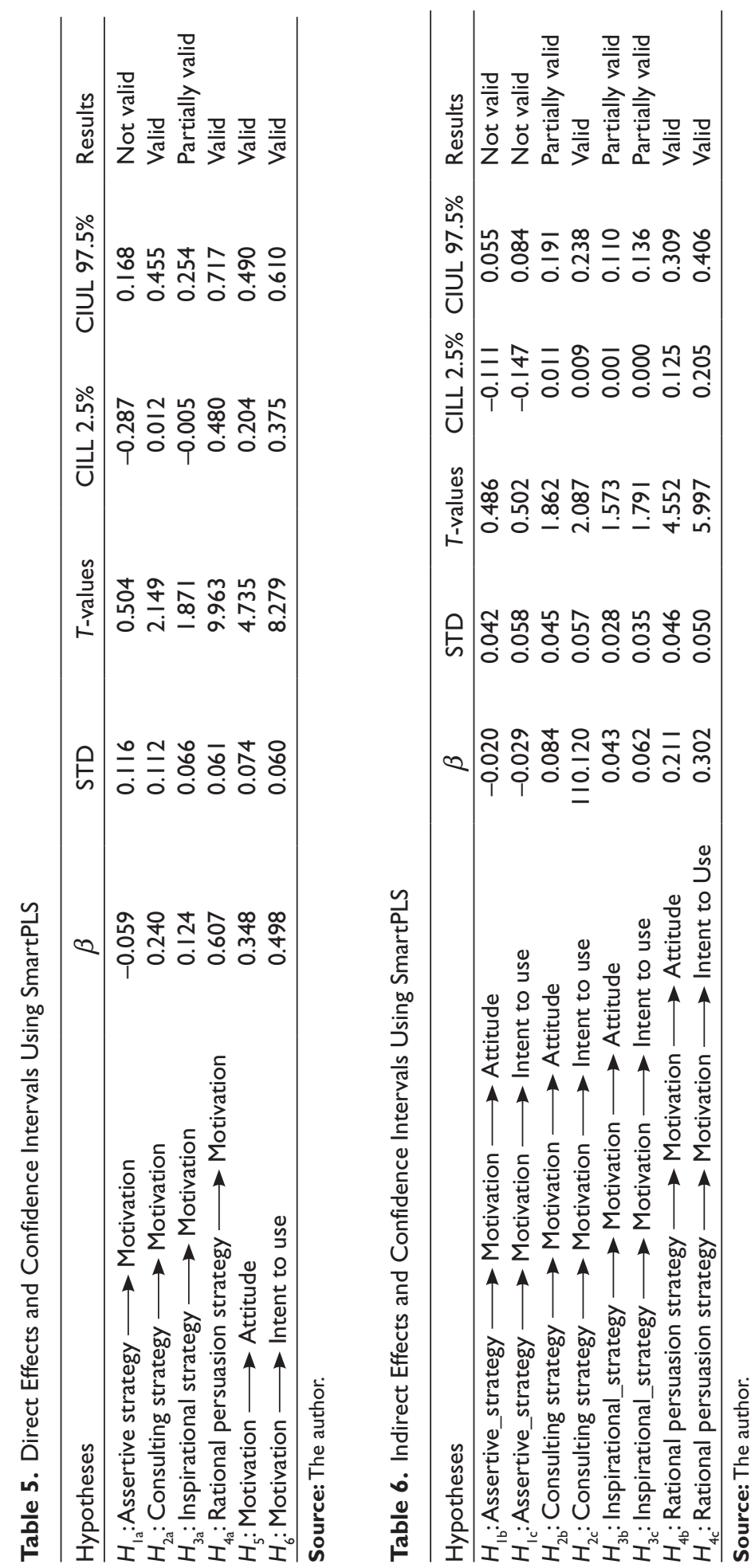
autonomy (based on SDT) (Gagne \& Deci, 2005), and the use of assertive strategies for IT-based innovation management/implementation lowered their sense of autonomy. Assertiveness has a negative relationship with motivation (Pierro et al., 2008), so the students perceived the educational innovation with negativity. The effect of both CS and IS was positive. However, CS affected attitude and intent significantly, but IS did not have a significant effect on attitude and intent. RPS was found to be very effective as the users are provided with enough evidence and support (Chin \& Benne, 2009; Sharma \& Yetton, 2007) for the use of the innovation, which diminishes the apparent complications associated with the innovation (Chiu \& Fogel, 2017). Cognitive evaluation theory proposes an emotional state of competence and self-reliance is significant for impetus/attitude/intent among the students. Moreover, RPS encourages the two emotions of competence and selfreliance, thereby positively influencing motivation (Gagne \& Deci, 2005).

The results of the study confirmed all the communication strategies except assertive exerted positive effects on the students' motivation, attitude, and intent to use the IT-based educational innovation. The results also endorsed the assumptions that communication augments students' motivation, attitude, and intent to use. Likewise, the use of appropriate communication strategies can maximize IT-based educational innovation management/implementation success (Chung et al., 2017). Moreover, the communication among the users and the management needs to be reliable (Johnson, 2001), to encourage constructive sentiments and diminish adverse feelings concerning the application of the innovation (Hoffman \& Roman, 1984).

\section{Theoretical Implications}

The study adds to the extant studies on communication, in a milieu of grounded/ organizational communication theory (Atun et al., 2007) for regulating the enactment and accomplishment employing diverse strategies, thus, assisting and facilitating the effective innovation implementation. This investigation contributes to the advancement of literature on innovation management/implementation by inspecting the effect of students' motivation on attitude toward educational innovations and on their perspectives toward utilizing them. Furthermore, this investigation adds to the literature on influence strategy by scrutinizing communication strategies for the management/implementation of IT-based educational innovations at the level of the main stakeholder, the students. The study is timely and pertinent; investigating the influence system at present is the need of the hour as the entire educational system is undergoing drastic changes due to the COVID-19 pandemic. The current study also adds to the literature on education and the adoption of Information Technology for education.

\section{Practical and Managerial Implications}

The outcomes of the current study may assist institutes in acquiring insight into appropriate tactics to encourage the implementation of educational innovations among students. The faculty and staff will also benefit from this survey and be able to eliminate any obstacles in implementing them. Moreover, the students will 
be aware of factors influencing specifically communication strategies. The investigation may likewise assist the researchers in determining the students' perceptions. The study will also be useful for the administrators/policymakers, who would better comprehend areas for enhancement for acknowledgment issues and will be able to find solutions based on the findings.

\section{Limitations and Scope for Future Studies}

There is a paucity of research studies when it comes to investigating the influence of communication strategies on the management and implementation of IT-based innovations in educational contexts. The study filled the research gap by scrutinizing the self-reported responses of the students. However, there is a possibility that the data may be skewed or biased, due to the means of collection and sampling adopted, as the sample was non-experimental, and the data was collected and assessed only one time. Furthermore, the data were obtained from only engineering students from Rajasthan, resulting in a fairly homogeneous populace, as such the findings may not be generalized to all. Additional factors can be used in future studies, as well as more varied samples and more diverse research methodologies employed to improve and augment the illustrative competence of the proposed model.

\section{Conclusion}

The study's main aim was to explore the effect of communication strategies on the students' motivation/attitude/intent, in the context of educational innovation implementation, which requires formulating communication strategies. It involves the procedure of utilization of advancement by users (Klein \& Sorra, 1996), strengthens a feeling of conviction, reliance, and commitment in both the institute and the innovation for the effective management/implementation. Subsequently, it results in innovation utilization (Maroulis \& Wilensky, 2015), adds approval (Lambooij \& Koster, 2016), and routinizes use (Lapiedra et al., 2011). Additionally, the study reveals the best-suited strategies for motivating the students to ensure successful use, which is the result of common adjustment between various stakeholders with the same/different/contradictory views (Cohen et al., 2004). Consequently, educational innovation management/implementation can be regarded as the quest for harmony and stability achieved by settling preliminary strain between users and innovation (Chung \& Choi, 2018; González-Blanco et al., 2019) for successful implementation of educational innovations.

\section{Declaration of Conflicting Interests}

The author declared no potential conflicts of interest with respect to the research, authorship, and/or publication of this article.

\section{Funding}

The author received no financial support for the research, authorship, and/or publication of this article. 


\section{References}

Al-Asfour, A., \& Lettau, L. (2014). Strategies for leadership styles for a multigenerational workforce. Journal of Leadership, Accountability and Ethics, 11, 58-70.

Ali, F., Rasoolimanesh, S. M., Sarstedt, M., Ringle Christian, M., \& Ryu, K. (2018). An assessment of the use of partial least squares structural equation modeling (PLSSEM) in hospitality research. International Journal of Contemporary Hospitality Management, 30(1), 514-538.

Alrawadieh, Z., Cetin, G., Dincer, M. Z., \& Dincer, F. I. (2020). The impact of emotional dissonance on quality of work-life and life satisfaction of tour guides. The Service Industries Journal, 40(1-2), 50-64.

Aryee, S., Walumbwa, F. O., Mondejar, R., \& Chu, C. W. (2015). Accounting for the influence of overall justice on job performance: Integrating self-determination and social exchange theories. Journal of Management Studies, 52, 231-252.

Atun, R. A., Kyratsis, I., Jelic, G., Rados-Malicbegovic, D., \& Gurol-Urganci, I. (2007). Diffusion of complex health innovations: Implementation of primary health care reforms in Bosnia and Herzegovina. Health Policy and Planning, 22(1), 28-39.

Baek, U., Olya, H., \& Lee, S. K. (2018). Effects of individual resources and team-member exchange on service quality. The Service Industries Journal, 38(9-10), 584-606.

Bagozzi, R. P., \& Yi, Y. (1988). On the evaluation of the structural equation model. Journal of the Academy of Marketing Science, 16(1), 74-94.

Baradarani, S., \& Kilic, H. (2018). Service innovation in the hotel industry: Culture, behavior, performance. The Service Industries Journal, 38(13-14), 897-924.

Brewer, D., \& Tierney, W. (2012). Barriers to innovation in the US education. In B. Wildavsky, A. Kelly \& K. Carey (Eds), Reinventing higher education: The promise of innovation (pp. 11-40). Harvard Education Press.

Burke, W. W. (2014). Organization change: Theory and practice (4th ed.). SAGE Publications.

Chen, G., Farh, J., Campbell-Bush, E., Wu, Z., \& Wu, X. (2013). Teams as innovative systems: Multilevel motivational antecedents of innovation in R\&D teams. Journal of Applied Psychology, 98, 1018-1027.

Chin, R., \& Benne, K. D. (2009). General strategies for effecting changes in human systems. In W. W. Burke, D. G. Lake \& J. W. Paine (Eds), Organization change: A comprehensive reader (pp. 89-117). Jossey-Bass.

Chiu, H. H. (2017). Employees' intrinsic and extrinsic motivations in innovation implementation: The moderation role of managers' persuasive and assertive strategies. Journal of Change Management, 18(3), 218-239.

Chiu, H., \& Fogel, J. (2017). The role of the manager influence strategies and innovation attributes in innovation implementation. Asia-Pacific Journal of Business Administration, 9(1), 16-36.

Choi, J. N., Sung, S. Y., Lee, K., \& Cho, D. (2011). Balancing cognition and emotion: Innovation implementation as a function of cognitive appraisal and emotional reactions toward innovation. Journal of Organizational Behavior, 32, 107-124.

Chong, M. (2014). Influence behaviors and organizational commitment: A comparative study. Leadership \& Organization Development Journal, 35, 54-78.

Chong, M. P., Muethel, M., Richards, M., Fu, P. P., Peng, T. K., Shang, Y. F., \& Caldas, M. P. (2013). Influence behaviors and employees' reactions: An empirical test among six societies based on a transactional-relational contract model. Journal of World Business, 48, 373-384.

Chong, M. P., Peng, T. K., Fu, P. P., Richards, M., Muethel, M., Caldas, M. P., \& Shang, Y. F. (2015). Relational perspectives on leaders' influence behavior: The mediation 
of western leader-member exchange and Chinese Guanxi. Journal of Cross-Cultural Psychology, 46, 71-87.

Christensen, M. (2014). Communication as a strategic tool in change processes. Journal of Business Communication, 51, 359-385.

Chung, G. H., \& Choi, J. N. (2018). Innovation implementation as a dynamic equilibrium: Emergent processes and divergent outcomes. Group and Organization Management, 43(6), 999-1036.

Chung, G. H., Choi, J. N., \& Du, J. (2017). Tired of innovations? Learned helplessness and fatigue in the context of continuous streams of innovation implementation. Journal of Organizational Behavior, 38(7), 1130-1148.

Cohen, J. (1988). Statistical power analysis for the behavioral sciences (2nd ed.). Lawrence Earlbaum Associates.

Cohen, L., Duberley, J., \& Mallon, M. (2004). Social constructionism in the study of career: Accessing the parts that other approaches cannot reach. Journal of Vocational Behavior, 64(3), 407-422.

Cronbach, L. J. (1971). Test validation. In R. L. Thorndike (Ed.) Educational measurement (2nd ed., pp. 443-507). American Council on Education.

Dearing, J., \& Cox, J. (2018). Diffusion of innovations theory, principles, and practice. Health Affairs, 37(2), 183-190.

Dhir, S., Ongsakul, V., Ahmed, Z. U., \& Rajan, R. (2019). Integration of knowledge and enhancing competitiveness: A case of acquisition of Zain by Bharti Airtel. Journal of Business Research, 119, 674-684.

digitalLearning Network. (2017, August 10). Rajasthan Higher Education embracing change for a new era of opportunities. https:/digitallearning.eletsonline.com/2017/08/ rajasthan-higher-education-embracing-change-for-new-era-of-opportunities/

Dube, G. (2018). The design and implementation of minibus taxi presumptive taxes. The Service Industries Journal, 38(11-12), 723-741.

Enu-Kwesi, F., \& Opoku, M. O. (2020). Relevance of the technology acceptance model (TAM) in information management research: A review of selected empirical evidence. Pressacademia, 7(1), 34-44.

Falter, M., \& Hadwich, K. (2020). Customer service well-being: Scale development and validation. The Service Industries Journal, 40(1-2), 181-202.

Field, A. P. (2005). Discovering statistics using SPSS. SAGE Publications.

Fornell, C., \& Larcker, D. F. (1981). Evaluating structural equation models with unobservable variables and measurement error. Journal of Marketing Research, 18(1), $39-50$.

Fu, P. P., Peng, T. K., Kennedy, J. C., \& Yukl, G. (2004). Examining the preferences of influence tactics in Chinese societies: A comparison of Chinese managers in Hong Kong, Taiwan, and Mainland China. Organizational Dynamics, 33, 32-46.

Gagne, M., \& Deci, E. (2005). Self-determination theory and work motivation. Journal of Organizational Behavior, 26, 331-362.

González-Blanco, J., Coca-Pérez, J. L., \& Guisado-González, M. (2019). Relations between technological and non-technological innovations in the service sector. The Service Industries Journal, 39(2), 134-153.

Gopalan, V., Abu-Bakar, J. A., \& Zulkifli, A. N. (2020). A review of motivation theories, models, and instruments in a learning environment. Journal of Critical Reviews, 7(6), $554-559$.

Hair, J. F., Anderson, R. E., Tatham, R. L., \& Black, W. C. (2010). Multivariate data analysis (7th ed.). Prentice-Hall.

Hair, J. F., Hult, G. T. M., Ringle, C. M., \& Sarstedt, M. (2016). A primer on partial. Least squares structural equation modeling (PLS-SEM) (2nd ed.). SAGE Publications. 
Hair, J. F., Hult, G. T. M., Ringle, C. M., \& Sarstedt, M. (2017). A primer on partial least squares structural equation modeling (PLS-SEM) (2nd ed.). SAGE Publications.

Hair, J. F., Ringle, C. M., \& Sarstedt, M. (2011). PLS-SEM: Indeed a silver bullet. Journal of Marketing Theory and Practice, 19(2), 139-151.

Haivas, S., Hofmans, J., \& Pepermans, R. (2013). Volunteer engagement and intention to quit from a self-determination theory perspective. Journal of Applied Social Psychology, 43, 1869-1880.

Harding, R. E. M. (1948). An anatomy of inspiration: And an essay on the creative mood. Routledge.

Henseler, J., Dijkstra, T. K., Sarstedt, M., Ringle, C. M., Diamantopoulos, A., Straub, D. W., Ketchen, D. J., Hair, J. F., Hult, G. T. M., \& Calantone, R. J. (2014). Common beliefs and reality about partial least squares: Comments on Rönkkö \& Evermann (2013). Organizational Research Methods, 17(2), 182-209.

Henseler, J., Hubona, G., \& Ray, P. A. (2016). Using PLS path modeling in new technology research: Updated guidelines. Review of Industrial Management \& Data Systems, 116(1), 2-20.

Henseler, J., Ringle, C. M., \& Sarstedt, M. (2015). A new criterion for assessing discriminant validity in variance-based structural equation modeling. Journal of Academy of Marketing Science, 43, 115-135.

Henseler, J., Ringle, C., \& Sinkovics, R. (2009). The use of partial least squares path modeling in international marketing. Review of Advances in International Marketing, 20, 277-320.

Hoffman, E., \& Roman, P. M. (1984). Information diffusion in the implementation of the innovation process. Communication Research, 11(1), 117-140.

Huy, Q., Corley, K., \& Kraatz, M. (2014). From support to mutiny: Shifting legitimacy judgments and emotional reactions impacting the implementation of radical change. Academy of Management Journal, 57, 1650-1680.

Johnson, J. D. (2001). Success in innovation implementation. Journal of Communication Management, 5(4), 341-359.

Kim, J. S., \& Chung, G. H. (2017). Implementing innovations within organizations: A systematic review and research agenda. Innovation: Management, Policy, and Practice, 19(3), 372-399

Kirillova, K., Fu, X., \& Kucukusta, D. (2020). Workplace design and well-being: Aesthetic perceptions of hotel employees. The Service Industries Journal, 40(1-2), 27-49.

Klein, K., \& Sorra, J. (1996). The challenge of innovation implementation. Academy of Management Review, 21, 1055-1080.

Klein, K. J., Conn, A. B., \& Sorra, J. S. (2001). Implementing computerized technology: An organizational analysis. Journal of Applied Psychology, 86(5), 811.

Lambooij, M. S., \& Koster, F. (2016). How organizational escalation prevention potential affects the success of the implementation of innovations: Electronic medical records in hospitals. Implementation Science, 11(1), 1-10.

Lapiedra, R., Alegre, J., \& Chiva, R. (2011). The importance of management innovation and consultant services on ERP implementation success. The Service Industries Journal, 31(12), 1907-1919.

Loscocco, K. A. (1989). The instrumentally oriented factory worker. Work and Occupations, $16,3-25$.

Maroulis, S., \& Wilensky, U. (2015). Social and task interdependencies in the street-level implementation of innovation. Journal of Public Administration Research and Theory, 25(3), 721-750.

Merli, R., Preziosi, M., Acampora, A., \& Ali, F. (2019). Why should hotels go green? Insights from guests experience in green hotels. International Journal of Hospitality Management, 81, 169-179. 
Murray, C. E. (2020). Diffusion of innovation theory: A bridge for the research-practice gap in counseling. Journal of Counseling and Development, 87(1), 108-116.

Nahavandi, A., Denhardt, R., Denhardt, J., \& Aristigueta, M. (2015). Organizational behavior (1st ed.). SAGE Publications.

Nunnally, J. C. (1978). Psychometric theory. McGraw-Hill.

Oleynick, V. C., Thrash, T. M., LeFew, M. C., Moldovan, E. G., \& Kieffaber, P. D. (2014). The scientific study of inspiration in the creative process: Challenges and opportunities. Frontiers in Human Neuroscience, 8, 436.

Pallant, J. (2005). SPSS survival manual: A step by step guide to data analysis using SPSS for Windows (Version 12) (2nd ed.). Open University Press.

Pierro, A., Cicero, L., \& Raven, B. (2008). Motivated compliance with bases of social power. Journal of Applied Social Psychology, 38, 1921-1944.

Podsakoff, P. M., MacKenzie, S. B., Lee, J.-Y., \& Podsakoff, N. P. (2003). Common method biases in behavioral research: A critical review of the literature and recommended remedies. Journal of Applied Psychology, 88(5), 879-903.

Rogers, E. M. (2003). Diffusion of innovations (5th ed.). Free Press.

Sharma, R., \& Yetton, P. (2007). The contingent effects of training, technical complexity, and task interdependence on successful information systems implementation. Management Information Systems Quarterly, 31, 219-238.

Singh, S., Akbani, I., \& Dhir, S. (2020). Service innovation implementation: A systematic review and research agenda. The Service Industries Journal, 40(7-8), 491-517.

Somech, A., \& Drach-Zahavy, A. (2013). Translating team creativity to innovation implementation: The role of team composition and climate for innovation. Journal of Management, 39(3), 684-708.

Sprenger, D. A., \& Schwaninger, A. (2021). Technology acceptance of four digital learning technologies (classroom response system, classroom chat, e-lectures, and mobile virtual reality) after three months' usage. International Journal of Educational Technology in Higher Education, 18, 8.

Stone, M. (1974). Cross-validatory choice and assessment of statistical predictions. Journal of the Royal Statistical Society, 36(2), 111-147.

Thrash, T. M., \& Elliot, A. J. (2003). Inspiration as a psychological construct. Journal of Personality and Social Psychology, 84(4), 871-889.

Tian, Q., Song, Y., Kwan, H. K., \& Li, X. (2019). Workplace gossip and frontline employees' proactive service performance. The Service Industries Journal, 39(1), 25-42.

Usakli, A., \& Kucukergin, K. G. (2018). Using partial least squares structural equation modeling in hospitality and tourism: Do researchers follow practical guidelines? International Journal of Contemporary Hospitality Management, 30(11), 3462-3512.

Wilcox, K. C., \& Lawson, H. A. (2018). Teachers' agency, efficacy, engagement, and emotional resilience during policy innovation implementation. Journal of Educational Change, 19(2), 181-204.

Woolllinscroft, J. O. (2020). Innovation in response to the COVID-19 pandemic crisis. Academic Medicine, 20(10), 1-3.

Yukl, G., Chavez, C., \& Seifert, C. F. (2005). Assessing the construct validity and utility of two new influence tactics. Journal of Organizational Behavior, 26, 705-725.

Yukl, G., Seifert, C. F., \& Chavez, C. (2008). Validation of the extended influence behavior questionnaire. The Leadership Quarterly, 19, 609-621.

Zaineldeen, S., \& Koffi, L. A. (2020). Technology acceptance model concepts, contribution, limitation, and adoption in education. Universal Journal of Educational Research, 8(11), 5061-5071. 


\title{
Change in Consumer Behavior Due to Covid Crisis: An Exploratory Study
}

IIMS Journal of Management Science

I3(I) 74-88, 2022

(C) The Author(s) 2022

DOI: $10.1177 / 0976030 \times 211053337$

ims.spectrumjps.com

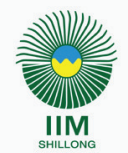

\section{Vikas Kumar Tyagi', Vikas Nain', Akhilesh Mishra' and Saurabh Garg'}

\begin{abstract}
The purpose of the study was to explore consumer behavior (purchase pattern, volume, and frequency), and household expenditure alteration due to the COVID crisis. Furthermore, to study the perpetuity of those changes. Researchers used a mixed-method approach based on qualitative interviews, secondary data, and media analysis, that is, using a qualitative, exploratory research design. Data were collected through Reflective Journal Logs, 34 in-depth interviews, extensive literature review of secondary sources, and netnography. The study was cross-sectional and applied in nature. Researchers divided the respondents based on income to explore the impact of income. Data reduction, analysis, and interpretation were made manually, and the overall method used was narrative qualitative research. Researchers found the consumer's purchase patterns of products and services in this study. Some new habits were also found towards purchase behavior, expenditures, and savings. Researchers also found the perceptions towards perpetuity of those changes and the impact of income on all those changes. Many researchers conducted studies on this subject, but no significant research from the micro, that is, household perspective, was found. Besides, the factors such as perceptions towards the perpetuity of the changes were missing, especially from the problem's qualitative aspects. This study will help marketers identify new demands and use them for better customer service, leading to a strengthened relationship with them and profit for the organization.
\end{abstract}

\footnotetext{
' Department of Management Studies, Panipat Institute of Engineering and Technology, Samalkha, Haryana, India
}

\section{Corresponding Author:}

Vikas Kumar Tyagi, Department of Management Studies, Panipat Institute of Engineering and Technology, Samalkha, Haryana I32102, India.

E-mail: vikaskumar.mba@piet.co.in 


\section{Keywords}

Consumer behavior, COVID crisis, household expenditure

\section{JEL Classification: DII,DI4, M3 I}

\section{Introduction}

COVID crisis affected the whole world. All the industries ranging from manufacturing, aviation, retail, tourism, education, and entertainment got impacted by this situation (Chaudhary et al., 2020). The imposition of social distancing, self-isolation at home, closure of institutions, and public facilities, restrictions on mobility, and even lockdown of the entire country. Not just the macro-economic impacts but the COVID crisis has a profound effect on consumer behavior as well. Stress, anxiety, depression, and frustration increased due to quarantine, and uncertainty of the future led to a change in the way consumers shop, what they shop and how they shop. Most of the changes were inevitable and destined to come soon, but the crisis accelerated the process quickly. Newer working methods such as e-learning, e-purchasing, e-health, e-entertainment, and e-networking either entered or flourished. As a result, the whole supply chain got disrupted. When the lockdown opened in between the things started moving towards normalization, the nation was hit by the second wave.

Consumer lifestyle, buying behavior, and attitude towards spending and saving have changed. Pandemic is sure to be temporary, but its impacts are long-lasting and may bring disruptive industry changes. While some of these changes are temporary, others are permanent. As the community is in adaptation mode, the digital adoption impetus is to carry forward and become permanent. Vaccines will be helpful, threats will be over, but many of these changes will be permanent and will undoubtedly disrupt the business models in the long run.

Moreover, according to Maxwell (1960), anything becomes a habit if practiced for more than 21 days. Although habit formation depends on how long one does something, what benefits one understands in the new routine, and what better alternatives one sees. So, it is imperative to understand the overall changes this crisis has brought to consumer behavior from the grassroots level. Furthermore, to understand what changes are to stay and what changes will move away as things move towards normalization.

Major economies shrunk substantially from the crisis; India $(23.9 \%)$, United Kingdom (21.7\%), France (18.9\%), and Italy (17.7\%). However, as it is rightly said, every problem or crisis opens up new possibilities. According to Bloomberg, the world's 500 richest people had become $\$ 1$ trillion richer in 2017, had lost $\$ 512$ billion in 2018 , gained $\$ 1.2$ trillion in 2019 , while the jump was $\$ 1.8$ trillion in 2020. The jump was substantially more than usual. So yes, it is all about recognizing the opportunities in the adversities. This research will study the change in household buying behavior and study the customer needs from the micro-level.

Any event brings changes in the attitude and behavior of a consumer. Similarly, the COVID has brought several changes, and many of them will last long. These behavior changes are going to change the market and business models as well. Every firm is perplexed about what the future lies after the pandemic fear is 
entirely over or how the firms will react to a series of lockdowns again as newer strains enter and successive infection waves continue. This study can help suggest to firms the areas of opportunities for innovation and make them aware of the consumer's behavior in the long term. Most importantly, this study is significant so that government and industries can be prepared for such unfortunate inspections in the future.

\section{Objectives}

This research aims to identify the impacts of the COVID crisis on consumer behavior (purchase pattern, volume, and frequency), household expenditure during the lockdown, and when things move towards normal.

\section{Literature Review}

Several researchers conducted studies to explore the impact of the COVID crisis on consumer behavior towards products, services, expenditures, and savings. Goswami and Chouhan (2021) found that the COVID crisis changed consumer behavior, especially in the priority of products and purchasing methods. Aday and Aday (2020) found that the COVID crisis severely affected the food supply chain. Fatoye et al. (2021) found that household expenditure for hand sanitizers, facemasks, and disinfectants increased significantly due to the crisis. On the other hand, spending on education, electricity, internet data, and clothing decreased considerably during the lockdown period.

Suryahadi et al. (2020) and Romano (2020) found that consumption and investment were reduced due to the crisis, leading to increased poverty. Whereas Dang and Nguyen (2020) found that consumption reduced and savings increased due to the crisis. According to CNBC (2020), more youth started stock trading (20\% new DMAT accounts), especially as they got more time and hunt for alternate income. Moreover, as per Srivastava (2020, August 2), first-time automobiles buyers increased as the people preferred private transport over public transportation.

Galhotra and Dewan (2020) found that the people's usage and comfort towards e-commerce and OTT platforms increased after the lockdown. Chang and Meyerhoefer (2020), Dannenberg et al. (2020), and Bounie et al. (2020) found that online retail shopping replaced the traditional shopping channels, especially in food products such as groceries, fruits, and vegetables. Madnani et al. (2020), Blasco et al. (2020), Sunitha and Sudha (2020), and Cellini et al. (2020) studied the impact of the crisis on media consumption and found that digital media consumption increased during and after the lockdown, time and money spend on OTT platforms increased drastically. Digital consumption surpassed television and newspaper consumption.

Travel and tourism were found to be the sector having impacted the maximum. Cavallo (2020), Suau-Sanchez et al. (2020), and Jaipuria et al. (2021) found that there was a substantial decrease in travel leading to a significant adverse impact on the aviation and hospitality industries. This all impacted the foreign exchange earnings, regional developments, and job opportunities in the region adversely. After reviewing the literature, researchers found several studies exploring the 
impact of the COVID crisis on the economy, consumer behavior, purchasing pattern of products and services, expenditure, and saving behavior. However, they found mixed responses from the respondents.

Moreover, they could not find any specific research studying all the factors together. More importantly, the researchers found no study that explores the perpetuity of those changes and consumers' propensity to stick to those changes. These gaps directed the researchers to conduct this study.

\section{Methodology}

There were only a few studies that researchers found explaining the impact of the COVID crisis on household buying behavior from India's perspectives. No study was found studying the perpetuity of those changes. Hence it was a relatively new area of research. Therefore, researchers used a mixed-method approach based on qualitative interviews, secondary data, and media analysis, that is, using a qualitative, exploratory research design. The study used data collection methods such as Reflective Journal Logs, in-depth interviews, extensive literature review of secondary sources, and auto-ethnography. The study was cross-sectional and applied in nature. As qualitative research, with the exploratory purpose of the investigation, hypotheses are neither used nor given to them. Qualitative research was undertaken because the researchers' objective was to explore the situation and develop a base for further studies. It will help in generating hypotheses and identifying variables in future researches.

The sampling strategy used was purposive (non-probability) sampling, with a sample size of 34 (15 telephonic and 19 personal interviews) for in-depth interviews using a semi-structured questionnaire where informants were questioned about the impacts of the COVID crisis on their buying behavior (purchase pattern, volume, and frequency), and household expenditure. They were also asked about the perpetuity of those changes. The sample size was determined through the "principle of saturation" as after that; data were not giving new patterns or new insights. It was also more than the size recommended by Dworkin (2012) for this kind of interview-based qualitative study. Respondents were of widely diverse experiences and occupations such as research scholars and students from different fields of studies, faculties of the management department, marketing professionals, entrepreneurs, and homemakers to gain their valuable broad perspectives and develop a deeper understanding of the issue. There was no monetary compensation for participating in the study. Their age group ranged 25-42, the average age of 33, and the male-female ratio of 20 males and 14 females. Family size ranged from two members to eight-membered family. Respondent's income ranged ₹5-₹24 lakh; average income was ₹10.44 lakh; researchers divided the respondents based on income for the analysis as explained in Table: 1, into IG-I and IG-II, that is, Income Group-I with respondents having income of ₹5-₹9 lakh per annum (average ₹6.41 lakh) and Income Group-II with respondents income ranging ₹10-₹24 lakh per annum (average ₹14.47 lakh), respectively.

The interviewee's only basic requisite eligibility was that it should not be from the family whose one or more members had lost their job after the COVID crisis. 
Table I. Division of the Respondents into Two Groups Based on Income

\begin{tabular}{lcc}
\hline Income Group & Income Range (₹ Lakh) & Average Income (₹ Lakh) \\
\hline IG-I & 05 to 09 & 06.41 \\
IG-II & 10 to 24 & I4.47 \\
\hline
\end{tabular}

Source: The authors.

Their behavior must be interfered due to financial setbacks. It could have focused on lower income groups, but the middle class's principal market is concentrated. The research was carried out between December 10, 2020, and January 30, 2021.

The whole research was divided into two parts; in the first phase, 5 interviews were conducted by the first interviewer, and the results were used to make minor variations in the wordings of the semi-structured questionnaire. In the second phase, the second interviewer interviewed 29 informants. All interviews were then transcribed; each interview lasted for 10-15 minutes. The entire transcribed documents had 65 pages. According to Kvale (1996), the steps covered for in-depth interviews in this research were thematizing, designing, interviewing, transcribing, analyzing, verifying, and reporting. Data reduction, analysis, and interpretation were made manually, and the overall method used was narrative qualitative research. No primary focus was given to quantifying the facts, just exploring the changes and probable reasons behind the changes; therefore, for checking the validity and reliability, authors got the paper evaluated and proofread by the faculties teaching subjects such as consumer behavior and economics.

\section{Finding and Discussions}

Researchers tried to capture all the impacts of the COVID crisis on household buying behavior but faced one limitation: The changes were so sudden and in phases that it was difficult to measure. However, researchers tried to cover the effect of changes in time phases. Consumers believe that nothing ever impacted their behavior more than the COVID crisis. Only a few consumers thought there were no significant changes in their purchase patterns and behavior, and those were the ones in the high-income group, that is, IG-II. When we talk about the comparison between (lower income group) IG-I and (higher income group) IG-II respondents, there was more difference in the purchase behavior of services than the buying behavior of the products.

\section{Change in Purchase Behavior of Products}

Earlier, most of the shopping was done by women, but males started purchasing more often during the lockdown and even after it. They took the experience of the things they usually did not buy earlier, more often like household items. Males were found to be more conservatives and purchased instead in larger volumes. Some respondents also said they believed the same things as the pre-COVID period, just their purchase pattern, that is, frequencies and volumes, changed. 
Health, Hygiene, and Wellness. As people become more self-aware and concerned about their healths. One category that showed the maximum growth in every customer segment was personal care-health, hygiene, and wellness. Products purchased maximum were face masks, sanitizers, immunity booster medicines, dietary supplements such as multi-vitamins, and generic medicines (Allopathy, ayurvedic, and homeopathy). However, the masks have also become a fashion statement after many companies entered their unique and innovative designs. Many respondents also believe to see designer face masks in marriages and other functions. Expenditure on medicines increased a lot. As for any slight ailment, the phobia involved was high. The primary cause of concern was that good-quality reliable sanitizers were not available in the market, and markets were filled with low-quality sanitizers. This was despite the fact that many diverse firms such as Nycil had started producing sanitizers in their firms. Second, parents were forced to postpone their child's vaccinations by a few months as they abstained from visiting the clinics.

Food and Grocery. Purchase of packaged (non-perishable) food products and snacks, such as biscuits, chocolates, cheese, sweets, powdered milk, and bread, increased. The consumers did not have outside fast food; therefore, they prepared them at home. Groceries were purchased in higher quantities by all the respondents surveyed, irrespective of the group IG-I and IG-II. Earlier, the reason for higher volume was the uncertainty of future availability, and later the reason was convenience.

Games and Sports. As the kids were home isolated for months and their schools were closed, parents purchased many things to engage them, such as sports, games, and toys. Even the adults who were having more time to relax involved themselves in such things. All the people surveyed purchased products such as badminton, carom board, chess, and toys. Initially, people were forced to buy at higher prices as cheaper Chinese substitutes were less available. Respondents in IG-II also purchased electronic games and play stations during the COVID situation. Almost all these purchases were made online.

Others. There was an increase in the purchase of electronic and electrical items. People in IG-I purchased electronic items such as smartphones, tablets, and laptops. On the other hand, the respondents in IG-II purchased electrical appliances such as smart televisions, home theatres, and play stations. Overall, for both IG-I and IG-II, the expenditure on clothing and fashion accessories decreased maximum.

Habits. Not only the purchase habits but also the consumption behaviors of the people changed. Most of the respondents had planned not to give electronic devices to the kids, but they brought mobile for e-classes. However, the parents believe that the firms should develop products that have a less adverse impact on the kid's eyes. 
In addition, people started preferring healthier food options. Options such as organic food products, green food, and food products perceived as healthier became more demanded. Consumers' awareness and consciousness towards product labeling also changed; people started reading nutritional values, constituents, and ingredients before purchasing. Products labeled as healthy and immunity-boosting were preferred over the usual products. Products with more clearly written nutritional contents were preferred. They supported that a new range of products came and became demanded as mentioned in Figure 1.

If we talk about food habits, then COVID, followed by Bird Flu, made people move towards vegetarianism at least temporarily. Researchers also believed availability could be the reason. In addition, families with facilities started kitchen gardening. A few families who opted for working from home also shifted to their villages and grew vegetables of their own.

It was not surprising that the consumers did not prefer the products manufactured in China, especially after the crisis. Earlier, the consumers first picked the factors that are price and quality, but after the crisis, another factor added to the critical deciding attributes, that is, manufacturing country.

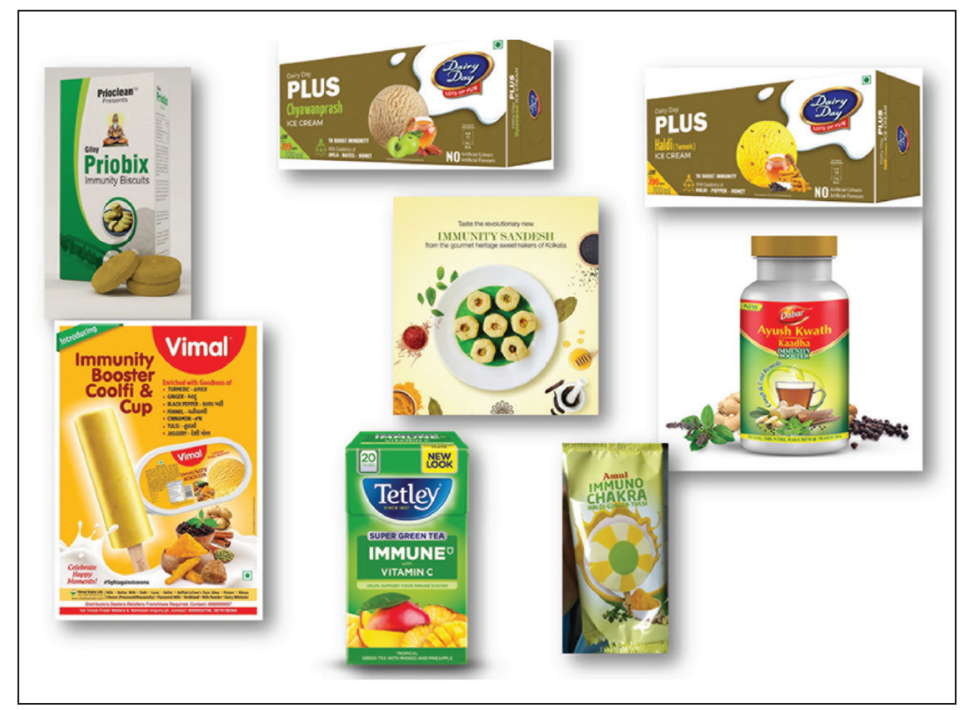

Figure I. Product that Became More Common After the Crisis

Source: Vimal Immunity Booster Cold \& Cup: https://social.vimalicecream.com/boost-up-yourimmunity-with-our-immunity-booster-coolfi-andamp-cup-which-contains-all-the-immunityrich-I 2789778658626I5042; Tetley Immune Vitamin C: https://www.tetley.in/our-teas/green-tea/tetleygreen-tea-lemon-honey; Amul Immuno Chakra: https://www.facebook.com/amul.coop/videos/amulpresents-an-icecream-thats-not-just-delicious-but-is-good-for-your-health-t/2448897052072189/; Dabur Ayush Kwath Kaadha: https://www.dabur.com/in/en-us/ayurvedic-herbal-products/dabur-ayushkwath-kaadha; Prioclean Priobix: https://klienzherbal.com/giloy-immunity-biscuits/; Dairy Day Chawanprash Ice Cream: https://www.arre.co.in/grub/chyawanprash-haldi-ice-cream-dairy-day/; Immunity Sandesh: https://indianexpress.com/article/cities/kolkata/kolkata-immunity-sandesh-tobattle-covid-19-644747// 
Our family always preferred to purchase products that were not made in China, but after the COVID crisis, our inclination shifted even more towards the products which were made in India, whether that was a toy for my child or a laptop for the online meetings of my wife, irrespective of the prices. (Respondent: Male, 35 years old, IG-II Group)

Besides food products, respondents from IG-I also believed that consumption of alcoholic beverages and cigarettes was also reduced. This is because people started purchasing more of the essential goods and services over the non-essential items. In addition, unavailability and lack of space in the house to consume those products was another reason for less usage.

Purchase frequency reduced, whereas the purchase volume increased. During the lockdown, but now after almost all the shops are open, the purchase volumes are still more than the purchase volumes of the COVID crisis. Purchase volumes of respondents from both IG-I and IG-II increased during the lockdown, but the increase in IG-II people was much higher. Availability of funds and storage space can be the reason. It was surprising to see the respondents' responses that the consumers' purchase volumes and consumption volumes increased. Families used to stay together and eat together, leading to the increased consumption, whereas earlier half of the family members used to eat in their canteens or messes. This bulk buying and hoarding were not only of the food items but also of the medicines. Families with medical patients also started bulk buying the prescriptions. Few IG-II families where some very elderly patients were there were found to stock even the oxygen cylinders and concentrators, which was found more often during the second wave of COVID. The habit of hoarding, which increased during the lockdown, is still the habit of consumers; still, they buy more than usual as they find it convenient.

As soon as we learned about the lockdown, our family's first thing was to create a new WhatsApp group, making a list of all the essentials and visiting the stores to purchase that. For safety purposes, our housemakers suggested that it would be fine if some product expired but still hoard in the quantities that there should not be the same shortage. (Respondent: Female, 40 years old, IG-I Group)

Not only had the behavior towards the products, but the mediums used for the purchase also changed. Although people's reliance on local stores had significantly increased during the complete lockdown, online deliveries also stopped for a while. Furthermore, many people are still following it. Purchasers moved towards local grocery stores, and the organized retail stores which did not offer home deliveries started offering home deliveries and WhatsApp deliveries during the crisis. People also moved towards purchasing from online stores when the restrictions were lifted due to convenience and readily available information. Therefore, price consciousness and consumers' price sensitivity also increased.

\section{Change in Purchase Behavior of Services}

Services saw overall maximum changes among all the respondents. Moreover, only the maximum differences between the respondents of IG-I and IG-II were found in this research. 
Self-improvement and Growth. The maximum change in the behavior of the consumers was seen in the self-improvement and growth services. The demand for self-development courses, self-help classes for yoga, and spirituality was increased among all the respondents. People's investment in courses for physical and mental health increased. This helped people move away from depression and frustration of isolation and anxiety for the future's uncertainty. Visiting salons reduced in both groups, that is, IG-I and IG-II, whereas among IG-II, people increased usage of grooming/salon services at home. People's sensitivity to the environment and sustainability has increased broadly, which may have shown positive results in the long run.

Medical Services. Visiting the small family clinic decreased, and people started increasing self-prescribed medicines for minor ailments. People visit more prominent hospitals more often as they are worried about the illnesses and perceive COVID. Therefore, they visited the hospitals in the panel of their medical insurance. The usage of telemedicine also increased significantly; people consulted their local hospitals or even consultants on various virtual platforms. Telemedicine was found to be better and less expensive, especially for taking a second opinion. It helped increase the outreach of the medical facilities to the far-fetched areas where it was not available earlier. Telemedicine is more convenient, safer, and affordable. Of course, it was spreading earlier too, but the COVID crisis increased its adaptability even more. People's anxiety to visit doctors promoted the usage of tele-medicines. Besides, the frequency of COVID tests, especially among the group IG-II, increased as they used to still travel for their business purposes. Furthermore, people started taking insurance services. Mostly, the IG-I respondents moved towards medical insurance, and the respondents in IG-II increased their insurance cover.

Online Delivery and Payments. Respondents of both the groups mentioned using online deliveries even before the pandemic, but all shared that their online purchase of groceries, fruits, and vegetables increased after the pandemic. Most of those grocery and vegetable online buyers were first-time buyers. Digital payment during online and offline shopping increased anonymously by all the respondents, whose reason could be to reduce the contact points at ATMs or while receiving cash. Digital payments can be made without contacting by just scanning the code.

Discretion and Entertainment. Respondents whose family members married believed that the travel (honeymoon) after the marriages decreased significantly during the pandemic. But they believe this travel may show a jump when things become routine. IG-II respondents believe that the spending on tours, travel, holidays, outings, and restaurant dinners reduced after the pandemic. In contrast, their expenditures on OTT platforms increased significantly. The reason for that was that the contents of the televisions were repeating during a period, and when things moved towards normalization, the consumers were already addicted. Many 
families also opted for Jio Fiber set-top boxes for both internet and entertainment purposes. It was surprising that males primarily took the OTT subscriptions as females believed their household chores increased much more than before. Furthermore, housemaids' services have not resumed fully yet. When things started moving, usually the second wave hit.

We subscribed to a few OTT platforms for only a few months, but every family member gets addicted to those serving as a surprise. We also disconnected our regular cable operator, which we used only to watch the news or the kids' cartoons. Still, kids prefer applications such as YouTube Kids and Voot Kids as there are no ads. My son now prefers to spend time on BYJU'S Junior as that application is more interactive. (Respondent: Male, 30 years old, IG-II Group)

Habit. The media consumption changed; people moved towards watching more OTT, but one probable reason apart from discretionary time was channels started telecasting the old episodes, and the theatres were also closed. Due to which the creators started making excellent online content. While watching YouTube and TikTok was so high that YouTube had to make significant changes in their policies, reels took over the Indian market when TikTok was banned. So, the frequency and the time used in digital and social media consumption increased drastically and still is very high. People spend time watching online videos, e-books, social media, and reading news online, as most of them had stopped their newspaper subscriptions. So even the avid readers of newspapers have started reading information online.

Apart from spending time digitally, people also started spending time on games and sports, and spending time with their families also increased. Most people began doing online yoga classes as the gyms were closed. Some gyms were also shut permanently due to the inability to run sustainably. However, most of them have continued the practice as they find it more convenient and believe that yoga's breathing exercises would better protect them from COVID. Many people also started Zoom and Google Meetings for family get together, birthdays, and attended marriages online. If this becomes a norm like earlier sending cards on WhatsApp, this will drastically change the ways ostentatious weddings are conducted in India.

Mostly all the respondents had stopped sending kids for tuitions and opted to go for online classing applications. Most parents plan to continue this after the normalization as they find online options better and more convenient. The student can learn at his own pace and can also revise the lectures if required. However, few parents believe they will stop students' online classes as this does not let the kid's most essential skills, that is, social or interpersonal skills, enhance.

Work from Home. Working from home increased people, especially in IG-I purchase of furniture, study table and chair, and electronic items. Furthermore, people in IG-II's purchase for Airtel and Jio Fibers increased. However, this change will continue to be long-lasting; several firms will also make this setting permanent. 


\section{Perception Towards Expenditures and Savings}

Among the respondents in IG-II, expenditure and saving remained almost the same. In some cases, it was even reduced as the expenditure on vacations and trips was reduced. Whereas, among the IG-I respondents, expenditures increased initially as they had to purchase electronic items, automobiles (increased fuel consumption), and believe the prices of almost everything raised during the lockdown are still higher than usual. That product might be a laptop or vegetables. Expenditures of some families in IG-I and IG-II also reduced as they shifted to their joint family house, and a few also moved to smaller homes with lesser rents to mitigate the uncertainties related to future worries. In the respondents of IG-I, savings increased after initial purchases to reduce the financial uncertainties in the future. Many respondents, especially IG-I, started spending on the stock market to keep themselves busy and save money. People who earlier brought gold now prefer to buy IPOs rather than that. Earlier, only the family's earning person bought life insurance, but people moved towards full family life insurance. Term insurance, which was not very common in India earlier, became more prevalent after this crisis. In addition, this situation not just added new policy buyers, but old buyers even increased the cover.

My father always invested in the stock market. Still, after COVID, my wife and I also started investing in the market, which could be the need for an extra income to reduce the financial uncertainty of the future. Earlier, we used to invest in PPF, but now we understand that the rate of return is too low, and we require more liquid money to deal with any situation. (Respondent: Male, 36 years old, IG-I Group)

\section{Perceptions Towards Perpetuity}

There were several changes in household consumption behavior. It was essential to understand what all changes were in the short term and what all changes tended to remain for the long term. Overall, respondents believed that almost all the changes were temporary and will come back to normal after the normalization. However, a few changes are about to sustain as per the respondents. Respondents felt that the decline in movies seems to be permanent. People started liking to see content on OTT; as there they have the flexibility to watch anytime and in parts and enjoy diverse kinds of content over there, which generally did not reach theatres due to low viewers density or regional or foreign language content subtitles.

Moreover, the whole family can share the same ID. Eating out and local fast food may reduce even in future as they have started cooking those things at home. And have switched to healthier options as they have become more healthconscious. Buying groceries, fruits, and vegetables from online stores will continue in the future too. Purchase volumes have increased and will tend to continue, too, as people find it convenient now.

Usage of sanitizers has been reduced and will reduce even more in the future, but the respondents believe they will continue consuming immunity booster products. People will keep having medical insurances in the future. They will increase the spending on insurance in the future as they realized that any amount is less when a medical crisis comes. 
However, the respondents believe that the decline in tourism, hotel, and airlines industry was temporary. People will increase holidays from next year as they have understood the importance of life and enjoyment a lot. Therefore, this industry will show a tremendous boom as and when things become better.

\section{Conclusions}

Overall, the customers' purchase behavior, habits, and patterns changed, but the service industry changes were more than the products.

Income-based differences between IG-I and IG-II were more evident in the services and less in the products. In products, just the volume of purchase was found to be more than the IG-I respondents. Of course, the lower middle class must have faced food shortage and malnutrition, but the middle class's nutrition standards must have risen. The sudden increase in the products' prices could be due to decreased supply and increased demand as the purchase volume increased. During the crisis, a significant hit on the FMCG sector was due to the supply chain and distribution pressure rather than the production disruption. Bulk buying and hoarding caused due to the scarcity and panic of the shortage lead to the bulk buying and hoarding, must have led to the actual deficiency.

The "word cloud" of the most frequent words in the transcripts is mentioned in Figure 2. This research will have significant practical implications. Researchers also believe that people move towards anti-consumerism; they buy more critical things as per their needs. Concepts such as living with less have come into action.

Firms can produce and market electronic equipment that has less impact on the eyes. Hospitals and clinics can start with the home vaccinations of the kids, as this was one of the most significant causes of concern for the families. Online

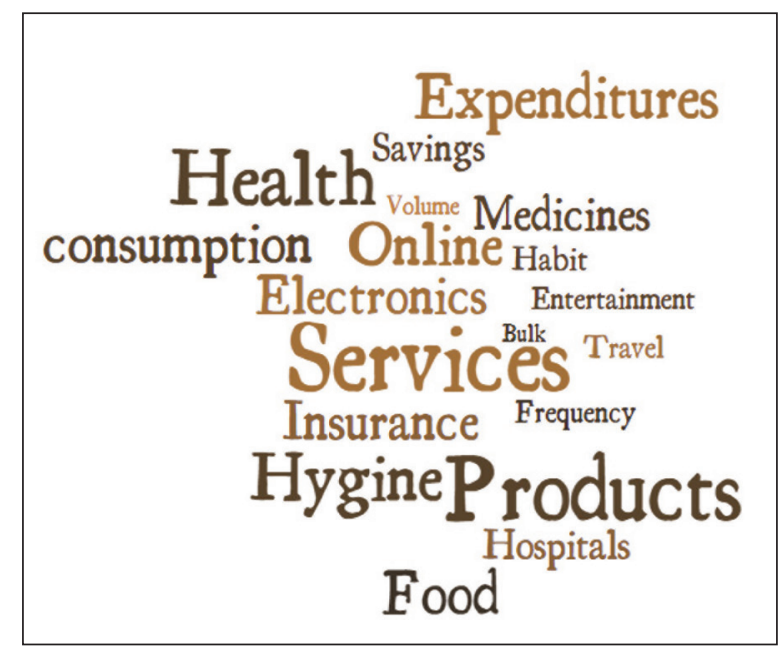

Figure 2. Word Cloud of the Most Frequent Words in the Transcript

Source: The authors. 
portals that deliver raw chicken, fish, and alcohol can be a good business opportunity in the future. Like these days, where hospitals are helping set up ICUs at homes, future firms can help set up homes offices as the work from home will stay high even after the normalization. Those firms can help with furniture, the right equipment, and making the rooms soundproof. Clothing, fashion accessories, and travel industries will get enormous demands as soon as things become normal, so they need to be prepared. Consumers have started making bulk purchases, so firms need to keep running sales promotions and promotional campaigns to make them keep buying in this manner in the future too. FMCG firms need to understand the behavioral change of the consumers where they give due consideration to the labeling of the products; this can be used to make changes in the products and labels and, in turn, the profit.

As the consumers have shifted towards online platforms from television and newspapers, marketers need to make the promotional changes accordingly. This study also found that customers have become more price-sensitive; therefore, the firms need to consider that fact while formulating the strategy. Furthermore, as new customers are moving towards the insurance firms, insurance firms should reap the benefits of this opportunity by offering new products to attract youth. This crisis has given lessons to every industry as a whole OTT platform should open the Apps for kids, and every hospital should start a telemedicine division in their hospitals. Moreover, as found in this study, patients are moving towards more prominent hospitals now; in the future, small clinics will have to make adjustments like a tie-up with insurance firms to regain their clients' back.

Changes after COVID were sudden, and the firms were unprepared, but a new phase of changes will be coming post-COVID, and firms need to be prepared for that in advance. Besides, this study will also help in any future crisis; the world has already faced SARS in 2003, H1N1 in 2009, and MERS in 2012. This research also suggests that the government should intervene in the production and supply of essential goods and services as it was seen that the supply chain got disrupted in the initial days itself. Therefore, if we have to reduce such inconveniences, the government needs to be prepared and have a few things in control.

As soon as the researchers completed this study, India was hit by another wave and much more prominent and fiercer this time; therefore, researchers suggest a future longitudinal study comparing the further changes in consumer behavior.

\section{Policy Implications}

The findings of this study might help the corporates better understand the customers' needs, leading to new business opportunities. Corporates will understand the requirements of new products and service offerings to the customers. This study can help in developing new business models altogether. Future market expectations will help understand the customers' needs and enable the businesses to frame the survival strategies. There is a significant change in consumer behavior in terms of spending and saving. Firms can use this understanding during the formulation of the strategy. The findings of this article can also help organizations in the preparations for such unfortunate times. This research will also help the 
academicians formulate the hypotheses for their studies. The government can understand the inconveniences caused to the public, which they can use in policymaking.

\section{Declaration of Conflicting Interests}

The authors declared no potential conflicts of interest with respect to the research, authorship, and/or publication of this article.

\section{Funding}

The authors received no financial support for the research, authorship, and/or publication of this article.

\section{References}

Aday, S., \& Aday, M. S. (2020). Impact of COVID-19 on the food supply chain. Food Quality and Safety, 4(4), 167-180.

Blasco, M. M., Castella, C. O., \& Raso, M. L. (2020). Impact of the Covid-19 pandemic on media consumption in Spain. Revista Latina de Comunicación Social, (78), 155-167.

Bounie, D., Camara, Y., \& Galbraith, J. W. (2020). Consumers' mobility, expenditure and online-offline substitution response to COVID-19: Evidence from French transaction data. http://dx.doi.org/10.2139/ssrn.3588373

Cavallo, A. (2020). Inflation with covid consumption baskets (No. w27352). National Bureau of Economic Research.

Cellini, N., Canale, N., Mioni, G., \& Costa, S. (2020). Changes in sleep pattern, sense of time and digital media use during COVID-19 lockdown in Italy. Journal of Sleep Research, 29(4), e13074.

Chang, H. H., \& Meyerhoefer, C. D. (2020). COVID-19 and the demand for online food shopping services: Empirical evidence from Taiwan. American Journal of Agricultural Economics. https://doi.org/10.1111/ajae.12170

Chaudhary, M., Sodani, P. R., \& Das, S. (2020). Effect of COVID-19 on economy in India: Some reflections for policy and programme. Journal of Health Management, 22(2), $169-180$.

CNBC. (2020). India's millennials are driving a surge in stock trading during the pandemic. https://www.cnbc.com/2020/10/02/indias-millennials-are-driving-a-surgein-stock-trading-during-covid.html

Dang, H. A. H., \& Nguyen, C. V. (2020). Gender inequality during the COVID-19 pandemic: Income, expenditure, savings, and job loss. World Development, 140, 105296.

Dannenberg, P., Fuchs, M., Riedler, T., \& Wiedemann, C. (2020). Digital transition by COVID-19 pandemic? The German food online retail. Tijdschrift voor economische en sociale geografie, 111(3), 543-560.

Dworkin, S. L. (2012). Sample size policy for qualitative studies using in-depth interviews. Archives of Sexual Behavior, 41(6), 1319-1320. https://doi.org/10.1007/s10508-0120016-6

Fatoye, F., Gebrye, T., Arije, O. O., Fatoye, C., Onigbinde, O., \& Mbada, C. (2021). PRS17 economic impact of COVID-19 lockdown on households in Nigeria. Value in Health, 24(Supp. 1), S215-S216.

Galhotra, B., \& Dewan, A. (2020). Impact of COVID-19 on digital platforms and change in E-commerce shopping trends. In 2020 Fourth International Conference on I-SMAC (IoT in Social, Mobile, Analytics and Cloud) (I-SMAC) (pp. 861-866). IEEE. 
Goswami, S., \& Chouhan, V. (2021). Impact of change in consumer behaviour and need prioritisation on retail industry in Rajasthan during COVID-19 pandemic. Materials Today: Proceedings, 46(4). https://doi.org/10.1016/j.matpr.2020.12.073

Jaipuria, S., Parida, R., \& Ray, P. (2021). The impact of COVID-19 on the tourism sector in India. Tourism Recreation Research, 46(2), 245-260.

Kvale, S. (1996). Interviews: An introduction to qualitative research interviewing. SAGE Publications.

Madnani, D., Fernandes, S., \& Madnani, N. (2020). Analyzing the impact of COVID-19 on over-the-top media platforms in India. International Journal of Pervasive Computing and Communications 16(5), 457-475.

Maxwell, J. C. (2007). The 21 indispensable qualities of a leader: Becoming the person others will want to follow. HarperCollins Leadership.

Romano, F. (2020). An estimate of the economic impact of COVID-19 on Australia. http:// dx.doi.org/10.2139/ssrn.3581382

Srivastava, S. (2020, August 2). Covid-19 impact: Rise in number of first-time buyers, additional purchase, says Maruti Suzuki. The Economic Times. https:/economictimes. indiatimes.com/industry/auto/cars-uvs/covid-19-impact-rise-in-number-of-first-timebuyers-additional-purchase-says-maruti-suzuki/articleshow/77312414.cms

Suau-Sanchez, P., Voltes-Dorta, A., \& Cugueró-Escofet, N. (2020). An early assessment of the impact of COVID-19 on air transport: Just another crisis or the end of aviation as we know it? Journal of Transport Geography, 86, 102749.

Sunitha, S., \& Sudha, S. (2020). Covid-19 conclusion: A media and entertainment sector perspective in India. Vichar Manthan, 8(24), 135-137.

Suryahadi, A., Al Izzati, R., \& Suryadarma, D. (2020). Estimating the impact of COVID-19 on poverty in Indonesia. Bulletin of Indonesian Economic Studies, 56(2), 175-192. 


\title{
Are Fama-French Factors Relevant? A Sub-Sectorial Analysis
}

IIMS Journal of Management Science

I3(I) 89-11।, 2022

(C) The Author(s) 2022

DOI: $10.1177 / 0976030 \times 211052205$

ims.spectrumjps.com

\section{Vanita Tripathi', Ritu Sapra' and Rishabh Gupta ${ }^{2}$}

\begin{abstract}
The purpose of the study is to empirically examine the sectoral-specific performance of the five-factor asset pricing model comprising of I7-years' data in the Indian stock market using the Fama-French methodology. The results highlighted the better performance of a five-factor model in the "Basic Material" and "Oil" industries. However, for the "consumer" industry, there is an existence of other risk factors which can better explain the portfolio's excess returns. The result further demonstrates the better explanatory power of the five-factor model in explaining the portfolio excess return for the "Industrial" sector. However, the findings support the better applicability of market mode for the "financial" sector in the Indian stock market. For the "Health Care" and "Technology" industries, the addition of two more risk factors does not lead to much improvement in the model's explanatory power. The current study evaluating the applicability of the asset pricing model will have a practical implication for portfolio managers, policymakers, researchers, and academicians in evaluating the performance of the portfolios on a sectoral basis and in determining the cost of equity in the overall cost of capital. The study will also aid the investors in their investment decisionmaking by helping them to identify the average stock return in different sectors.
\end{abstract}

\section{Keywords}

Asset pricing model, Fama-French, sectors, risk factors, Indian stock market

JEL Classification: C22, F65, G4, GI I, GI2

\footnotetext{
' Department of Commerce, Delhi School of Economics, Delhi, India

${ }^{2}$ Department of Commerce, Delhi College of Arts \& Commerce, Delhi, India
}

\section{Corresponding Author:}

Ritu Sapra, Department of Commerce, Delhi School of Economics, University Enclave, Delhi I I0007, India. E-mail: Sapra.ritu@gmail.com 


\section{Introduction}

Financial management revolves around various decisions, particularly, capital budgeting, capital structure, and dividend decisions. The cost of equity is considered as a heart or a center point of attraction for all these decisions. Thus, the correct estimation of the cost of equity is crucial in order to make vital decisions like whether to invest in a particular company or not or whether to undertake a particular project or not. The correct estimation of equity is vital for both the companies as well as for the investors. In the finance literature, there is an existence of various model which can assist in the calculation of the cost of equity. One such prominent model to calculate the cost of equity is Capital Asset Pricing Model (CAPM). The CAPM was introduced in the 1960s by Treynor (1961), Sharpe (1964), Linter (1965), and Mossin (1966) depicting the direct and linear relationship between the security's expected return and market risk. CAPM was considered as a follower of modern portfolio theory which was introduced by Harry Markowitz in 1964. The theory investigates the relationship between the financial asset's risk and expected return. In continuation of Harry Markowitz's theory, CAPM attempts to capture the relationship between the expected return and market risk. Failure of CAPM in capturing the security's expected returns has led to the development of alternative versions of CAPM such as zero beta version of CAPM, consumptionoriented CAPM, and multi-beta CAPM. The introduction of multi-beta CAPM by Ross (1976) in the 1980s has led to the development of a plethora of research specifying the presence of various other risk factors which can explain the security's expected returns. Thus, in order to improve the explanatory power of the model, various asset pricing models have been empirically developed and tested by the researchers. But the end of the 20th century marked the arrival of one of the famous multifactor models called the Fama-French three-factor model. Fama and French (1993) included market, size, and value risk factors. But the failure of the three-factor model in capturing the anomalies such as accrual anomaly, profitability, and investment anomaly has led to the development of the Fama-French fivefactor model which incorporates profitability and investment risk factor along with the market, size, and value risk factors (Fama \& French, 2015). With the advent of the five-factor model, various research are forgoing in the finance literature with regard to the testing of the five-factor model amongst various nations. Numerous researchers have tested the empirical applicability and the explanatory power of the five-factor model in the Indian stock market. The present research tries to go one step ahead by testing the sectoral-specific applicability of one of the widely used five-factor model in the Indian stock market. The objective of the research article is to identify the risk factors which can capture the size, value, profitability, and investment risk factors amongst various sectors of India. The study also tries to shed a light that whether the five-factor asset pricing model has a sectoral orientation or not in India. Also, because of different industry characteristics, the same model may not be universally applicable across various sectors of India. Thus, findings will give an opportunity to examine the in-depth validity of the asset pricing model in India. It tries to address an important research question, that is, whether a five-factor model can explain industrial returns in India. It will also assist the portfolio managers to build a portfolio of those companies belonging to 
compute the industry-specific cost of capital, and thereby will help them in evaluating the performance of their sectoral-specific portfolios. The study will also assist the mutual fund managers in their investment decision-making as it helps them to identify the average stock returns in various sectors.

\section{Literature Review}

The CAPM which was introduced by Treynor (1961), Sharpe (1964), Linter (1965), and Mossin (1966) in their empirical findings independently found out that security's expected returns are explained by market risk factor and degree of sensitivity of security return to market return is being measured by "beta" of a security. However, with the passage of time, it was found that security's expected returns are not merely the function of the market risk factor but can also be explained by various other factors. Merton's (1973) Intertemporal CAPM and Ross's (1976) arbitrage pricing theories were two such models which gave a direction towards the path of the multifactor asset pricing model. Failure of CAPM to explain the size and value anomaly has led to the development of a three-factor model comprising of the market, size, and value risk factor (Fama \& French, 1992). However, the three-factor model still lacked in explaining the momentum anomaly which has led to the emergence of the Carhart four-factor model. There existed a large body of literature with regard to testing of the explanatory power of the three-factor model amongst various nations. Gaunt (2004) empirically tested the applicability of size effect, value effect, and Fama-French three-factor model in the Australian stock market and highlighted the improved explanatory power of the three-factor model. The authors also highlighted the important role of the value factor in asset pricing in the Australian stock market. However, despite of recommendations from the academic world, Bartholdy and Peare (2005) found the inferior performance of a three-factor model in the U.S. stock market for the study period from 1970 to 1996 . The outperformance of the three-factor model over the traditional CAPM has also been found in the Indian stock market by Bartholdy and Peare (2005). Similar evidences were being reported by Taneja (2010) and Aldaarmi et al. (2015) in the Indian and Saudi Arabian stock markets, respectively. Walid (2009) in his paper provided stronger support for the characteristic model rather than Fama-French three-factor model in explaining return dynamics of the Japanese stock market. The inferior performance of the four-factor model is also being witnessed by Nartea et al. (2009) in the New Zealand stock market. Similar evidence of the weaker performance of the fourfactor model was found in the Italian stock market by Brighi et al. (2010). The period also witnessed the introduction of liquidity augmented three-factor model which is another effort being done (Chen et al., 2011) in the Chinese stock market wherein the results revealed the better explanatory power of the new four-factor model. Later on, similar evidences were quoted by Bhattacharya et al. (2020) who documented a liquidity-based asset pricing model in the Indian stock market using high-frequency data after controlling for up and down market, volatility, and effect of derivatives trading. Bhattacharya et al. (2021) further found the importance of illiquidity during periods of extreme high and low returns in the 
Indian stock market. Further, the existence of a large body of literature that emphasized the importance of profitability and investment risk factors in explaining the security's expected returns has led to the development of a fivefactor asset pricing model. Supported by the theoretical justification, Fama and French (2015) introduced the five-factor asset pricing model comprising of profitability and investment risk factors along with the market, size, and value risk factor. Various studies were conducted with regard to the testing of the five-factor model in various stock markets of the world (Chiah et al., 2015; Elliot et al., 2016; Huynh, 2017; Jain \& Singla, in press; Khudoykulov, 2020). The availability of limited literature on the sectoral performance of the five-factor asset pricing model in the Indian stock market and inconclusive research with the regard to the fivefactor model in such a market inspires us to study the sectoral-based testing of five-factor model performance in the context of Indian stock market.

The following objectives have been studied in this article:

1. To examine the market, size, value, profitability, and investment effect amongst various sectors of the Indian stock market.

2. To examine the explanatory power of the three, and five-factor asset pricing model amongst the various industries.

\section{Data and Research Methodology}

\section{Data}

The study tests the sectoral-specific applicability of the five-factor model in India by considering NSE 500 companies as a broad market index for the sample period from March 2002 to June 2019. All the NSE 500 companies are categorized into various sectors namely Basic Materials, Consumer Goods, Financials, Health Care, Industrial, Oil \& Gas, and Technology. Sectors particularly Consumer services, Telecommunications, and Utilities are excluded for the select sample period as the number of companies belonging to such sectors falls short for the portfolio formation purpose. The study considers the monthly stock price and accounting data of each company belonging to different sectors of India. The sector-specific data have been retrieved from the Bloomberg database. For each sector, the study further excludes companies with a negative book value of equity and market value of equity (BE/ME) ratio, with missing stock price and accounting data. For the estimation and analysis purpose, the data is being converted into monthly simple return series using the following formula:

$$
R_{t}=\frac{\left(P_{t}-P_{t-1}\right)}{P_{t-1}},
$$

where $R_{t}=$ return on stock I for month $t$;

$P_{t}=$ closing stock price in period $t$; and

$P_{t-1}=$ closing stock price in period $t-1$.

The stylized portfolios are formed on the basis of size (measured by market cap), BE/ME ratio, profit before tax (PBT)/BE, and growth in total assets. 
The study employs 91 days T-bill as a proxy for the risk-free rate of return and NSE 500 as a proxy for the market portfolio.

\section{Methodology}

The study adopts Davis et al. (2000) and Chan et al. (1991) methodology of portfolio construction. The study adopts portfolio analysis instead of individual security analysis in order to avoid measurement accuracy problems as it is difficult to estimate the betas of individual securities with high degrees of accuracy because of potential structural and cyclical changes (Fama \& French, 2004). The study further adopts a single sorting procedure of portfolio formation because of the paucity of securities belonging to each sector.

For each sector, the ranking of all companies included in such sector is being made in ascending order on the basis of June-end market capitalization. The ranked sample companies for each sector have been named as P1S, P2S, P3S, P4S, and P5S. P1S portfolio consists of small size companies, while P5S constitutes stock price data of big size companies. A similar single sorting procedure is being repeated for $\mathrm{BE} / \mathrm{ME}$ ratio wherein portfolios sorted on the basis of value factor have been named as P1V, P2V, P3V, P4V, and P5V. Similarly, stocks belonging to their respective sector are ranked on the basis of the PBT/BE ratio which is the proxy for the profitability factor. The portfolio sorted on the basis of profitability has been named as P1P, P2P, P3P, P4P, and P5P. Ranking in the ascending order is also being made for the formation of investment sorted portfolios. Growth in the total asset has been used as a proxy for investment which leads to the resultant portfolios, namely P1I, P2I, P3I, P4I, and P5I. All the portfolios are rebalanced on annual basis, and then monthly portfolio excess return and market index return have been calculated for the study period from July 2003 to June 2019.

For the construction of risk factors, namely SMB, HML, RMW, and CMA, the study employs a single sorting procedure. SMB risk premium has been defined and calculated as the monthly return difference between the small stock (P1S) and the big size portfolio (P5S). Similarly, the HML risk premium has been defined and calculated as the monthly return difference between the high-value (P5V) and low-value portfolio (P1V). The monthly return difference between the robust (P5P) and weak profitability portfolio (P1P) have been used for the calculation of the RMW risk premium. Similarly, the CMA risk premium has been defined and calculated as the monthly return difference between the conservative (P1I) and aggressive investment portfolio (P5I).

The relationship between the portfolio excess return and various risk factors is represented by the following:

Fama-French Three-Factor Model

$$
R_{i t}-R_{f}=\alpha_{i}+\beta\left(R_{M}-R_{f}\right)+\mathrm{s}_{i} \mathrm{SMB}_{t}+\mathrm{h}_{i} \mathrm{HML}+\mathrm{e}_{i t},
$$

where $R_{i t}$ means a return of portfolio $i$ on month $t$, and $R_{f}$ represents risk-free rate of return. SMB is the size factor, HML the value factor, RMW is the profitability 
factor and CMA as investment factor, while $\alpha_{i}$ is defined as the intercept term and $\beta, \mathrm{s}, \mathrm{v}, \mathrm{r}$ and $\mathrm{c}$ measure the sensitivities of various factors, and $\mathrm{e}_{i t}$ is the error term.

Fama-French Five-Factor Model

$R_{i t}-R_{f}=\alpha_{i}+\beta\left(R_{M}-R_{f}\right)+\mathrm{s}_{i} \mathrm{SMB}_{t}+\mathrm{h}_{i} \mathrm{HML}+\mathrm{r}_{i} \mathrm{RMW}+\mathrm{c}_{i} \mathrm{CMA}+\mathrm{e}_{i t}$

\section{Empirical Results}

Table 1 represents the monthly excess returns of the portfolio sorted on the basis of size, value, profitability, and investment risk factors for different sectors of the

Table I. Descriptive Statistics of Portfolio Excess Returns

\begin{tabular}{|c|c|c|c|c|c|c|c|c|c|}
\hline \multicolumn{7}{|c|}{$S E$} & \multicolumn{3}{|c|}{ SE } \\
\hline Portfolio & Mean & SD & (Mean) & $T$ (Mean) & Portfolio & Mean & $S D$ & (Mean) & $T$ (Mean) \\
\hline \multicolumn{5}{|c|}{ Panel A: Basic materials } & \multicolumn{5}{|c|}{ Panel B: Consumer goods } \\
\hline PIS & 0.032 & 0.1114 & 0.0078 & 4.0934 & PIS & 0.0306 & 0.0992 & 0.007 & 4.3857 \\
\hline P2S & 0.0233 & 0.9062 & 0.0636 & 0.3669 & P2S & 0.0228 & 0.0971 & 0.0068 & 3.3441 \\
\hline P3S & 0.0239 & 0.1193 & 0.0084 & 2.8497 & P3S & 0.0171 & 0.0844 & 0.0059 & 2.8909 \\
\hline P4S & 0.0124 & 0.0921 & 0.0065 & 1.9231 & P4S & 0.0185 & 0.0723 & 0.0051 & 3.6352 \\
\hline P5S & 0.0099 & 0.1066 & 0.0075 & 1.3285 & P5S & 0.0134 & 0.0604 & 0.0042 & 3.1511 \\
\hline PIV & 0.0201 & 0.0751 & 0.0053 & 3.8207 & PIV & 0.0189 & 0.0626 & 0.0044 & 4.2908 \\
\hline $\mathrm{P} 2 \mathrm{~V}$ & 0.0165 & 0.0974 & 0.0068 & 2.415 & $\mathrm{P} 2 \mathrm{~V}$ & 0.023 & 0.0762 & 0.0053 & 4.295 \\
\hline P3V & 0.0115 & 0.0918 & 0.0064 & 1.7873 & P3V & 0.0186 & 0.0823 & 0.0058 & 3.2164 \\
\hline P4V & 0.0259 & 0.1199 & 0.0084 & 3.0751 & P4V & 0.0176 & 0.0926 & 0.0065 & 2.7138 \\
\hline P5V & 0.0343 & 0.1351 & 0.0095 & 3.6128 & P5V & 0.0254 & 0.1049 & 0.0074 & 3.4488 \\
\hline PIP & 0.0174 & 0.1098 & 0.0077 & 2.2619 & PIP & 0.0172 & 0.096 & 0.0067 & 2.546 \\
\hline P2P & 0.0192 & 0.1215 & 0.0085 & 2.2533 & P2P & 0.0193 & 0.0961 & 0.0067 & 2.8598 \\
\hline P3P & 0.0191 & 0.1092 & 0.0077 & 2.4872 & P3P & 0.0238 & 0.0863 & 0.0061 & 3.924 \\
\hline P4P & 0.0166 & 0.0921 & 0.0065 & 2.5621 & P4P & 0.0232 & 0.0756 & 0.0053 & 4.3719 \\
\hline P5P & 0.035 & 0.1508 & 0.0106 & 3.3038 & P5P & 0.0198 & 0.0618 & 0.0043 & 4.5555 \\
\hline PII & 0.0233 & 0.1095 & 0.0077 & 3.0359 & PII & 0.0189 & 0.0838 & 0.0059 & 3.2068 \\
\hline P2I & 0.0182 & 0.0926 & 0.0065 & 2.7967 & P2I & 0.0217 & 0.089 & 0.0062 & 3.4757 \\
\hline P3I & 0.0166 & 0.1042 & 0.0073 & 2.2756 & P3I & 0.0182 & 0.068 & 0.0048 & $3.824 I$ \\
\hline P4I & 0.0192 & 0.1091 & 0.0077 & 2.5034 & P4I & 0.0177 & 0.0829 & 0.0058 & 3.0379 \\
\hline P5I & 0.0112 & 0.1464 & 0.0103 & $1.087 \mid$ & P5I & 0.0255 & 0.086 & 0.006 & 4.2236 \\
\hline \multicolumn{5}{|c|}{ Panel C: Financials } & \multicolumn{5}{|c|}{ Panel D: Health care } \\
\hline PIS & 0.0235 & 0.104 & 0.0073 & 3.2145 & PIS & $0.024 I$ & 0.0897 & 0.0063 & $3.824 I$ \\
\hline P2S & 0.0137 & 0.0991 & 0.007 & 1.9772 & P2S & 0.0175 & 0.0798 & 0.0056 & 3.1279 \\
\hline P3S & 0.0132 & 0.0968 & 0.0068 & 1.9456 & P3S & 0.0152 & 0.0756 & 0.0053 & 2.8646 \\
\hline P4S & 0.0109 & 0.1066 & 0.0075 & 1.4628 & P4S & 0.0142 & 0.0704 & 0.0049 & 2.8684 \\
\hline P5S & 0.0123 & 0.0996 & 0.007 & 1.759 & P5S & 0.0099 & 0.0659 & 0.0046 & 2.1378 \\
\hline PIV & 0.0179 & 0.0891 & 0.0063 & 2.8673 & PIV & 0.0156 & 0.0705 & 0.0049 & 3.154 \\
\hline $\mathrm{P} 2 \mathrm{~V}$ & 0.0152 & 0.0997 & 0.007 & 2.1683 & P2V & 0.0102 & 0.0638 & 0.0045 & 2.2816 \\
\hline P3V & 0.0166 & 0.094 & 0.0066 & 2.5108 & P3V & 0.0146 & 0.069 & 0.0048 & 3.0224 \\
\hline P4V & 0.0131 & 0.1047 & 0.0073 & I.777| & P4V & 0.0214 & 0.0805 & 0.0056 & 3.7869 \\
\hline P5V & 0.0136 & 0.1226 & 0.0086 & 1.5773 & P5V & 0.0177 & 0.0943 & 0.0066 & 2.6743 \\
\hline PIP & 0.0152 & 0.1083 & 0.0076 & 1.9995 & PIP & 0.0094 & 0.0855 & 0.006 & 1.5715 \\
\hline $\mathrm{P} 2 \mathrm{P}$ & 0.0127 & 0.1103 & 0.0077 & 1.6357 & $\mathrm{P} 2 \mathrm{P}$ & 0.0205 & 0.0819 & 0.0058 & 3.5675 \\
\hline P3P & 0.0134 & 0.0974 & 0.0068 & 1.9531 & P3P & 0.0154 & 0.073 & $0.005 \mathrm{I}$ & 3.0066 \\
\hline
\end{tabular}

(Table I continued) 
(Table I continued)

\begin{tabular}{|c|c|c|c|c|c|c|c|c|c|}
\hline & & & $S E$ & & & & & $S E$ & \\
\hline Portfolio & Mean & $S D$ & (Mean) & $T$ (Mean) & Portfolio & Mean & $S D$ & (Mean) & $T$ (Mean) \\
\hline P4P & 0.0176 & 0.0933 & 0.0065 & 2.6803 & P4P & 0.0154 & 0.069 & 0.0048 & 3.1794 \\
\hline P5P & 0.017 & 0.0957 & 0.0067 & 2.5314 & P5P & 0.0196 & 0.0682 & 0.0048 & 4.0911 \\
\hline PII & 0.0121 & 0.1009 & 0.0071 & 1.715 & PII & 0.0147 & 0.073 & 0.0051 & 2.8702 \\
\hline P2I & 0.018 & 0.1037 & 0.0073 & 2.47 & P2I & 0.015 & 0.0775 & 0.0054 & 2.767 \\
\hline P3I & 0.0122 & 0.0943 & 0.0066 & 1.8353 & P3I & 0.0177 & 0.0691 & 0.0048 & 3.6499 \\
\hline P4I & 0.0128 & 0.0904 & 0.0063 & 2.0154 & P4I & 0.0152 & 0.0801 & 0.0056 & 2.7051 \\
\hline P5I & 0.0192 & 0.1147 & 0.008 & 2.3811 & P5I & 0.0176 & 0.0773 & 0.0054 & 3.2502 \\
\hline Panel E: In & ustrial & & & & Panel F: C & & & & \\
\hline PIS & 0.0339 & 0.129 & 0.0091 & 3.7377 & PIS & 0.003 & 0.1112 & 0.0078 & 0.3809 \\
\hline $\mathrm{P} 2 \mathrm{~S}$ & 0.0187 & 0.0903 & 0.0063 & 2.9595 & $\mathrm{P} 2 \mathrm{~S}$ & 0.0053 & 0.1118 & 0.0078 & 0.6715 \\
\hline P3S & 0.0197 & 0.0865 & 0.0061 & 3.2432 & P3S & 0.0092 & 0.0935 & 0.0066 & 1.394 \\
\hline P4S & 0.0154 & 0.089 & 0.0062 & 2.4722 & P4S & 0.0158 & 0.1087 & 0.0076 & 2.0723 \\
\hline P5S & 0.0152 & 0.0801 & 0.0056 & 2.7006 & P5S & 0.009 & 0.0873 & 0.0061 & I.4727 \\
\hline PIV & 0.0201 & 0.0819 & 0.0057 & 3.5007 & PIV & 0.0081 & 0.113 & 0.0079 & 1.0162 \\
\hline $\mathrm{P} 2 \mathrm{~V}$ & 0.0167 & 0.0831 & 0.0058 & $2.87 / 3$ & $\mathrm{P} 2 \mathrm{~V}$ & 0.0054 & 0.0931 & 0.0065 & 0.8286 \\
\hline P3V & 0.0266 & 0.1108 & 0.0078 & 3.4184 & P3V & 0.0157 & 0.1035 & 0.0073 & 2.1602 \\
\hline P4V & 0.019 & 0.1057 & 0.0074 & 2.5667 & P4V & 0.0076 & 0.1094 & 0.0077 & 0.9911 \\
\hline P5V & 0.0317 & 0.1432 & 0.0101 & 3.1511 & P5V & 0.0051 & 0.108 & 0.0076 & 0.6733 \\
\hline PIP & 0.0255 & 0.1372 & 0.0096 & 2.6447 & PIP & 0.0185 & 0.1084 & 0.0076 & 2.4248 \\
\hline $\mathrm{P} 2 \mathrm{P}$ & 0.0159 & 0.0894 & 0.0063 & 2.5304 & $\mathrm{P} 2 \mathrm{P}$ & & 0.1063 & 0.0075 & 0.8068 \\
\hline P3P & $0.026 \mathrm{I}$ & 0.1046 & 0.0073 & 3.562 & P3P & 0.0063 & 0.0986 & 0.0069 & 0.9125 \\
\hline P4P & 0.0175 & 0.0796 & 0.0056 & 3.141 & P4P & 0.0044 & 0.1055 & 0.0074 & 0.5946 \\
\hline P5P & $0.024 I$ & 0.0798 & 0.0056 & $4.297 \mid$ & P5P & 0.0082 & 0.0964 & 0.0068 & I.2068 \\
\hline PII & 0.0212 & 0.1171 & 0.0082 & 2.5773 & PII & 0.0091 & 0.1091 & 0.0077 & I.1846 \\
\hline P2I & 0.0216 & 0.0887 & 0.0062 & 3.4638 & P2I & 0.0174 & 0.104 & 0.0073 & 2.3863 \\
\hline P3I & 0.0188 & 0.0874 & $0.006 \mathrm{I}$ & 3.0579 & P3I & 0.0078 & 0.1034 & 0.0073 & 1.0785 \\
\hline P4I & 0.0194 & 0.0793 & 0.0056 & 3.4875 & P4I & 0.0053 & 0.1023 & 0.0072 & 0.7334 \\
\hline P5I & 0.0222 & 0.0977 & 0.0069 & 3.2397 & P5I & 0.0051 & 0.0941 & 0.0066 & 0.7709 \\
\hline Panel G:1 & hnology & & & & Panel G & chnology & & & \\
\hline PIS & 0.0277 & 0.1265 & 0.0089 & 3.1251 & PIP & 0.0214 & 0.1192 & 0.0084 & 2.5552 \\
\hline $\mathrm{P} 2 \mathrm{~S}$ & 0.0245 & 0.1063 & 0.0075 & 3.2773 & $\mathrm{P} 2 \mathrm{P}$ & 0.0151 & 0.0926 & 0.0065 & 2.3254 \\
\hline P3S & 0.0116 & 0.1096 & 0.0077 & I.5074 & P3P & 0.0146 & $0.097 \mid$ & 0.0068 & 2. 1456 \\
\hline P4S & 0.0118 & 0.0954 & 0.0067 & I.7646 & P4P & 0.0196 & 0.0942 & 0.0066 & 2.9706 \\
\hline P5S & 0.0128 & 0.0735 & 0.0052 & 2.4817 & P5P & 0.0107 & 0.0804 & 0.0056 & I.896I \\
\hline PIV & 0.0149 & 0.0807 & 0.0057 & 2.6219 & PII & 0.0134 & 0.1098 & 0.0077 & 1.7446 \\
\hline P2V & 0.0156 & 0.0894 & 0.0063 & 2.4796 & P2I & 0.0222 & 0.1062 & 0.0075 & 2.9759 \\
\hline P3V & 0.016 & 0.097 & 0.0068 & 2.3482 & P3I & 0.0159 & 0.0872 & 0.0061 & $2.605 I$ \\
\hline P4V & 0.0183 & 0.1083 & 0.0076 & 2.4067 & P4I & 0.0193 & 0.0893 & 0.0063 & 3.0784 \\
\hline P5V & 0.0219 & 0.1342 & 0.0094 & 2.3247 & P5I & 0.013 & 0.103 & 0.0072 & I.8054 \\
\hline
\end{tabular}

Source: The authors.

Indian stock market. Except for the "oil" sector, the result indicates the higher mean monthly excess returns for the small stock portfolio in comparison to the large stock portfolios for all the sectors. This indicates the outperformance of small over the mega-stock portfolios. For the portfolio sorted on the basis of value, the mean monthly excess returns of high-value portfolios $(\mathrm{P} 1 \mathrm{~V})$ were found to be higher than that of low-value portfolios (P1V) for all the industries except for the "Financial" and "Oil" sectors which shows a different trend pattern. 
The portfolios sorted on the basis of profitability also indicate the increasing pattern of mean monthly excess returns with the increase in firm's profitability for the majority of the sectors, particularly "Basic Materials," "Consumer Goods," "Financials," and "Health Care." However, no specific pattern is indicated in the "Industrial," "Oil," and "Technology" sectors. In the case of portfolios sorted on the basis of investment risk factors, the mean monthly portfolio excess return exhibits a diminishing trend with a movement from P1I to P5I for the "Basic Material," "Oil" and "Technology" sectors. The descriptive results indicate the outperformance of conservative over aggressive investment portfolios. However, the increasing trend is witnessed for the other industries.

The results of Table 2 highlight the summary statistics of factor returns, namely market, size, value, profitability, and investment risk factors. The market premium for all the sectors is found to be $0.93 \%$ per month and is about $11.8 \%$ per annum. For the "Basic Material" industry, the SMB, HML, RMW, and CMA premiums are reported to $2.21 \%, 1.41 \%, 1.75 \%$, and $1.22 \%$, respectively, per month. The "Consumer Goods" industry indicated the positive size (1.72\% per month), value $(0.65 \%$ per month), and profitability premium $(0.26 \%$ per month). However, investment premium $(-0.66 \%$ per month) comes out to be negative in this industry showing a weak or no investment effect in the "Consumer Goods" industry. The descriptive results of the "Financial" sector indicate positive SMB and RMW risk premium of $1.12 \%$ per month and $0.18 \%$ per month, respectively. However, the risk premiums for the value and investment risk factors are found to be negative. In the "Health Care" sector, size, and profitability risk premium are reported to be positive and significant. The HML risk premium has also been reported to be positive $(0.21 \%$ per month) but insignificant $(t$ mean $)=0.45)$. The descriptive results further reported a negative investment premium of $-0.29 \%$ per month. For the "Industrial" sector, SMB and HML risk premium are found to be positive. However, RMW $(-0.14 \%$ per month $)$ and CMA risk premium $(-0.10 \%$ per month $)$ are reported to be negative for the "Industrial" sector. The "Oil" sector reports a negative SMB, HML, and RMW risk premium of $-0.61 \%,-0.30 \%,-1.03 \%$, respectively, while CMA risk premium is reported to be positive. The "Technology" sector indicates the positive SMB, HML, and CMA risk premium of $1.49 \%$, $0.70 \%$, and $0.04 \%$, respectively, per month while the risk premium appears to be negative for the RMW risk factor $(-1.07 \%$ per month).

Table 3 sheds a light on the regression results of the Fama-French three-factor model. It is evident from the results that with the incorporation of two more risk factors, a significant reduction in the alpha value is being observed. The presence of positive and significant alpha denotes the possibility of other risk factors which have the capacity to affect the portfolio's excess returns. Thus, after controlling for the market, size, and value risk factors, alpha values are found to be statistically insignificant. In terms of model performance, as indicated by the adjusted $R^{2}$, the result highlights the outperformance of the three-factor over one-factor asset pricing model for the industries, namely Basic Materials, Consumer Goods, Health Care, Industrial, Oil, and Technology. The result indicated the improved explanatory power for such industries.

Table 2 shows the regression results of the Fama-French five-factor model for various sectors. Regressing monthly portfolio excess returns on the five-factor 
Table 2. Summary Statistics of Factor Returns

\begin{tabular}{|c|c|c|c|c|c|c|c|c|c|}
\hline Portfolios & Mean & $S D$ & $\begin{array}{c}\text { SE } \\
\text { (Mean) }\end{array}$ & $\begin{array}{c}T \\
\text { (Mean) }\end{array}$ & Portfolios & Mean & $S D$ & $\begin{array}{c}S E \\
\text { (Mean) }\end{array}$ & $\begin{array}{c}T \\
\text { (Mean) }\end{array}$ \\
\hline \multicolumn{5}{|c|}{ Panel A: Basic materials } & \multicolumn{5}{|c|}{ Panel B: Consumer goods } \\
\hline Market & 0.0093 & 0.0695 & 0.0049 & 1.9088 & Market & 0.0093 & 0.0695 & 0.0049 & 1.9088 \\
\hline SMB & 0.0221 & 0.1043 & 0.0073 & 3.0144 & SMB & 0.0172 & 0.0795 & 0.0056 & 3.0786 \\
\hline HML & 0.0141 & 0.7473 & 0.0524 & 0.2688 & HML & 0.0065 & 0.0857 & 0.006 & 1.0878 \\
\hline RMW & 0.0175 & 0.8929 & 0.0627 & 0.2797 & RMW & 0.0026 & 0.0765 & 0.0054 & 0.4844 \\
\hline CMA & 0.0122 & 0.8749 & 0.0614 & 0.1987 & CMA & -0.0066 & 0.0497 & 0.0035 & -1.902 \\
\hline \multicolumn{5}{|c|}{ Panel C: Financials } & \multicolumn{5}{|c|}{ Panel D: Health care } \\
\hline Market & 0.0093 & 0.0695 & 0.0049 & 1.9088 & Market & 0.0093 & 0.0695 & 0.0049 & 1.9088 \\
\hline SMB & 0.0112 & 0.0657 & 0.0046 & 2.4216 & SMB & 0.0142 & 0.0679 & 0.0048 & 2.9756 \\
\hline HML & -0.0044 & 0.0767 & 0.0054 & -0.8101 & HML & 0.0021 & 0.0648 & 0.0045 & 0.4586 \\
\hline RMW & 0.0018 & 0.0623 & 0.0044 & 0.4117 & RMW & 0.0101 & 0.0655 & 0.0046 & 2.2068 \\
\hline CMA & -0.007 & 0.0589 & 0.0041 & -1.6959 & CMA & -0.0029 & 0.0618 & 0.0043 & -0.6757 \\
\hline \multicolumn{5}{|c|}{ Panel E: Industrial } & \multicolumn{5}{|c|}{ Panel F: Oil } \\
\hline Market & & & 0.0049 & & & & & & 1.9088 \\
\hline SMB & 0.0187 & 0.1018 & $0.007 \mid$ & $2.614 \mid$ & SMB & -0.0061 & 0.1015 & $0.007 \mid$ & -0.8501 \\
\hline HML & 0.0116 & 0.1162 & 0.0082 & 1.4176 & HML & -0.003 & 0.1105 & 0.0078 & -0.3818 \\
\hline RMW & -0.0014 & 0.0997 & 0.007 & -0.1983 & RMW & -0.0103 & 0.104 & 0.0073 & -1.4086 \\
\hline CMA & -0.001 & 0.0818 & 0.0057 & -0.181 & CMA & 0.004 & 0.0975 & 0.0068 & 0.5825 \\
\hline \multicolumn{5}{|c|}{ Panel G:Technology } & \multicolumn{5}{|c|}{ Panel G:Technology } \\
\hline Market & 0.0093 & 0.0695 & 0.0049 & 1.9088 & RMW & -0.0107 & 0.098 & 0.0069 & -1.5536 \\
\hline SMB & 0.0149 & 0.0903 & 0.0063 & $2.357 \mid$ & CMA & 0.0004 & 0.094 & 0.0066 & 0.0604 \\
\hline HML & 0.007 & 0.1203 & 0.0084 & 0.8332 & & & & & \\
\hline
\end{tabular}

Source: The authors.

model for the "Basic Materials" industry leads to a slight improvement in the regression intercepts. The regression intercepts of the five-factor model are found to be more shrink towards zero in comparison to the three-factor model regression intercepts for the "Basic Material" industry. The intercepts of the five-factor model are not found to be distinguishably different from zero and, thus, leads to non-rejection of the null hypothesis of intercepts being equal to zero. Similar evidence are revealed from the "Health Care" and "Technology" sectors showing a marginal decline in the regression intercept value with a movement from the three-to five-factor model. Parallel results are also witnessed for the "Consumer Goods" industry. However, the presence of significant abnormal returns in the regression results of the specific industry highlights the presence of other risk factors not covered by the five-factor model but have the capacity to affect the portfolio's excess return. In terms of the explanatory power of a model, the average adjusted $R^{2}$ of Basic Materials, Consumer Goods, Health Care, Industrial, Oil, and Technology are found to be $75.4 \%, 77.4 \%, 82.6 \%, 55.4 \%, 80.4 \%, 61.6 \%$, and $53.3 \%$, respectively. The result shows a better explanatory power of the five-factor model for all the specific sectors. There appears to be a marginal improvement in the asset pricing model performance with the inclusion of two more risk factors, namely profitability and investment in the "Health care" and "Technology" sectors. 


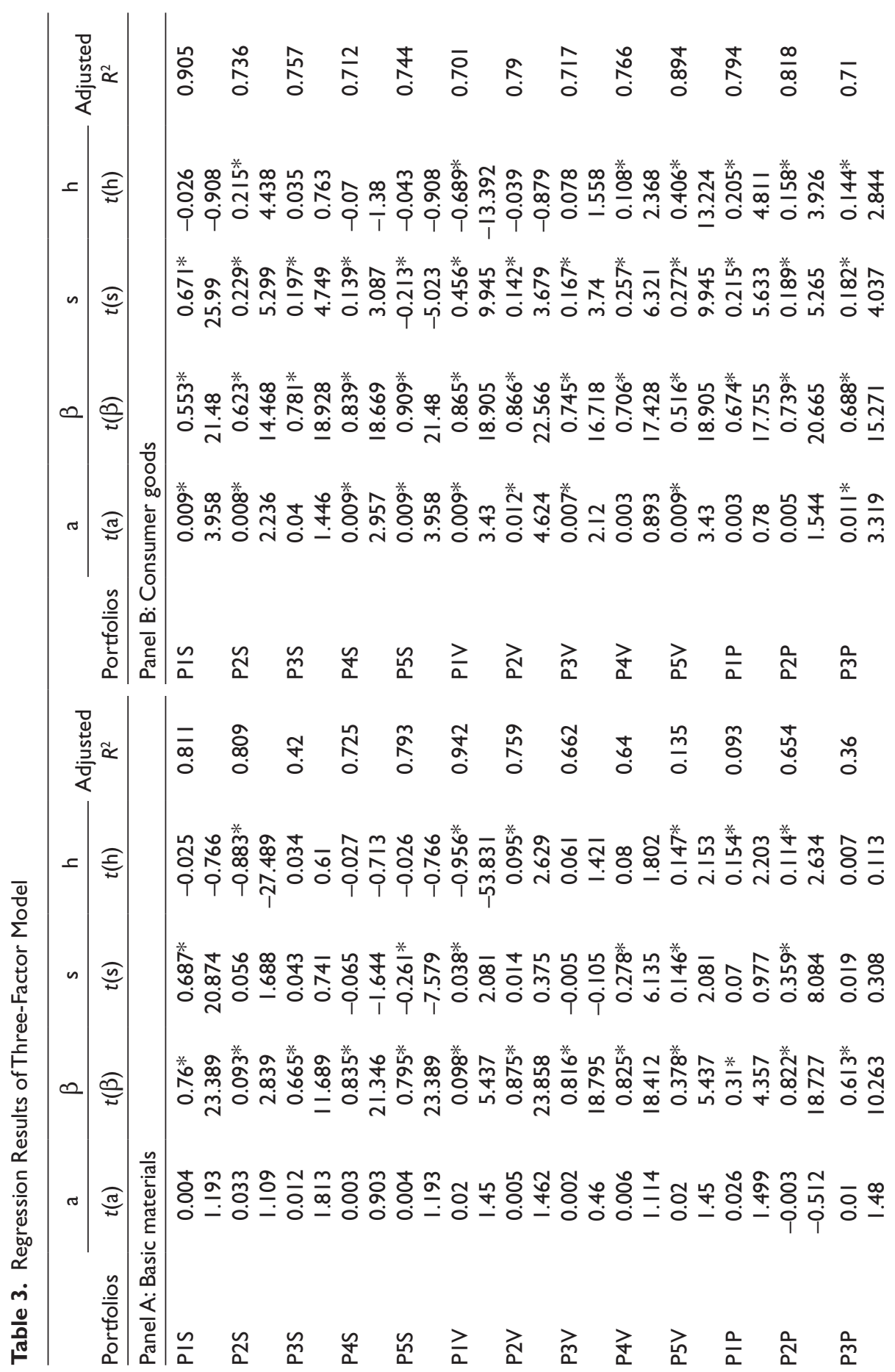




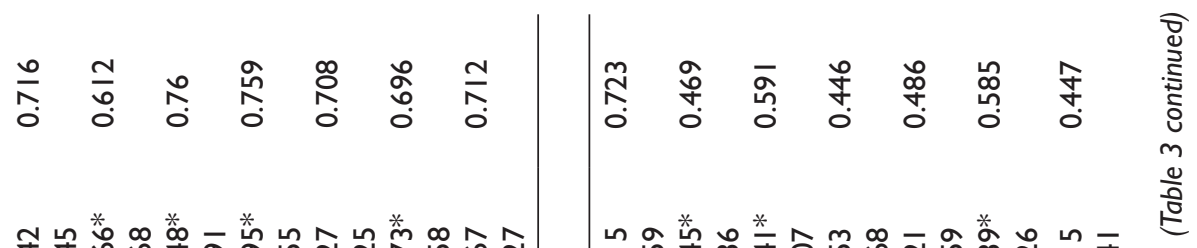

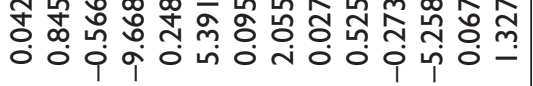

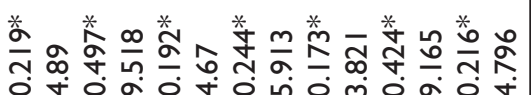

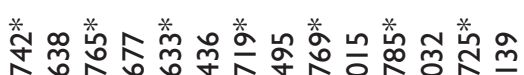

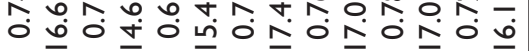

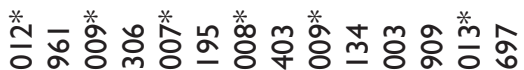

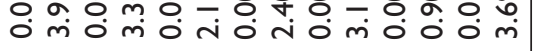

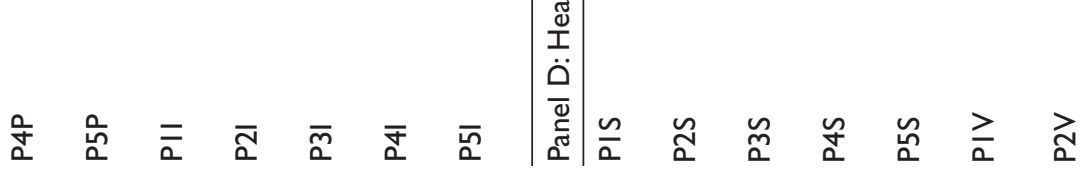

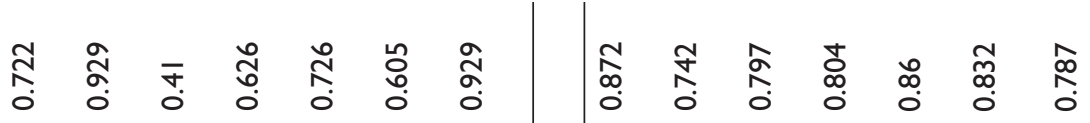

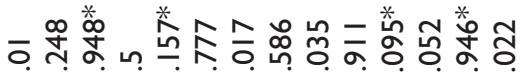

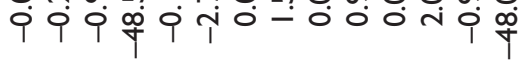

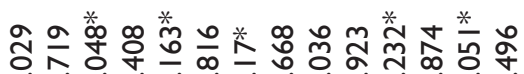

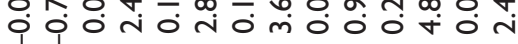

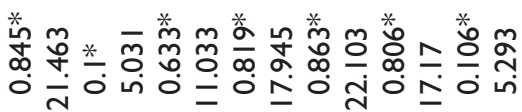

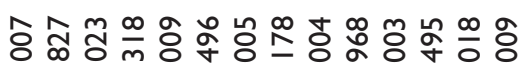

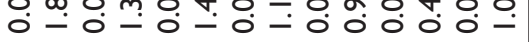

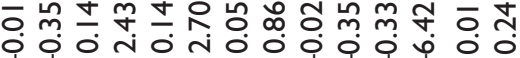

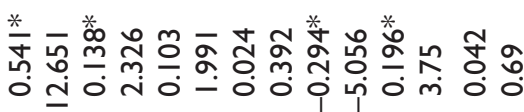

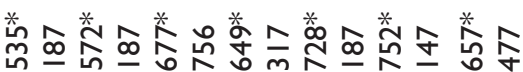

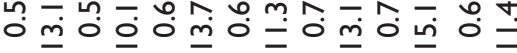

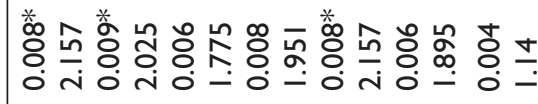

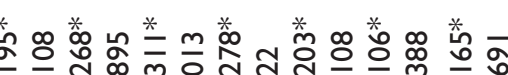

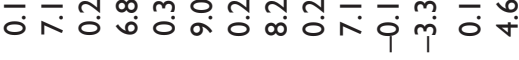

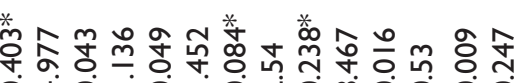

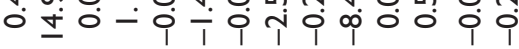

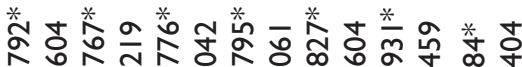

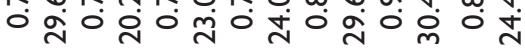

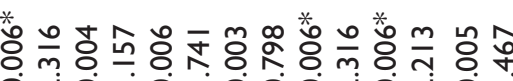
O

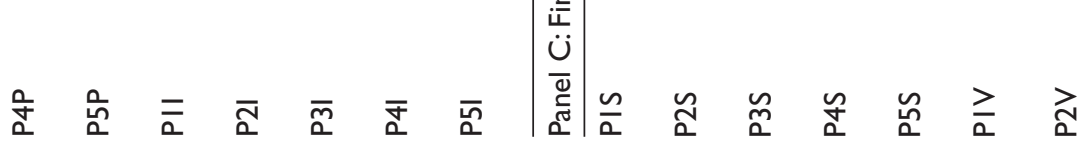




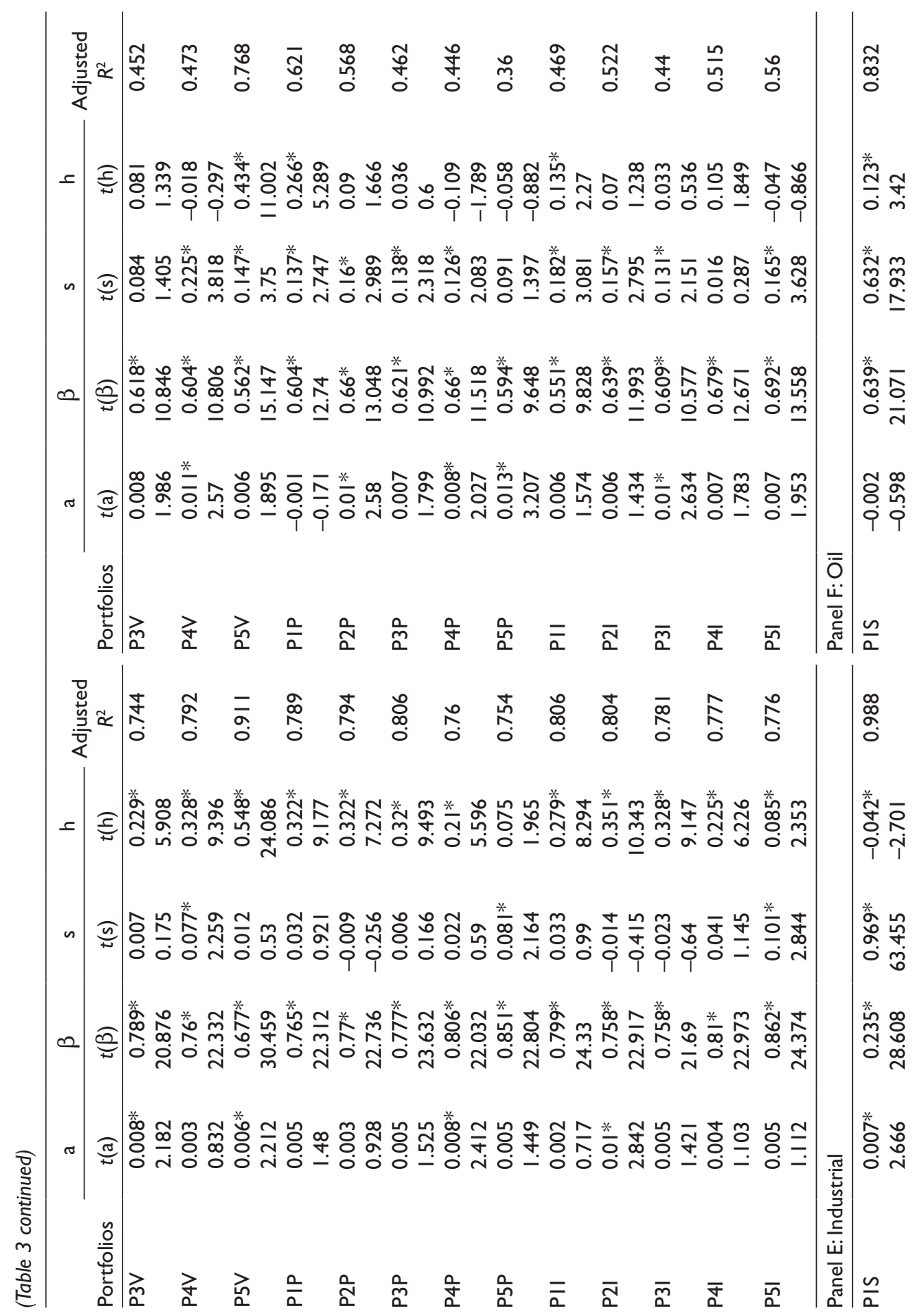




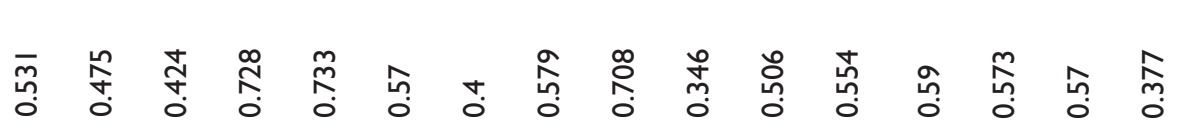

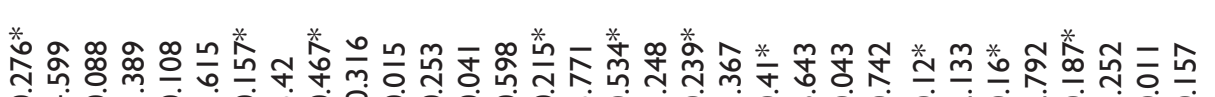

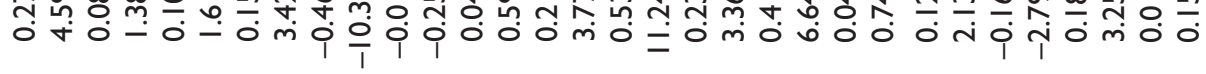

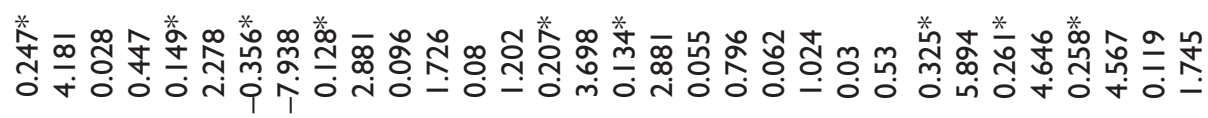

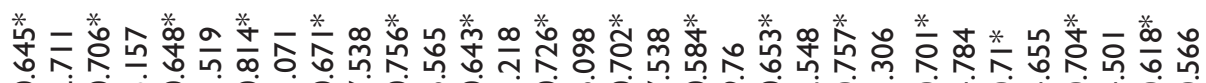

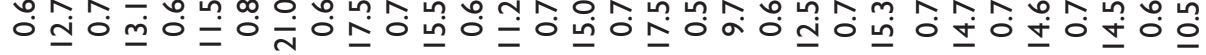

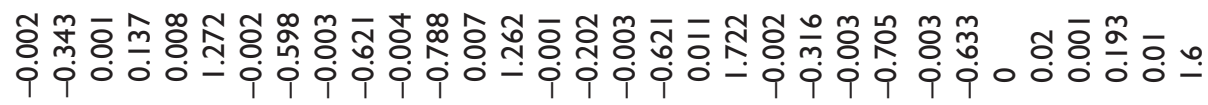

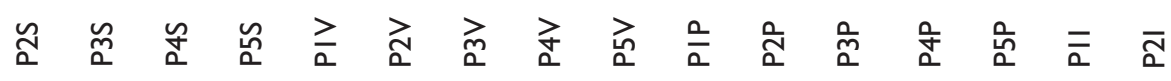

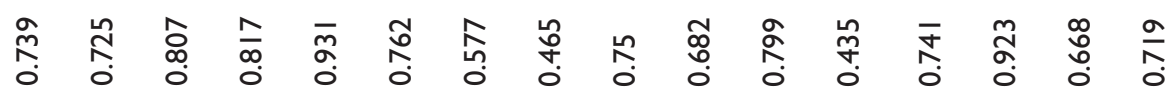

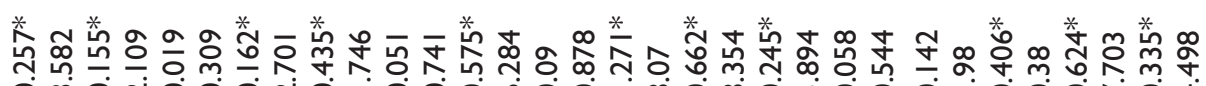

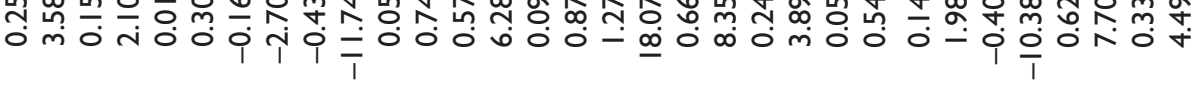

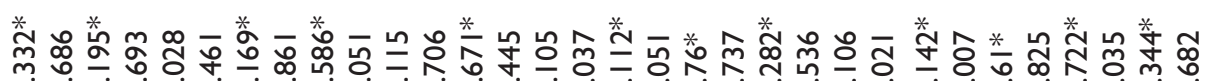

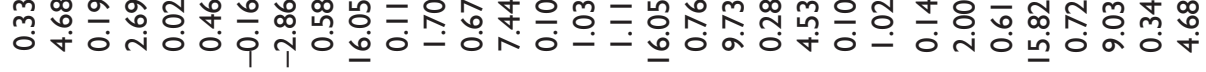

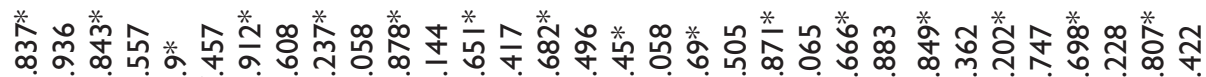

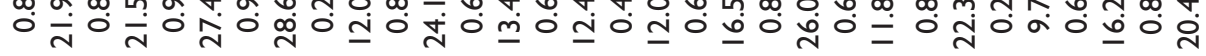

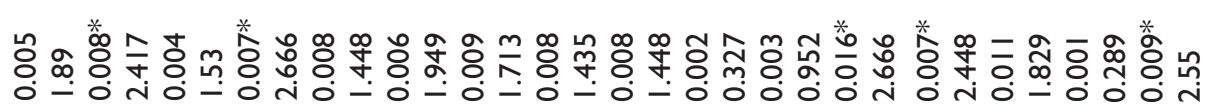

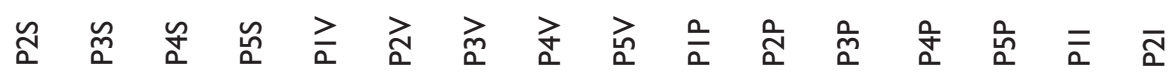




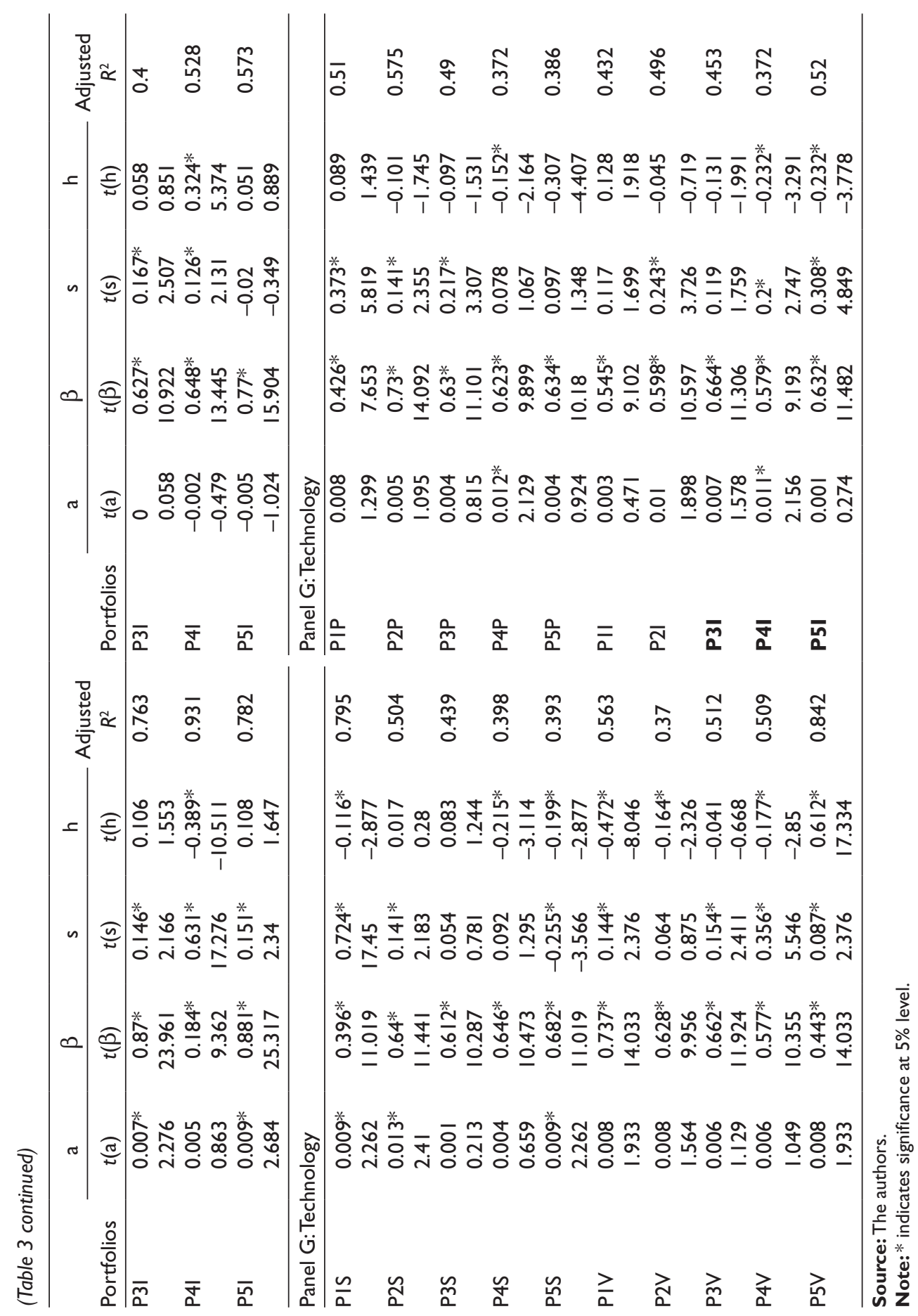


Table 4. Regression Results of the Fama-French Five-Factor Model

\begin{tabular}{|c|c|c|c|c|c|c|c|}
\hline & a & $\beta$ & s & $\mathrm{h}$ & $r$ & c & \\
\hline Portfolios & $t(\mathrm{a})$ & $t(\beta)$ & $t(s)$ & $t(\mathrm{~h})$ & $t(r)$ & $t(c)$ & $R^{2}$ \\
\hline \multicolumn{8}{|c|}{ Panel A: Basic materials } \\
\hline \multirow[t]{2}{*}{ PIS } & 0.004 & $0.760 *$ & $0.686 *$ & -0.004 & 0.043 & 0.024 & 0.809 \\
\hline & 1.196 & 23.037 & 20.196 & -0.015 & 0.151 & 0.199 & \\
\hline \multirow[t]{2}{*}{ P2S } & 0.017 & $0.067 *$ & $0.04 I *$ & $-0.532^{*}$ & $-1.08 *$ & $-1.493^{*}$ & 0.974 \\
\hline & 1.531 & 5.429 & 3.225 & -5.429 & -10.078 & -34.012 & \\
\hline \multirow[t]{2}{*}{ P3S } & $0.012 *$ & $0.719 *$ & $0.13 *$ & $-2.85 I^{*}$ & $-2.439 *$ & $0.504 *$ & 0.558 \\
\hline & 2.049 & 14.338 & 2.516 & -7.113 & -5.563 & 2.807 & \\
\hline \multirow[t]{2}{*}{ P4S } & 0.003 & $0.853^{*}$ & -0.036 & $-0.997^{*}$ & $-0.898^{*}$ & 0.087 & 0.737 \\
\hline & 0.885 & 22.047 & -0.905 & -3.225 & -2.658 & 0.629 & \\
\hline \multirow[t]{2}{*}{ P5S } & 0.004 & $0.795 *$ & $-0.26 I^{*}$ & -0.004 & 0.045 & 0.025 & 0.791 \\
\hline & 1.196 & 23.037 & -7.354 & -0.015 & 0.151 & 0.199 & \\
\hline \multirow[t]{2}{*}{ PIV } & 0.012 & $0.089 *$ & $0.038 *$ & $-1.032 *$ & $-0.829 *$ & $-0.782 *$ & 0.986 \\
\hline & 1.86 & 10.056 & 4.166 & -14.644 & -10.758 & -24.779 & \\
\hline \multirow[t]{2}{*}{ P2V } & 0.006 & $0.872 *$ & 0.005 & 0.399 & 0.462 & 0.160 & 0.759 \\
\hline & 1.537 & 23.58 & 0.141 & 1.349 & 1.428 & 1.208 & \\
\hline \multirow[t]{2}{*}{ P3V } & 0.002 & $0.817^{*}$ & -0.006 & 0.105 & 0.185 & 0.146 & 0.66 \\
\hline & 0.502 & 18.583 & -0.122 & 0.299 & 0.483 & 0.928 & \\
\hline \multirow[t]{2}{*}{ P4V } & 0.006 & $0.828 *$ & $0.288 *$ & -0.246 & -0.491 & -0.167 & 0.639 \\
\hline & 1.048 & 18.295 & 6.167 & -0.681 & $-|.24|$ & $-|.03|$ & \\
\hline \multirow[t]{2}{*}{ P5V } & 0.012 & $0.342 *$ & $0.146 *$ & -0.145 & $-3.194 *$ & $-3.012 *$ & 0.797 \\
\hline & 1.86 & 10.056 & 4.166 & -0.534 & -10.758 & -24.779 & \\
\hline \multirow[t]{2}{*}{ PIP } & $0.015^{*}$ & $0.286^{*}$ & $0.097^{*}$ & $-1.07^{*}$ & $-4.346 *$ & $-3.228^{*}$ & 0.875 \\
\hline & 2.407 & 10.762 & 3.534 & -5.031 & -18.689 & -33.904 & \\
\hline \multirow[t]{2}{*}{ P2P } & -0.002 & $0.828 *$ & $0.36 *$ & 0.136 & 0.447 & $0.44 I^{*}$ & 0.665 \\
\hline & -0.392 & 18.964 & 8.008 & 0.39 & 1.172 & 2.825 & \\
\hline \multirow[t]{2}{*}{ P3P } & 0.009 & $0.682 *$ & $0.130 *$ & $-3.695^{*}$ & $-3.209 *$ & $0.563^{*}$ & 0.583 \\
\hline & 1.777 & 13.993 & 2.599 & -9.491 & -7.538 & 3.227 & \\
\hline \multirow[t]{2}{*}{ P4P } & 0.007 & $0.855^{*}$ & -0.012 & -0.544 & -0.409 & 0.137 & 0.725 \\
\hline & $1.84 \mid$ & 21.626 & -0.303 & -1.72 & -1.184 & 0.966 & \\
\hline \multirow[t]{2}{*}{ P5P } & $0.015^{*}$ & $0.077 *$ & $0.026 *$ & $-0.288^{*}$ & $-0.168 *$ & $-0.869 *$ & 0.991 \\
\hline & 2.407 & 10.762 & 3.534 & -5.031 & -2.679 & -33.904 & \\
\hline \multirow[t]{2}{*}{ PII } & 0.009 & $0.691 *$ & $0.257^{*}$ & $-3.263^{*}$ & $-2.65^{*}$ & $0.516^{*}$ & 0.568 \\
\hline & 1.713 & 13.948 & 5.045 & -8.241 & -6.12 & 2.913 & \\
\hline \multirow[t]{2}{*}{ P2I } & 0.005 & $0.82 *$ & $0.169 *$ & 0.08 & 0.05 & 0.043 & 0.622 \\
\hline & 1.183 & 17.686 & 3.55 & 0.213 & 0.123 & 0.257 & \\
\hline \multirow[t]{2}{*}{ P3I } & 0.004 & $0.862 *$ & 0.028 & 0.337 & 0.596 & $0.302 *$ & 0.731 \\
\hline & 1.093 & 22.071 & 0.706 & 1.08 & 1.746 & 2.156 & \\
\hline \multirow[t]{2}{*}{ P4I } & 0.003 & $0.813^{*}$ & $0.239 *$ & -0.12 & 0.033 & 0.261 & 0.607 \\
\hline & 0.552 & 17.183 & 4.901 & -0.317 & 0.08 & 1.54 & \\
\hline \multirow[t]{2}{*}{ P5I } & 0.009 & $0.084^{*}$ & $0.031 *$ & $-0.399 *$ & $-0.324 *$ & $-0.913 *$ & 0.994 \\
\hline & 1.713 & 13.948 & 5.045 & $-8.24 \mid$ & -6.12 & -42.157 & \\
\hline Panel B: Cc & nsumer gc & ods & & & & & \\
\hline PIS & $0.008^{*}$ & $0.558^{*}$ & $0.668^{*}$ & -0.008 & 0.024 & -0.005 & 0.904 \\
\hline & 3.75 & 20.289 & 25.264 & -0.193 & 0.641 & -0.217 & \\
\hline P2S & $0.008 *$ & $0.587^{*}$ & $0.239 *$ & $0.159 *$ & -0.105 & -0.063 & $0.74 I$ \\
\hline & 2.268 & 12.965 & 5.502 & 2.391 & -1.721 & -1.652 & \\
\hline
\end{tabular}


(Table 4 continued)

\begin{tabular}{|c|c|c|c|c|c|c|c|}
\hline Portfolios & $\frac{\mathrm{a}}{t(\mathrm{a})}$ & $\frac{\beta}{t(\beta)}$ & $\frac{s}{t(s)}$ & $\frac{\mathrm{h}}{t(\mathrm{~h})}$ & $\frac{r}{t(r)}$ & $\frac{c}{t(c)}$ & $\begin{array}{c}\text { Adjusted } \\
R^{2}\end{array}$ \\
\hline \multirow[t]{2}{*}{ P3S } & 0.006 & $0.728^{*}$ & $0.225^{*}$ & -0.115 & $-0.219 *$ & -0.021 & 0.773 \\
\hline & 1.946 & 17.152 & 5.504 & -1.846 & -3.816 & -0.585 & \\
\hline \multirow[t]{2}{*}{ P4S } & $0.008^{*}$ & $0.782^{*}$ & $0.148 *$ & -0.113 & $-0.123 *$ & $-0.15^{*}$ & 0.737 \\
\hline & $2.86 I$ & 17.16 & 3.373 & -1.684 & -2.002 & -3.911 & \\
\hline \multirow[t]{2}{*}{ P5S } & $0.009 *$ & $0.916 *$ & $-0.219 *$ & -0.013 & 0.039 & -0.008 & 0.742 \\
\hline & 3.75 & 20.289 & -5.036 & -0.193 & $0.64 I$ & -0.217 & \\
\hline \multirow[t]{2}{*}{ PIV } & $0.008^{*}$ & $0.864 *$ & $0.447 *$ & $-0.64^{*}$ & 0.044 & -0.056 & 0.702 \\
\hline & 3.107 & 17.79 & 9.577 & -8.991 & 0.678 & -1.38 & \\
\hline \multirow[t]{2}{*}{ P2V } & $0.012 *$ & $0.845^{*}$ & $0.147 *$ & -0.066 & -0.057 & -0.043 & 0.79 \\
\hline & 4.547 & 20.749 & 3.763 & -1.112 & -1.028 & $-1.24 \mid$ & \\
\hline \multirow[t]{2}{*}{ P3V } & $0.008 *$ & $0.696 *$ & $0.187^{*}$ & -0.026 & $-0.168 *$ & -0.053 & 0.727 \\
\hline & 2.345 & 14.996 & 4.181 & -0.386 & -2.683 & -1.358 & \\
\hline \multirow[t]{2}{*}{ P4V } & 0.004 & $0.655^{*}$ & $0.28 I^{*}$ & -0.024 & -0.197 & -0.031 & 0.779 \\
\hline & 1.298 & 15.667 & 6.996 & -0.386 & -3.488 & -0.888 & \\
\hline \multirow[t]{2}{*}{ P5V } & $0.008^{*}$ & $0.516^{*}$ & $0.267^{*}$ & $0.435^{*}$ & 0.027 & -0.034 & 0.895 \\
\hline & 3.107 & 17.79 & 9.577 & 10.244 & 0.678 & -1.38 & \\
\hline \multirow[t]{2}{*}{ PIP } & $0.006 *$ & $0.559 *$ & $0.275^{*}$ & $-0.12^{*}$ & $-0.472 *$ & -0.041 & 0.878 \\
\hline & 2.422 & 17.976 & 9.198 & -2.628 & -11.234 & -1.563 & \\
\hline \multirow[t]{2}{*}{$P 2 P$} & 0.005 & $0.723 *$ & $0.198 *$ & 0.106 & -0.07 I & 0.004 & 0.818 \\
\hline & 1.728 & 19.03 & 5.427 & 1.902 & -1.382 & 0.121 & \\
\hline \multirow[t]{2}{*}{ P3P } & $0.011 *$ & $0.677^{*}$ & $0.181 *$ & $0.15 I^{*}$ & -0.01 & -0.045 & 0.709 \\
\hline & 3.141 & 14.118 & 3.932 & 2.143 & -0.151 & -1.108 & \\
\hline \multirow[t]{2}{*}{ P4P } & $0.012 *$ & $0.697 *$ & $0.23 *$ & -0.016 & -0.121 & $-0.094^{*}$ & 0.728 \\
\hline & 3.961 & 15.009 & 5.159 & -0.235 & -1.939 & -2.42 & \\
\hline \multirow[t]{2}{*}{ P5P } & $0.006 *$ & $0.868^{*}$ & $0.427 *$ & $-0.186 *$ & $0.505^{*}$ & -0.063 & 0.705 \\
\hline & 2.422 & 17.976 & 9.198 & -2.628 & 7.738 & -1.563 & \\
\hline \multirow[t]{2}{*}{ PII } & $0.01 *$ & $0.658^{*}$ & $0.216 *$ & 0.111 & -0.089 & $0.243^{*}$ & 0.816 \\
\hline & 3.612 & 17.249 & 5.887 & 1.987 & -1.729 & 7.582 & \\
\hline \multirow[t]{2}{*}{ P2I } & $0.008 *$ & $0.664 *$ & $0.258 *$ & 0.022 & $-0.148 *$ & $-0.11 *$ & 0.777 \\
\hline & 2.459 & 15.826 & 6.386 & 0.361 & -2.615 & -3.115 & \\
\hline \multirow[t]{2}{*}{ P3I } & $0.009 *$ & $0.7 I^{*}$ & $0.196 *$ & -0.094 & $-0.199 *$ & -0.074 & 0.726 \\
\hline & 3.407 & 15.247 & 4.378 & -1.375 & -3.173 & -1.884 & \\
\hline \multirow[t]{2}{*}{ P4I } & 0.003 & $0.815^{*}$ & $0.4 I^{*}$ & $-0.20 I^{*}$ & 0.11 & 0.024 & 0.698 \\
\hline & 0.726 & 16.682 & 8.737 & -2.815 & 1.662 & 0.584 & \\
\hline \multirow[t]{2}{*}{ P5I } & $0.01 *$ & $0.64 I *$ & $0.21 *$ & 0.108 & -0.087 & $-0.34 I^{*}$ & 0.825 \\
\hline & 3.612 & 17.249 & 5.887 & 1.987 & -1.729 & -10.894 & \\
\hline
\end{tabular}

Panel C: Financials

\begin{tabular}{llccllll}
\hline PIS & $0.006^{*}$ & $0.759^{*}$ & $0.39 *$ & $0.218^{*}$ & -0.023 & $-0.108^{*}$ & 0.879 \\
& 2.226 & 27.185 & 14.733 & 7.391 & -0.702 & -3.407 & \\
P2S & 0.004 & $0.722^{*}$ & 0.027 & $0.292^{*}$ & -0.047 & $-0.143^{*}$ & 0.753 \\
& 1.036 & 18.138 & 0.703 & 6.923 & -1.01 & -3.17 & \\
P3S & 0.005 & $0.76^{*}$ & -0.056 & $0.326^{*}$ & -0.002 & -0.052 & 0.797 \\
& 1.683 & 21.04 & -1.645 & 8.532 & -0.044 & -1.264 & \\
P4S & 0.002 & $0.765^{*}$ & $-0.103^{*}$ & $0.334^{*}$ & 0.054 & $-0.102^{*}$ & 0.819 \\
& 0.72 & 22.407 & -3.173 & 9.254 & 1.36 & -2.654 &
\end{tabular}


(Table 4 continued)

\begin{tabular}{|c|c|c|c|c|c|c|c|}
\hline \multirow[b]{2}{*}{ Portfolios } & a & $\beta$ & $\mathrm{s}$ & $\mathrm{h}$ & $r$ & c & \multirow{2}{*}{$\begin{array}{c}\text { Adjusted } \\
R^{2}\end{array}$} \\
\hline & $t(a)$ & $t(\beta)$ & $t(s)$ & $t(\mathrm{~h})$ & $t(r)$ & $t(c)$ & \\
\hline \multirow[t]{2}{*}{ P5S } & $0.006^{*}$ & $0.792 *$ & $-0.252 *$ & $0.228^{*}$ & -0.024 & $-0.112^{*}$ & 0.868 \\
\hline & 2.226 & 27.185 & -9.132 & 7.391 & -0.702 & -3.407 & \\
\hline \multirow[t]{2}{*}{ PIV } & $0.006^{*}$ & $0.887^{*}$ & 0 & $-0.087^{*}$ & -0.056 & $0.141 *$ & 0.844 \\
\hline & 2.108 & 28.001 & 0.013 & -2.6 & -1.525 & 3.934 & \\
\hline \multirow[t]{2}{*}{$\mathrm{P} 2 \mathrm{~V}$} & 0.004 & $0.79 *$ & -0.038 & $0.256 *$ & $0.084 *$ & $-0.17^{*}$ & 0.829 \\
\hline & 1.448 & 23.82 & -1.219 & 7.292 & 2.179 & -4.526 & \\
\hline \multirow[t]{2}{*}{ P3V } & $0.008^{*}$ & $0.767^{*}$ & -0.006 & $0.266^{*}$ & 0.033 & -0.073 & 0.749 \\
\hline & 2.135 & 19.108 & -0.155 & 6.265 & 0.709 & -1.605 & \\
\hline \multirow[t]{2}{*}{ P4V } & 0.003 & $0.745^{*}$ & $0.074 *$ & $0.319 *$ & -0.052 & -0.047 & 0.792 \\
\hline & 0.774 & 20.383 & 2.15 & 8.245 & -1.23 & -1.125 & \\
\hline \multirow[t]{2}{*}{ P5V } & $0.006 *$ & $0.644^{*}$ & 0 & $0.562^{*}$ & -0.041 & $-0.102 *$ & 0.917 \\
\hline & 2.108 & 28.001 & 0.013 & 23.075 & -1.525 & -3.934 & \\
\hline \multirow[t]{2}{*}{ PIP } & 0.005 & $0.735^{*}$ & 0.045 & $0.193^{*}$ & $-0.343 *$ & $-0.073 *$ & $0.87 \mid$ \\
\hline & 1.7 & 25.161 & 1.637 & 6.237 & -10.067 & -2.212 & \\
\hline \multirow[t]{2}{*}{$P 2 P$} & 0.003 & $0.733^{*}$ & -0.021 & $0.334 *$ & -0.053 & $-0.115^{*}$ & 0.801 \\
\hline & 0.81 & $20.5 I$ & -0.625 & 8.807 & -1.278 & -2.837 & \\
\hline \multirow[t]{2}{*}{ P3P } & 0.005 & $0.746^{*}$ & -0.015 & $0.384 *$ & 0.068 & $-0.109 *$ & 0.824 \\
\hline & 1.488 & 22.214 & -0.459 & $10.82 \mid$ & 1.746 & -2.87 & \\
\hline \multirow[t]{2}{*}{ P4P } & $0.008 *$ & $0.758^{*}$ & -0.006 & $0.292 *$ & 0.072 & $-0.162 *$ & 0.794 \\
\hline & 2.444 & 20.878 & -0.177 & 7.607 & 1.693 & -3.949 & \\
\hline \multirow[t]{2}{*}{ P5P } & 0.005 & $0.832 *$ & 0.051 & $0.218^{*}$ & $0.263^{*}$ & $-0.083 *$ & 0.83 \\
\hline & 1.7 & 25.161 & 1.637 & 6.237 & 6.839 & -2.212 & \\
\hline \multirow[t]{2}{*}{ PII } & 0.003 & $0.837^{*}$ & $0.06 I^{*}$ & $0.178^{*}$ & $-0.136^{*}$ & $0.131 *$ & 0.85 \\
\hline & 0.953 & 26.955 & $2.06 \mathrm{I}$ & 5.414 & -3.753 & 3.728 & \\
\hline \multirow[t]{2}{*}{ P2I } & $0.009 *$ & $0.73^{*}$ & -0.026 & $0.375^{*}$ & -0.009 & $-0.09 *$ & 0.808 \\
\hline & 2.77 I & 20.809 & -0.779 & $10.09 \mid$ & -0.215 & -2.275 & \\
\hline \multirow[t]{2}{*}{ P3I } & 0.005 & $0.743 *$ & -0.041 & $0.408 *$ & $0.137 *$ & -0.061 & 0.804 \\
\hline & 1.457 & 20.963 & -1.208 & 10.864 & 3.317 & $-|.5|$ & \\
\hline \multirow[t]{2}{*}{ P4I } & 0.003 & $0.79 *$ & 0.022 & $0.3^{*}$ & $0.12 *$ & -0.071 & 0.798 \\
\hline & I.I & 21.982 & 0.654 & 7.888 & 2.859 & -1.744 & \\
\hline \multirow[t]{2}{*}{ P5I } & 0.003 & $0.736 *$ & $0.053^{*}$ & $0.157^{*}$ & $-0.12^{*}$ & $-0.399 *$ & 0.884 \\
\hline & 0.953 & 26.955 & 2.061 & 5.414 & -3.753 & $-|2.89|$ & \\
\hline
\end{tabular}

Panel D: Health care

\begin{tabular}{llclllll}
\hline PIS & 0.006 & $0.548^{*}$ & $0.547^{*}$ & 0.011 & 0.069 & 0.007 & 0.723 \\
& 1.746 & 12.907 & 12.738 & 0.232 & 1.5 & 0.182 & \\
P2S & 0.006 & $0.592^{*}$ & $0.149 *$ & $0.209 *$ & $0.145^{*}$ & -0.021 & 0.48 \\
& 1.432 & 10.175 & 2.539 & 3.243 & 2.319 & -0.382 & \\
P3S & 0.007 & $0.692^{*}$ & $0.104^{*}$ & 0.112 & -0.025 & 0.09 & 0.596 \\
& 1.879 & 13.501 & 2.002 & 1.964 & -0.453 & 1.861 & \\
P4S & 0.006 & $0.68 I^{*}$ & 0.034 & 0.071 & 0.089 & 0.081 & 0.449 \\
& 1.605 & 11.38 & 0.554 & 1.074 & 1.372 & 1.427 & \\
P5S & 0.006 & $0.746 *$ & -0.2868 & 0.015 & 0.093 & 0.01 & 0.487 \\
& 1.746 & 12.907 & -4.894 & 0.232 & 1.5 & 0.182 & \\
PIV & 0.005 & $0.772 *$ & $0.206 *$ & $-0.298^{*}$ & 0.106 & 0.011 & 0.588 \\
& 1.403 & 14.914 & 3.925 & -5.194 & 1.9 & 0.226 &
\end{tabular}

(Table 4 continued) 
(Table 4 continued)

\begin{tabular}{|c|c|c|c|c|c|c|c|}
\hline & a & $\beta$ & $s$ & $\mathrm{~h}$ & $r$ & c & Adjusted \\
\hline Portfolios & $t(\mathrm{a})$ & $t(\beta)$ & $t(s)$ & $t(h)$ & $t(r)$ & $t(\mathrm{c})$ & $R^{2}$ \\
\hline \multirow[t]{2}{*}{ P2V } & 0.003 & $0.691^{*}$ & 0.053 & 0.047 & 0.115 & 0.067 & 0.467 \\
\hline & 0.715 & I I.576 & 0.882 & 0.706 & $\mathrm{I} .78$ & 1.187 & \\
\hline \multirow[t]{2}{*}{ P3V } & 0.006 & $0.649 *$ & 0.095 & 0.111 & 0.106 & 0.06 & 0.456 \\
\hline & 1.565 & 10.907 & 1.581 & 1.688 & 1.656 & 1.063 & \\
\hline \multirow[t]{2}{*}{ P4V } & $0.011 *$ & $0.598 *$ & $0.224 *$ & -0.017 & -0.008 & 0.02 & 0.468 \\
\hline & 2.51 & 10.168 & 3.759 & -0.256 & -0.13 & -0.356 & \\
\hline \multirow[t]{2}{*}{ P5V } & 0.005 & $0.577 *$ & $0.154^{*}$ & $0.464 *$ & 0.079 & 0.008 & 0.77 \\
\hline & 1.403 & $14.9 \mid 4$ & 3.925 & 10.819 & 1.9 & 0.226 & \\
\hline \multirow[t]{2}{*}{ PIP } & 0.006 & $0.553 *$ & $0.109 *$ & $0.115^{*}$ & $-0.349 *$ & 0.039 & 0.713 \\
\hline & 1.607 & $12.80 \mid$ & 2.491 & 2.411 & -7.496 & 0.957 & \\
\hline \multirow[t]{2}{*}{ P2P } & $0.009 *$ & $0.68^{*}$ & $0.167 *$ & 0.117 & 0.081 & 0.027 & 0.568 \\
\hline & 2.182 & 12.825 & 3.118 & 1.988 & 1.42 & 0.533 & \\
\hline \multirow[t]{2}{*}{ P3P } & 0.005 & $0.642 *$ & $0.148^{*}$ & 0.083 & 0.119 & 0.007 & 0.467 \\
\hline & 1.313 & 10.906 & 2.489 & $1.27 \mid$ & 1.878 & 0.13 & \\
\hline \multirow[t]{2}{*}{ P4P } & 0.006 & $0.689 *$ & $0.139 *$ & -0.05 & $0.153 *$ & 0.016 & 0.457 \\
\hline & 1.43 & II.596 & 2.317 & -0.761 & 2.385 & 0.289 & \\
\hline \multirow[t]{2}{*}{ P5P } & 0.006 & 0.693* & $0.137 *$ & $0.145^{*}$ & $0.523 *$ & 0.049 & 0.549 \\
\hline & 1.607 & $|2.80|$ & 2.491 & 2.411 & 8.957 & 0.957 & \\
\hline \multirow[t]{2}{*}{ PII } & $0.007 *$ & $0.649 *$ & $0.196 *$ & 0.041 & 0.009 & $0.449 *$ & 0.655 \\
\hline & 2.053 & 13.709 & 4.093 & 0.783 & 0.183 & 10.019 & \\
\hline \multirow[t]{2}{*}{ P2I } & 0.004 & $0.658^{*}$ & $0.168^{*}$ & $0.125^{*}$ & $0.129 *$ & -0.013 & 0.529 \\
\hline & 0.889 & | | .888 & 2.992 & 2.042 & 2.159 & -0.239 & \\
\hline \multirow[t]{2}{*}{ P3I } & $0.009 *$ & $0.62 *$ & $0.138 *$ & 0.074 & 0.091 & -0.02 & $0.44 I$ \\
\hline & 2.224 & 10.289 & 2.259 & I.III & 1.397 & -0.354 & \\
\hline \multirow[t]{2}{*}{ P4I } & 0.005 & $0.726^{*}$ & 0.031 & $0.141 *$ & $0.144 *$ & $0.106 *$ & 0.531 \\
\hline & 1.228 & 13.152 & 0.564 & 2.301 & 2.42 & 2.032 & \\
\hline \multirow[t]{2}{*}{ P5I } & $0.007 *$ & $0.613 *$ & $0.185^{*}$ & 0.039 & 0.009 & $-0.376^{*}$ & 0.693 \\
\hline & 2.053 & 13.709 & 4.093 & 0.783 & 0.183 & -8.898 & \\
\hline
\end{tabular}

Panel E: Industrial

\begin{tabular}{llclllll}
\hline PIS & $0.007^{*}$ & $0.24 I^{*}$ & $0.944^{*}$ & -0.022 & 0.048 & 0.016 & 0.988 \\
& 2.672 & 27.24 & 43.727 & -1.113 & 1.833 & 1.308 & \\
P2S & 0.005 & $0.792^{*}$ & $0.539^{*}$ & 0.158 & $-0.325^{*}$ & $-0.152^{*}$ & 0.748 \\
& 1.486 & 19.553 & 5.462 & 1.72 & -2.729 & -2.731 & \\
P3S & $0.007^{*}$ & $0.809^{*}$ & $0.40 I^{*}$ & 0.147 & -0.22 & $-0.18^{*}$ & 0.737 \\
& 2.186 & 19.538 & 3.982 & 1.568 & -1.808 & -3.169 & \\
P4S & 0.004 & $0.874^{*}$ & 0.153 & -0.036 & -0.19 & -0.094 & 0.809 \\
& 1.434 & 24.792 & 1.787 & -0.446 & -1.838 & -1.936 & \\
P5S & $0.007^{*}$ & $0.936^{*}$ & $-0.266^{*}$ & -0.087 & 0.185 & 0.062 & 0.819 \\
& 2.672 & 27.24 & -3.181 & -1.113 & 1.833 & 1.308 & \\
PIV & 0.004 & $0.293^{*}$ & $0.46 I^{*}$ & $-0.11 I^{*}$ & $0.497^{*}$ & 0.007 & 0.972 \\
& 1.164 & 21.847 & 14.128 & -3.638 & 12.631 & 0.369 & \\
P2V & 0.005 & $0.854^{*}$ & $0.272^{*}$ & 0.058 & -0.151 & $-0.14 I^{*}$ & 0.769 \\
& 1.723 & 22.015 & 2.88 & 0.664 & -1.331 & -2.658 & \\
P3V & $0.014^{*}$ & $0.562^{*}$ & $0.752^{*}$ & -0.12 & $-0.873^{*}$ & $0.15 I^{*}$ & 0.797 \\
& 3.64 & 15.461 & 8.488 & -1.458 & -8.181 & 3.021 & \\
P4V & 0.008 & $0.66^{*}$ & 0.228 & 0.073 & -0.144 & -0.103 & 0.464 \\
& 1.327 & 11.175 & 1.583 & 0.548 & -0.833 & -1.276 &
\end{tabular}

(Table 4 continued) 
(Table 4 continued)

\begin{tabular}{|c|c|c|c|c|c|c|c|}
\hline \multirow[b]{2}{*}{ Portfolios } & $\mathrm{a}$ & $\beta$ & $s$ & $\mathrm{~h}$ & $r$ & c & \multirow{2}{*}{$\begin{array}{c}\text { Adjusted } \\
R^{2}\end{array}$} \\
\hline & $t(a)$ & $t(\beta)$ & $t(\mathrm{~s})$ & $t(\mathrm{~h})$ & $t(r)$ & $t(c)$ & \\
\hline \multirow[t]{2}{*}{$\overline{P 5 V}$} & 0.004 & $0.556 *$ & $0.875^{*}$ & $1.887^{*}$ & $0.943 *$ & 0.013 & 0.901 \\
\hline & 1.164 & 21.847 & 14.128 & 32.723 & $|2.63|$ & 0.369 & \\
\hline \multirow[t]{2}{*}{ PIP } & $0.007^{*}$ & $0.589 *$ & $0.925^{*}$ & -0.055 & $-0.984 *$ & $0.084 *$ & 0.902 \\
\hline & 2.154 & 23.323 & 15.024 & -0.967 & -13.268 & 2.427 & \\
\hline \multirow[t]{2}{*}{$\mathrm{P} 2 \mathrm{P}$} & 0.002 & $0.83 I^{*}$ & $0.522 *$ & $0.234^{*}$ & $-0.258^{*}$ & $-0.2 I^{*}$ & 0.817 \\
\hline & 0.615 & 24.064 & 6.204 & 2.99 & -2.546 & -4.422 & \\
\hline \multirow[t]{2}{*}{ P3P } & $0.015^{*}$ & $0.615^{*}$ & $0.362 *$ & -0.032 & $-0.362 *$ & $-0.198 *$ & 0.447 \\
\hline & 2.539 & 10.255 & 2.475 & -0.234 & -2.057 & -2.403 & \\
\hline \multirow[t]{2}{*}{ P4P } & $0.007^{*}$ & $0.80 I^{*}$ & $0.37^{*}$ & 0.039 & $-0.35 I^{*}$ & $-0.17^{*}$ & 0.753 \\
\hline & 2.342 & 19.959 & 3.789 & 0.425 & -2.978 & -3.086 & \\
\hline \multirow[t]{2}{*}{ P5P } & $0.007^{*}$ & $0.273^{*}$ & $0.429 *$ & -0.026 & $0.618^{*}$ & $0.039 *$ & 0.979 \\
\hline & 2.154 & 23.323 & 15.024 & -0.967 & 17.968 & 2.427 & \\
\hline \multirow[t]{2}{*}{ PII } & $0.007 *$ & $0.652 *$ & $0.582 *$ & -0.005 & $-0.573 *$ & $0.325 *$ & 0.908 \\
\hline & 2.628 & 26.618 & 9.755 & -0.085 & -7.973 & 9.681 & \\
\hline \multirow[t]{2}{*}{ P2I } & $0.008^{*}$ & $0.746 *$ & $0.647^{*}$ & $0.227^{*}$ & $-0.433^{*}$ & $-0.235^{*}$ & 0.742 \\
\hline & 2.402 & 18.204 & 6.483 & 2.439 & -3.601 & -4.17 & \\
\hline \multirow[t]{2}{*}{ P3I } & $0.006 *$ & $0.837^{*}$ & $0.338^{*}$ & 0.08 & -0.225 & $-0.162 *$ & 0.772 \\
\hline & 2.07 & 21.706 & 3.598 & 0.921 & -1.99 & -3.057 & \\
\hline \multirow[t]{2}{*}{ P4I } & 0.001 & $0.248^{*}$ & $0.47^{*}$ & -0.042 & 0.559* & 0.031 & 0.978 \\
\hline & 0.306 & 20.607 & 16.035 & -1.525 & $|5.84|$ & 1.879 & \\
\hline \multirow[t]{2}{*}{ P5I } & $0.007^{*}$ & $0.78 I^{*}$ & $0.697^{*}$ & -0.006 & $-0.686^{*}$ & $-0.447^{*}$ & 0.868 \\
\hline & 2.628 & 26.618 & 9.755 & -0.085 & -7.973 & -11.114 & \\
\hline \multicolumn{8}{|c|}{ Panel F: Oil } \\
\hline \multirow[t]{2}{*}{ PIS } & -0.002 & $0.637^{*}$ & $0.623 *$ & $0.132 *$ & 0.028 & 0.014 & 0.831 \\
\hline & -0.52 & 20.914 & 16.87 & 3.374 & 0.853 & 0.409 & \\
\hline \multirow[t]{2}{*}{$\mathrm{P} 2 \mathrm{~S}$} & -0.003 & $0.635^{*}$ & $0.185^{*}$ & $0.262 *$ & 0.037 & $0.179 *$ & 0.557 \\
\hline & -0.479 & $12.85 \mid$ & 3.086 & 4.145 & 0.698 & 3.291 & \\
\hline \multirow[t]{2}{*}{ P3S } & 0.002 & $0.688^{*}$ & -0.061 & $0.166 *$ & $0.252^{*}$ & $0.139 *$ & 0.556 \\
\hline & 0.524 & 13.914 & -1.023 & 2.624 & 4.774 & 2.555 & \\
\hline \multirow[t]{2}{*}{ P4S } & 0.004 & $0.65 I^{*}$ & $0.141 *$ & 0.001 & $-0.207^{*}$ & $0.15 I^{*}$ & 0.463 \\
\hline & $0.74 I$ & 11.972 & 2.135 & 0.014 & -3.572 & 2.53 & \\
\hline \multirow[t]{2}{*}{ P5S } & -0.002 & $0.81 \mathrm{I}^{*}$ & $-0.368^{*}$ & $0.168 *$ & 0.035 & 0.017 & 0.727 \\
\hline & -0.52 & 20.914 & -7.832 & 3.374 & 0.853 & 0.409 & \\
\hline \multirow[t]{2}{*}{ PIV } & -0.003 & $0.667^{*}$ & $0 . I^{*}$ & $-0.484^{*}$ & -0.004 & $0.092 *$ & 0.745 \\
\hline & -0.77 & 17.538 & 2.18 & -9.926 & -0.087 & 2.203 & \\
\hline \multirow[t]{2}{*}{$\mathrm{P} 2 \mathrm{~V}$} & -0.002 & $0.75 I^{*}$ & 0.086 & 0.055 & $0.152 *$ & -0.054 & 0.585 \\
\hline & -0.392 & 15.719 & 1.488 & 0.891 & 2.978 & -1.038 & \\
\hline P3V & 0.006 & $0.64 I^{*}$ & 0.056 & -0.008 & -0.074 & 0.124 & 0.408 \\
\hline & 0.996 & 11.235 & 0.805 & -0.115 & -1.206 & 1.972 & \\
\hline P4V & -0.002 & $0.719 *$ & $0.159 *$ & $0.183^{*}$ & -0.014 & $0.163 *$ & 0.596 \\
\hline & -0.436 & 15.247 & 2.781 & 3.029 & -0.277 & 3.15 & \\
\hline P5V & -0.003 & $0.698 *$ & $0.105^{*}$ & $0.517^{*}$ & -0.004 & $0.096 *$ & 0.712 \\
\hline & -0.77 & 17.538 & 2.18 & 10.129 & -0.087 & 2.203 & \\
\hline PIP & 0.002 & $0.612 *$ & $0.146^{*}$ & -0.055 & $-0.691 *$ & $0.121 *$ & 0.749 \\
\hline & 0.6 & 16.465 & 3.233 & -1.149 & -17.387 & 2.95 & \\
\hline P2P & -0.001 & $0.646 *$ & 0.025 & $0.433 *$ & 0.086 & 0.068 & 0.514 \\
\hline & -0.216 & 12.48 & 0.402 & 6.524 & 1.548 & 1.197 & \\
\hline
\end{tabular}


(Table 4 continued)

\begin{tabular}{lccccccc}
\hline & $\mathrm{a}$ & $\beta$ & $\mathrm{s}$ & $\mathrm{h}$ & $\mathrm{r}$ & $\mathrm{c}$ & \multirow{2}{*}{ Adjusted } \\
\cline { 2 - 8 } Portfolios & $t(\mathrm{a})$ & $t(\beta)$ & $t(\mathrm{~s})$ & $t(\mathrm{~h})$ & $t(\mathrm{r})$ & $t(\mathrm{c})$ & $R^{2}$ \\
\hline P3P & -0.002 & $0.742^{*}$ & -0.044 & 0.098 & $0.189^{*}$ & $0.13^{*}$ & 0.606 \\
& -0.475 & 15.918 & -0.787 & 1.635 & 3.797 & 2.545 & \\
P4P & -0.001 & $0.69 I^{*}$ & $0.288^{*}$ & $0.202^{*}$ & $0.205^{*}$ & -0.004 & 0.623 \\
& -0.172 & 15.178 & 5.224 & 3.463 & 4.222 & -0.089 & \\
P5P & 0.002 & $0.689^{*}$ & $0.164^{*}$ & -0.062 & $0.303^{*}$ & $0.136^{*}$ & 0.682 \\
& 0.6 & 16.465 & 3.233 & -1.149 & 6.776 & 2.95 & \\
PII & -0.001 & $0.677^{*}$ & $0.087^{*}$ & $0.143^{*}$ & $0.09 *$ & $0.50 I^{*}$ & 0.804 \\
& -0.309 & 20.596 & 2.189 & 3.383 & 2.557 & 13.864 & \\
P2I & 0.005 & $0.627^{*}$ & $0.135^{*}$ & $-0.148^{*}$ & $-0.339^{*}$ & $0.15 I^{*}$ & 0.473 \\
& 0.895 & 11.644 & 2.06 & -2.143 & -5.889 & 2.558 & \\
P3I & 0.001 & $0.616^{*}$ & 0.111 & 0.074 & 0.093 & $0.128^{*}$ & 0.42 \\
& 0.101 & 10.903 & 1.617 & 1.026 & 1.54 & 2.055 & \\
P4I & -0.002 & $0.681^{*}$ & 0.107 & $0.335^{*}$ & 0.042 & 0.036 & 0.526 \\
& -0.426 & 13.321 & 1.732 & 5.117 & 0.774 & 0.636 & \\
P51 & -0.001 & $0.785^{*}$ & $0.101^{*}$ & $0.165^{*}$ & $0.104^{*}$ & $-0.455^{*}$ & 0.736 \\
& -0.309 & 20.596 & 2.189 & 3.383 & 2.557 & -10.868 & \\
\hline
\end{tabular}

Panel G:Technology

\begin{tabular}{|c|c|c|c|c|c|c|c|}
\hline \multirow[t]{2}{*}{ PIS } & $0.009 *$ & $0.399 *$ & $0.703 *$ & $-0.163^{*}$ & -0.082 & 0.045 & 0.798 \\
\hline & 2.163 & 11.164 & 15.763 & -3.598 & -1.899 & 1.296 & \\
\hline \multirow[t]{2}{*}{ P2S } & $0.013^{*}$ & $0.64^{*}$ & 0.082 & -0.034 & $-0.152 *$ & -0.009 & 0.513 \\
\hline & 2.319 & |l.52| & I.185 & -0.479 & $-2.28 \mathrm{I}$ & -0.167 & \\
\hline \multirow[t]{2}{*}{ P3S } & 0.001 & $0.616 *$ & 0.053 & 0.046 & -0.035 & 0.059 & 0.437 \\
\hline & 0.173 & 10.308 & 0.706 & 0.611 & -0.482 & 1.028 & \\
\hline \multirow[t]{2}{*}{ P4S } & 0.003 & $0.652 *$ & 0.059 & $-0.305^{*}$ & -0.142 & 0.097 & $0.4 \mathrm{II}$ \\
\hline & 0.545 & 10.662 & 0.768 & -3.934 & -1.929 & 1.647 & \\
\hline \multirow[t]{2}{*}{ P5S } & $0.009 *$ & $0.687^{*}$ & $-0.292 *$ & $-0.28 I^{*}$ & -0.14 & 0.077 & 0.402 \\
\hline & 2.163 & 11.164 & -3.805 & -3.598 & -1.899 & 1.296 & \\
\hline \multirow[t]{2}{*}{ PIV } & 0.007 & $0.737^{*}$ & $0.136 *$ & $-0.484^{*}$ & -0.025 & 0.007 & 0.559 \\
\hline & 1.899 & |3.95| & 2.063 & -7.216 & -0.391 & 0.128 & \\
\hline \multirow[t]{2}{*}{ P2V } & 0.008 & $0.632 *$ & 0.036 & $-0.224^{*}$ & -0.104 & 0.055 & $0.37 \mathrm{I}$ \\
\hline & 1.483 & 10.007 & 0.455 & -2.793 & -1.369 & 0.898 & \\
\hline \multirow[t]{2}{*}{ P3V } & 0.005 & $0.66 I *$ & 0.093 & -0.083 & $-0.147^{*}$ & -0.03 & 0.521 \\
\hline & 1.037 & 11.992 & I.357 & -1.182 & -2.227 & -0.555 & \\
\hline \multirow[t]{2}{*}{ P4V } & 0.006 & $0.579 *$ & $0.36 I^{*}$ & $-0.197 *$ & -0.009 & 0.041 & 0.505 \\
\hline & 1.025 & $|0.34|$ & 5.173 & -2.776 & -0.133 & 0.757 & \\
\hline \multirow[t]{2}{*}{ P5V } & 0.007 & $0.444 *$ & $0.082^{*}$ & $0.65^{*}$ & -0.015 & 0.004 & 0.84 \\
\hline & 1.899 & |3.95| & 2.063 & 15 & -0.391 & 0.128 & \\
\hline \multirow[t]{2}{*}{ PIP } & 0.005 & $0.43 I^{*}$ & $0.148 *$ & $-0.166 *$ & $-0.636^{*}$ & 0.065 & 0.743 \\
\hline & 1.124 & 10.685 & 2.947 & -3.25 & -13.132 & 1.681 & \\
\hline \multirow[t]{2}{*}{$P 2 P$} & 0.005 & $0.726^{*}$ & 0.086 & -0.105 & -0.103 & -0.082 & 0.584 \\
\hline & 1.049 & 14.135 & 1.336 & -1.613 & -1.676 & -1.656 & \\
\hline \multirow[t]{2}{*}{ P3P } & 0.004 & $0.636^{*}$ & $0.208^{*}$ & $-0.166 *$ & -0.078 & 0.101 & 0.497 \\
\hline & 0.733 & II.26| & 2.948 & -2.32 & -1.15 & 1.858 & \\
\hline \multirow[t]{2}{*}{ P4P } & $0.011 *$ & $0.623 *$ & 0.028 & $-0.188^{*}$ & -0.122 & -0.019 & 0.375 \\
\hline & 2.056 & 9.893 & 0.357 & -2.359 & -1.61 & -0.317 & \\
\hline
\end{tabular}


(Table 4 continued)

\begin{tabular}{lccccccc}
\hline & $\mathrm{a}$ & $\beta$ & $\mathrm{s}$ & $\mathrm{h}$ & $\mathrm{r}$ & $\mathrm{c}$ & Adjusted \\
\cline { 2 - 8 } Portfolios & $t(\mathrm{a})$ & $t(\beta)$ & $t(\mathrm{~s})$ & $t(\mathrm{~h})$ & $t(\mathrm{r})$ & $t(\mathrm{c})$ & $R^{2}$ \\
\hline P5P & 0.005 & $0.639^{*}$ & $0.22^{*}$ & $-0.247^{*}$ & $0.276^{*}$ & 0.097 & 0.436 \\
& 1.124 & 10.685 & 2.947 & -3.25 & 3.842 & 1.681 & \\
PII & 0.002 & $0.575^{*}$ & $0.193^{*}$ & -0.113 & -0.079 & $0.527^{*}$ & 0.679 \\
& 0.362 & 12.749 & 3.436 & -1.982 & -1.467 & 12.108 & \\
P2I & 0.01 & $0.601^{*}$ & $0.215^{*}$ & -0.103 & -0.101 & 0.052 & 0.498 \\
& 1.812 & 10.662 & 3.061 & -1.433 & -1.487 & 0.948 & \\
P3I & 0.007 & $0.667^{*}$ & 0.124 & $-0.156^{*}$ & -0.014 & 0.051 & 0.45 \\
& 1.547 & 11.301 & 1.686 & -2.087 & -0.199 & 0.887 & \\
P4I & $0.01^{*}$ & $0.581^{*}$ & 0.107 & $-0.337^{*}$ & $-0.26 I^{*}$ & 0.028 & 0.405 \\
& 2.033 & 9.468 & 1.403 & -4.326 & -3.539 & 0.465 & \\
P5I & 0.002 & $0.613^{*}$ & $0.206 *$ & -0.121 & -0.085 & $-0.35 I^{*}$ & 0.635 \\
& 0.362 & 12.749 & 3.436 & -1.982 & -1.467 & -7.568 & \\
\hline
\end{tabular}

Source: The authors.

Note: * indicates significance at $5 \%$ level.

\section{Conclusion}

In this article, we tried to test the empirical applicability of the Fam-French fivefactor model amongst various sectors of India with an objective to find out that whether the five-factor model can explain the industry's expected return or not. The results of sectoral-specific analysis for India shows that after controlling for risk factors, the profitability and value effect comes out to be non-existent in the "Basic Material" industry. The regression results of other industries exhibited moderate to strong size, value, profitability, and investment effect. The findings further stipulated that the five-factor model works well in the "Basic Material" and "Oil" industries. However, for the "consumer" industry, the five-factor model combining with market, size, value, profitability, and some other risk factors might work well. The result further demonstrated the better explanatory power of the five-factor model in explaining the portfolio excess return for the "Industrial" sector. However, there is still a possibility of other risk factors which can better explain the expected return in the "Industrial" sector. The result further showed that the one-factor model or model combining with market, value, and investment factors holds valid for the "Financials" sector in the Indian stock market. Results also highlighted the low explanatory power of the three-factor model in explaining the expected return in the "Health Care" industry while a better performance of a three-factor model is found in the "Technology" sector. As far as practical applications are concerned, the study will help the portfolio managers in evaluating the sectoral-specific performance of the portfolios and determining the cost of equity of various sectors of India. The study will also aid the investors in their investment decision-making by helping them to identify the average stock return in different sectors. The application of the asset pricing model will further assist the policymakers in making efforts for greater financial integration and long-term economic cooperation. The study will help the researchers to identify the additional 
risk factor supported by theoretical evidence which can improve the explanatory power of a model. The future study can try to evaluate the sectoral-wise applicability of the asset pricing model in other emerging nations of the world.

\section{Declaration of Conflicting Interests}

The authors declare that there is no conflict of interest.

\section{Funding}

The authors received no financial support for the research, authorship, and/or publication of this article.

\section{References}

Aldaarmi, A., Abbod, M., \& Salameh, H. (2015). Implement Fama and French and capital asset pricing models in Saudi Arabia stock market. The Journal of Applied Business Research, 31(3), 953-968.

Bartholdy, J., \& Peare, P. (2005). Estimation of expected return: CAPM vs Fama and French. International Review of Financial Analysis, 14(2), 407-427.

Bhattacharya, M., Bhattacharya, S. N., \& Jha, S. K. (2021). Does time-varying illiquidity matter for the Indian stock market? Evidence from high-frequency data. Australian Journal of Management. https://doi.org/10.1177/03128962211010243

Bhattacharya, S. N., Bhattacharya, M., \& Jha, S. K. (2020). Liquidity and asset pricing: Evidence from Indian stock market. Indian Journal of Finance and Banking, 4(1), 109-116.

Brighi, P., Addona, S. D., \& Bina, A. C. F. D. (2010). Too small or to low? New evidence on the 4-factor model. In Modern bank behavior (pp. 176-199). Palgrave Macmillan.

Chan, L. K., Hamao, Y., \& Lakonishok, J. (1991). Fundamentals and stock returns in Japan. The Journal of Finance, 49(5), 1739-1764.

Chen, L., Li, S., \& Wang, J. (2011). Liquidity, skewness and stock returns: Evidence from Chinese stock market. Asia Pacific Financial Market, 18(4), 405-427.

Chiah, M., Chai, D., \& Zhong, A. (2015). A better model? An empirical investigation of the Fama-French five-factor model in Australia. International Review of Finance, 16(4), 595-638.

Davis, J. L., Fama, E. F., \& French, K. R. (2000). Characteristics, covariances, and average returns: 1929 to 1997. The Journal of Finance, 55(1), 389-406.

Elliot, B., Docherty, P., Easton, S., \& Lee, D. (2016). Profitability and investment-based factor pricing models. Accounting and Finance, 58, 397-421.

Fama, E. F., \& French, K. R. (1992). The cross-section of expected stock returns. The Journal of Finance, 47(2), 427-465.

Fama, E. F., \& French, K. R. (1993). Common risk factors in the returns on stocks and bonds. Journal of Financial Economics, 33(1), 3-56.

Fama, E. F., \& French, K. R. (2004). The capital asset pricing model: Theory and evidence. American Economic Association, 18(3), 25-46.

Fama, E. F., \& French, K. R. (2015). A five-factor asset pricing model. Jounal of Finance, $116(1), 1-22$. 
Gaunt, C. (2004). Size and book to market effects and the Fama French three factor asset pricing model: Evidence from the Australian stock market. Accounting \& Finance, 44(1), 27-44.

Huynh, T. (2017). Explaining anomalies in Australia with a five factor asset pricing model. International Review of Finance, 18(1), 123-135.

Jain, M., \& Singla, R. (In press). Role of leverage and liquidity risk in asset pricing: Evidence from Indian stock market. Vilakshan: XIMB Journal of Management.

Khudoykulov, K. (2020). Asset-pricing models: A case of Indian capital market. Cogent Economics \& Finance, 8(1), 1-15.

Linter, J. (1965). The valuation of risk assets and the selection of risky investments in stock portfolios and capital budgets. The Review of Economics and Statistics, 47(1), 13-37.

Merton, R. C. (1973). An intertemporal capital asset pricing model. Econometrica, 41(5), $867-887$.

Mossin, J. (1966). Equilibrium in a capital asset market. Economterica, 34(4), 768-783.

Nartea, G. V., Ward, B. D., \& Djajadikerta, H. G. (2009). Size, BM, and momentum effects and the robustness of the Fama-French three-factor model evidence from New Zealand. International Journal of Managerial Finance, 5(2), 179-200.

Ross, S. A. (1976). The arbitrage theory of capital asset pricing. Journal of Economic Theory, 13(3), 341-360.

Sharpe, W. F. (1964). Capital asset prices: A theory of market equilibrium under conditions of risk. The Journal of Finance, 19(3), 425-442.

Taneja, Y. P. (2010). Revisiting Fama French three-factor model in Indian Stock Market. The Journal of Business Perspective, 14(4), 267-274.

Treynor, J. L. (1961). Market, value, time and risk. https://papers.ssrn.com/sol3/papers. cfm?abstract id $=2600356$

Walid, E. M. (2009). New evidence on risk factors, characteristics and the cross-sectional variation of Japanese stock returns. Asia Pacific Financial Market, 16(1), 33-50. 


\title{
Exploring the Influence of Emotional Intelligence on the Academic Performance of MBA Students
}

IIMS Journal of Management Science I3(I) II2-128, 2022

(C) The Author(s) 2022 DOI: $10.1177 / 0976030 \times 211052193$ ims.spectrumjps.com

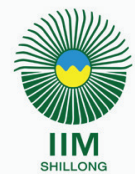

\section{Abhishek Venkteshwar' and Uma Warrier'}

\begin{abstract}
Emotional intelligence (El) has seen a rapid growth in the past decade and affects every aspect of human life.Academic performance is a key indicator of a students' progress in higher education.This study is rooted in Bar-On et al.'s (2006) model of El. The research aims to study the relationship between $\mathrm{El}$ and academic performance of MBA students. Review of Literature has been done from 2010 to 2020, which spans across a decade.A total of 25 research articles were reviewed to identify the research gap.A conceptual model was framed and a research objective was identified. Hypotheses were formulated, in line with the objective of this study. This empirical study is based on a sample drawn from 960 MBA students across Karnataka using stratified sampling. Warrier's El Scale $(a=0.887)$ has been adapted, developed, and utilized for gathering the El responses from the participants. Pearson's correlation analysis reports that there is a direct relationship between academic performance and $\mathrm{El}(r=0.520)$. The study implicates that El has a significant influence on academic performance. The findings are relevant to students, teachers, professors, educators, consultants, and parents who need to understand the role of El in academics. It is recommended that the Ministry of Human Resource Development (MHRD) introduce El as a subject for high school students, to enhance their academic performance as well as the quality of life. El is effective and imperative for success in any job. Students deal with the emotions of faculty, non-teaching staff, peers, and family, therefore they need emotional management skills, to handle situations, that make for a healthier, productive, and rewarding life.
\end{abstract}

' Jain (Deemed-to-be University), Bangalore, Karnataka, India

\section{Corresponding Author:}

Abhishek Venkteshwar, Jain (Deemed-to-be University), Bangalore, Karnataka 560069, India.

E-mail: abhishekv@cms.ac.in 


\section{Keywords}

Emotional intelligence, academic performance, MBA, students, education

JEL Classification: I2I, J24

\section{Introduction}

Emotional intelligence (EI) has become the lifeline of organizations and institutions over the past few years. EI is becoming a subject of extensive research by research scholars, scientists, academicians as well as management professionals (Asghar et al., 2020). EI empowers an individual to deal with situations by using both reasoning and emotional abilities (Venkteshwar \& Warrier, 2018). Intelligence accounts for only $20 \%$ of an individual's success and the remaining $80 \%$ are contributed by EI (Boyatzis et al., 2000). When an individual has low EI, the performance is comparatively inferior to those who have higher EI (Asghar et al., 2020). The lifestyle and living conditions of the youth have induced stress in multiple forms. They need to have high EI to overcome those challenges. Students often have to interact with other students, faculty members, recruiters, and others in the society who have completely diverse backgrounds and EI plays a key role in helping them adapt to such diversity (Goleman, 1995).

\section{Introduction to Higher Education}

Higher education is the art of choosing, commercializing, and utilizing information for the advancement of society (Oyerinde et al., 2008). Through higher education, information of different horizons is presented to students in the form of subjects and modules that leads to their personal and professional growth. Higher education is normally, the formal education given to a student in educational institutions. The students must complete secondary education with a passing score to have the option to get into higher educational institutions (Adeoye et al., 2020). Higher education includes undergraduate and postgraduate education. Higher education consists of a structured syllabus that is planned for giving the student a global viewpoint. This normally attempts to give the student a holistic view and free's $\mathrm{him} /$ her from the assumptions or other ethnocentric thoughts. Higher education empowers a student to make him/her a globalized citizen.

India has a highly structured and integrated higher education system, that offers courses in various fields such as sciences, arts and humanities, and commerce and management, along with social sciences, which was established by the parliament in the form of central, state, deemed, and private universities.

\section{Emotional Intelligence}

The term Emotional Intelligence was coined by Mayer and Salovey and then commercialized by Goleman in 1996 through his book (Goleman, 1995). EI is 
being aware of emotions and to learn to manage emotions under pressure. For both personal and professional success, EI is the key element. EI is a measure to understand emotions of self and others. The appropriate use of EI may predict up to $80 \%$ of life successes including the sense of contentment (Goleman, 1995).

1. Daniel Goleman's definition: "Emotional intelligence refers to the capacity for recognizing our own feelings and those of others, for motivating ourselves, and for managing emotions well in ourselves and our relationships" (Boyatzis et al., 2000).

2. Mayer and Salovey's Definition: "Emotional intelligence is the ability to perceive emotions, to access and generate emotions so as to assist thought, to understand emotions and emotional knowledge, and to reflectively regulate emotions so as to promote emotional and intellectual growth" (Mayer \& Salovey, 2007).

3. Mayer and Salovey (2007) states that "Emotional intelligence (EI) refers to the processes involved in the recognition, use, understanding and management of one's own and other emotional states to solve emotionladen problems and to regulate behavior" (Mayer \& Salovey, 2007).

\section{Theoretical Framework}

According to Bar-On et al. (2006), "EI is the ability of an individual to understand oneself as well as other people." It has been viewed as a process which aims at performance and achievement. This is viewed as procedure-oriented as opposed to result-oriented (Bar-On, 2004). Bar-On stated that EI can be enhanced with the help of training and therapy (Bar-On, 2004).

Warrier et al. (2021) reiterates, the Bar-On Model shown in Figure 1.

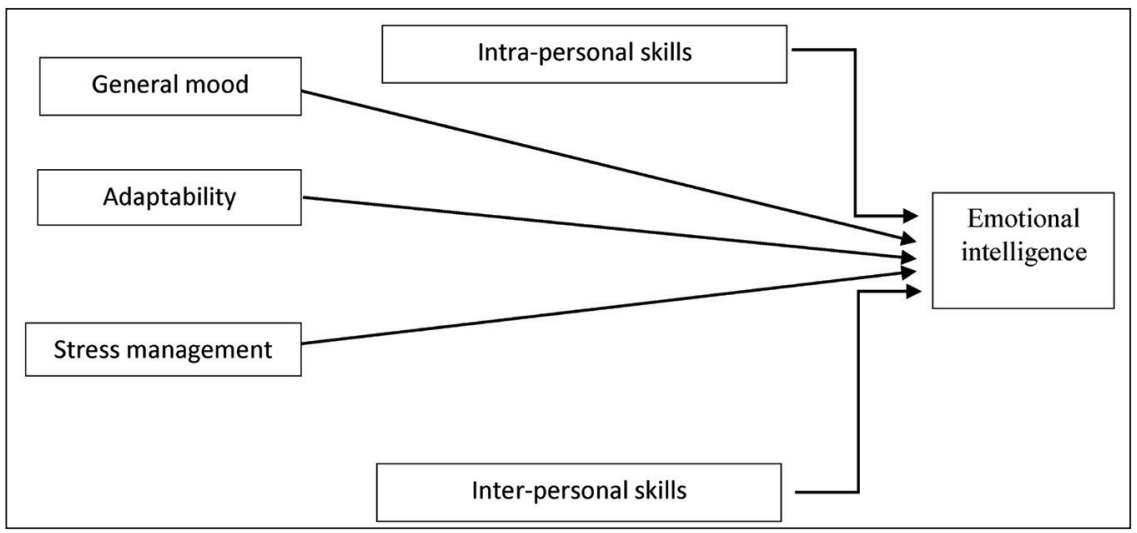

Figure I. Five-dimensional Model of El

Source: Bar-On et al. (2006). 


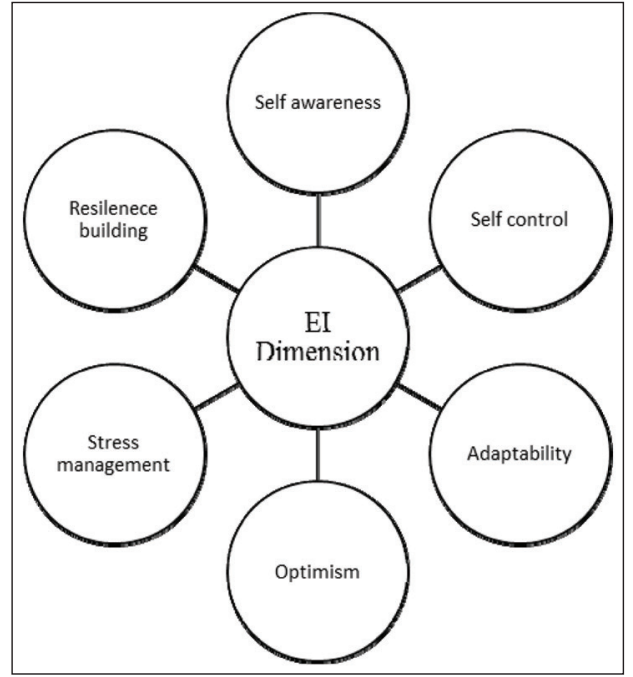

Figure 2. El Dimensions

Source: Warrier et al. (202I).

Warrier et al. (2021) studied EI through thematic analysis with the help 21 psychologists. EI dimensions such as self-awareness, self-control, adaptability, and general mood shown in Figure 2 have become key components of mental health profiling (Warrier et al., 2021).

\section{Need for the Study}

A growing number of educators recognize that students who receive an exclusive academic education may be ill-equipped for future challenges. Educational institutions are increasingly concerned about violence in classroom, challenging behaviors, discipline problems, disrespectful conduct, and bullying (Festus \& Ekpete, 2012). In India, there is a paucity of systematic data on levels of social and emotional problems and their impact on academic performance in educational institutions (MacCann et al., 2020). Research on social and emotional problems and academic performance did not converge (Gupta \& Huang, 2014). Therefore, the present study investigates the effect of EI on the academic performance of MBA students.

\section{Review of Literature}

\section{Studies on Emotional Intelligence and Academic Performance}

MacCann et al. (2020) conducted a meta-analysis that examined the extent to which EI and academic performance are related. The overall effect of $\rho=.20$ using robust variance estimation ( $N=42,529, k=1,246$ from 158 citations). 
The association is significantly stronger for ability EI $(\rho=.24, k=50)$ compared with self-rated $(\rho=.12, k=33)$ or mixed EI $(\rho=.19, k=90)$. This meta-analysis shows that EI has a small to moderate association with academic performance.

Asghar et al. (2020) investigated the influence of EI on academic performance (AP) of engineering students. 350 students of engineering universities of northern Punjab, Pakistan, took part in the survey. The results from the analysis of variance (ANOVA) and correlation stated that there is positive influence of EI on academic performance. It was also found that senior students were found to be more emotionally intelligent than junior students.

Jafari and Eftekhari (2020) conducted a study on 100 Shiraz medical students using Bradberry's EQ tool. The results stated that there was a significant relationship between EI and academic achievement $(p=.949)$.

Chan et al. (2020) examined how EI is associated with student engagement and how EI and engagement jointly predict key learning outcomes in higher education, including the students' GPA, generic outcomes, and satisfaction with the university experience. The study adopted a prospective longitudinal design involving 560 firstyear students from 10 faculties of a university in Hong Kong. The data were collected at two-time points, namely, before the start and after the end of the student's first year in the university. Structural equation modeling (SEM) was employed to test the measurement and hypothesized models. Results indicated that EI positively predicted all dimensions of student engagement and promoted key learning outcomes (including GPA, generic learning outcomes, and student's satisfaction with the university) via the different dimensions of student engagement. The model also explained $16 \%, 44 \%$, and $38 \%$ of the student's GPA, generic learning outcomes, and satisfaction with their university experience, respectively.

Al-Musa et al. (2017) conducted a study to estimate the academic performance of students with the help of EI and economic status. 292 students of 11th standard of Aligarh district were selected. EI brought $18.4 \%$ variance in academic performance.

Moshahid and Vadakkayil (2017) conducted a study on 160 Engineering Students of Telangana, India, using Mangal EI tool. The results stated that there was a significant relationship between EI and academic performance.

Dhillon et al. (2015) conducted a study entitled "Study of EI among Adolescents Concerning Their Gender." The purpose of the study was to examine the EI of male and female adolescents, that is, 12th class students. It was found that the male adolescents were stronger emotionally than females which was attributed to the fact that male children were exposed to the more congenial physical and socio-cultural environment and become emotionally stronger than girls.

Saleem (2015) conducted a study entitled "Relationship Between EI and Academic Achievement of Postgraduate Students in Pakistan." The study intended to analyze the relationship between EI and academic achievement of students at the postgraduate level in public sector universities of Rawalpindi, Pakistan. Pearson correlation was used as a statistical technique. The findings of the study revealed that a significant relationship between EI and academic achievement of postgraduate students was found.

Umaru and Umma (2015) conducted a study entitled "Effect of Instruction in EI Skills on Locus of Control and Academic Self-efficacy Among Junior Secondary 
School Students in Niger State, Nigeria." A sample of 40 students were selected and the data were analyzed by using $t$-test. The findings revealed that EI skills were effective in moderating locus of control and improve academic self-efficacy of secondary school students.

And there was no gender difference in the effect of EI skills on the locus of control and academic self-efficacy of respondents.

Adnan (2014) conducted a study entitled "Study on EI and Religious Orientation Among Secondary School Student." The study aimed to find the differences in EI and religious orientation between students in Government and Religious secondary schools. The study compressed 224 respondents that were selected via the purposive sampling method. The EI questionnaire used in the study was based on Bar-On's EI theory while religious orientation was measured using the religion orientation scale. Collected data were analyzed using the SPSS software version 19.0. A $t$-test was used to view the differences in EI and religious orientation between students in government and religious secondary schools. The findings showed that there were significant differences in EI, but no difference was seen in religious orientation between students from government and religious secondary schools.

Gupta and Huang (2014) conducted a study entitled "EI Among Students Concerning Type of School, Locality \& Gender: A Comparative Study." The purpose of the study was to examine EI among secondary school students concerning the type of school, locality, and gender. The descriptive survey method was adopted for this study. A sample of 200 secondary school students studying in 10 standards was selected randomly from the Jind district. Mangal EI tool was used for data collection. Different statistical techniques were used such as Mean, $S D$, and $t$-test. The findings of the study showed that female students were more emotionally intelligent in comparison to male students. It was also found that students belong to the urban area and private school students were highly emotionally intelligent than their counterparts.

Jenaabadi (2014) conducted a study on the relationship between EI and SelfEsteem with Academic Achievement. It was a descriptive-correlative study. The investigator aimed to find out the relationship between EI and self-esteem with academic achievement. The statistical population of the study included 2,000 students of Kahnooj Payam-e Nour University, 300 students (150 females and 150 males) were selected randomly as a sample. Bar-Ann's EI questionnaire and Pop's self-esteem questionnaire were used to collect data. Findings showed that EI and self-esteem of students did not affect their academic achievements and selfesteem. Findings further revealed that female students were stronger than male students in EI.

Sharma (2014) conducted a study entitled "EI Predictor of Academic Performance?" A sample of 200 senior secondary students (male and female) was selected randomly from the Delhi region. The finding showed a positive correlation between EI and academic performance which means that students with high EI have better academic performance in their scholastic achievements. The study also found that there was a significant difference between the mean academic performance scores of students having high and low EI.

Nwadinigwe and Azuka-Obieke (2012) conducted a study entitled "The Impact of EI on Academic Achievement of Senior Secondary School Students in Lagos, 
Nigeria." A sample of 156 students was selected randomly from three senior secondary schools from Nigeria. The schools were randomly assigned to two treatment conditions (EI training techniques) and control groups. The hypotheses were tested using the descriptive statistical technique such as analyses of covariance (ANCOVA) and Pearson product-moment correlation coefficient. The findings revealed that a positive relationship between EI skills and academic achievement such that developing the EI skills of a student will lead to the enhancement of his/her academic achievement.

Sekar and Lawrence (2016) conducted a study entitled "Role of EI in Managing Academic Stress." The purpose of the investigator was to major academic stressors and how to manage the academic stress by using EI. The study was based on engineering students in South Tamil Nadu, concentrated on six districts, and the researcher collected 510 samples from engineering college students. Students' academic stress scale (SASS) and EI scale (EWAS) were used for data collection. The study concludes that EI was a key to manage academic stress and creating a pleasant environment for the students and supports them to present their best.

Sharma et al. (2012) conducted a study entitled "EI \& Academic Motivation Among Adolescents: A Relationship Study." A sample of 156 (78 boys and 78 girls) Class XI of Allahabad city were selected. Test of EI (student-form) developed by K. S. Misra and academic motivation inventory developed by J. P. Srivastava were used for the study. To analyze the data product-moment coefficients of correlation and ANOVA were used. The findings revealed that EI and academic motivation were positively correlated. The findings further revealed that students with high, moderate, and low academic motivation differ from one another on EI.

Festus and Ekpete (2012) conducted a study entitled "The Relationship Between EI and Academic Achievement of Senior Secondary School Students in the Federal Capital Territory, Abuja." A sample of 1,160 senior secondary school students was selected through a proportionately stratified sampling technique. The instruments used for the study were the EI inventory by, YingMing et al. (2007), and the mathematics achievement test developed by the researcher. Mean and Pearson product-moment correlation statistical techniques were used to analyze the data. The findings revealed that a significant low positive relationship between the EI of SS2 students and their academic achievement in Mathematics.

Muhammad et al. (2011) conducted a study entitled "Relationship Between EI and Academic Achievement Among Higher Secondary School Students." The Bar-On Emotional Quotient Inventory was used for data collection. The academic achievement of the participants was measured through their annual findings. Pearson correlation and $t$-test statistical techniques were used to analyze data. Findings revealed that a significant relationship was found between the two constructs. Firstborn students scored high on EI as compared to later-born students. Urban area students scored high as compared to rural area students in EI. The result further revealed that in terms of EI female students scored high as compared to male students.

Osho et al. (2010) conducted a study entitled "Emotional Intelligence and Selfregulation among School-going Adolescents: Self-efficacy as a Mediator." The study investigated the mediating effects of self-efficacy on the relationship between EI and self-regulation among school-going adolescents. A total of 467 
adolescents from 10 schools in Ogun State, Nigeria, were selected. Findings showed among others that (a) self-efficacy, self-regulation, and EI were severally positively related (b) there was a significant 66 relationship between EI and selfregulation, and (c) no relationship existed between EI and self-regulation while adjusting for self-efficacy, indicating complete mediating effects of self-efficacy on the EI and self-regulation relations. Based on the findings, it was established that self-efficacy was a strong factor in the relationship between EI and self-regulation.

Olatoye et al. (2010) studied "EI, Creativity and Academic Achievement of Business Administration Students." The purpose of the investigator was to investigate the extent to which the level of creativity and EI influenced the level of academic achievement of higher national diploma business administration students of polytechnics in the southwestern states of Nigeria. A sample of 235 students was selected. There was a very low negative, no significant relationship between creativity and CGPA scores. Findings further revealed that no significant difference between male and female students in academic achievement, creativity, and EI.

The studies conducted so far by MacCann et al. (2020), Asghar et al. (2020), Adnan (2014), Gupta and Huang (2014), Arcari et al. (2014), Sharma (2014), Pinyol and Sabater-Mir (2013), Sharma et al. (2012), Sekar and Lawrence (2016), and Joibari and Mohammadtaheri (2011) confirm that EI directly influences academic performance, however the extent varies from situation to situation. The studies also state that an increase in the EI will lead to better academic performance and vice versa. The studies of Jafari and Eftekhari (2020), Moshahid and Vadakkayil (2017), Jenaabadi (2014), Javed and Nasreen (2013), Festus and Ekpete (2012), and Olatoye et al. (2010) confirm that EI does not directly influence academic performance.

\section{Research Gap}

The gaps identified in this chapter are arrived after reviewing 25 papers spanning across a decade. Findings from the review of literature, do not converge to establish the relationship between EI and academic performance, because the studies conducted thus far by MacCann et al. (2020), Asghar et al. (2020), Adnan (2014), Gupta and Huang (2014), Arcari et al. (2014), Sharma (2014), Pinyol and SabaterMir (2013), Sharma et al. (2012), Sekar and Lawrence (2016), and Joibari and Mohammadtaheri (2011) confirm that EI directly influences academic performance, however the extent varies from situation to situation. The studies also state that an increase in the EI will lead to better academic performance and vice versa. The studies of Jafari and Eftekhari (2020), Moshahid and Vadakkayil (2017), Jenaabadi (2014), Javed and Nasreen (2013), Festus and Ekpete (2012), and Olatoye et al. (2010) confirm that EI does not directly influence academic performance. The published research has focused on the relationship between EI and academic performance of students in the Middle East and Africa (Adnan, 2014; Kumar, 2009; MacCann et al., 2020; Pinyol \& Sabater-Mir, 2013; Joibari \& Mohammadtaheri, 2011; Oke, 2006; Parker, 2005; Petrides et al., 2004; Asghar et al., 2020; Sekar \& Lawrence, 2016). This is a geographical limitation as the results can vary in India due to cultural differences and the academic evaluation standards. There is a paucity of published research on the relationship between EI 


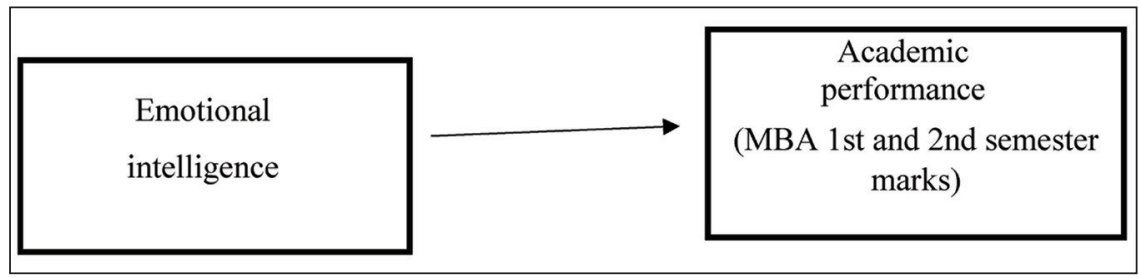

Figure 3. Conceptual Model

Source: Authors' own.

and academic performance of postgraduate students in India. Thereby, a population void is identified.

\section{Conceptual Model}

This conceptual model shown in Figure 3 is developed based on the gaps identified in the research. This model focusses on understanding the influence of EI (independent variable) on the academic performance (dependent variable) of students.

\section{Research Methodology}

\section{Research Question}

Does EI affect academic performance of students?

\section{Objective}

To understand the influence of EI on academic performance of MBA students.

\section{Hypothesis}

EI has an influence on academic performance of MBA students.

\section{Tool}

The scale used for this study is Warrier's EI tool which comprises of 49 EI Quotient Questions with six subcategories such as self-awareness and impulse control, response to adversity, pro-social behavior, inspirational leadership, optimism, and tolerance to ambiguity, achievement orientation. The scale was developed to measure the EI.

The EI Questionnaire-Warrier's EI Scale 2.0 comprises of two parts. The first section comprises the demographic questions. The second section comprises of 49 EI questions in six categories. The scoring was on a 5-point Likert Scale from 1 to 5, Strongly Disagree (1), Disagree (2), Neutral (3), Agree (4), and Strongly Agree 
Table I. Norms for Measuring El

\begin{tabular}{ll}
\hline Score on 100 & Interpretation \\
\hline $90<$ & Superior El \\
$61-89$ & Good El \\
$41-60$ & Average El \\
$>40$ & Poor El \\
\hline
\end{tabular}

Source: Venkteshwar and Warrier (2018).

(5) (Schutte, 1998). The sum of the individual EI score of each respondent has been divided by the total number of EI questions, which gives the net EI score. This net EI score is considered for all other correlations with other variables.

Table 1 depicts the level of EI. Net EI score above 90 is considered superior EI; 61-89 is considered good EI; 41-60 is considered average EI; 40 and below is considered inferior EI. The interpretation of the Warrier's EI Scale is listed below after reviewing all mentioned scales:

1. Superior EI: When a person has superior EI he/she will have very high empathy, very self-aware, and be well balanced. They also tend to be extremely curious and gracious (Power, 2017).

2. Good EI: When a person has good EI, he/she will have high empathy, selfawareness, and balanced. They also tend to be curious and gracious (Power, 2017).

3. Average EI: When a person has average EI, he/she will have average empathy, somewhat self-aware, and somewhat balanced. They also tend to be not very curious and gracious (Power, 2017).

4. Poor EI: When a person has poor EI, he/she will have very low empathy, not very self-aware, and not balanced. They are not very curious and gracious (Power, 2017).

\section{Sampling Design}

A total of 200,000 students are pursuing MBA in India and close to 23,000 students in Karnataka pursue MBA. The population for this study is MBA students in Karnataka (Shiksha.com, 2017).

Sampling Frame. Sampling frame is being drawn from the target population. Sampling frame helps in narrowing down infinite respondents into required respondents for the study. Sampling frame is the list of units from which the sample is selected. According to Karnataka Administration (2016), there are four administrative divisions in Karnataka. First Division consisting of Bengaluru, Ramanagara, and Davanagere. Second Division consisting of Belagavi, Vijayapura, and Haveri. Third Division consisting of Mysuru, Haasan, and Udupi. Fourth Division consisting of Kalaburgi, Ballari, Bidar, and Koppal. There are 456 MBA colleges and 23,000 students in Karnataka (Shiksha.com, 2017).

This study was exclusively conducted for MBA students who have completed their first two semesters and have their SGPA scores with them. 
Sample Size. The samples were selected after considering sample size formulae developed by Cochran (David, 2005).

Cochran's Formula was the second formula used to calculate the sample size (David, 2005).

$$
n=\frac{n_{0}}{1+\frac{\left(n_{0}-1\right)}{N}}
$$

The Original Sample is 1,000. MBA population in Karnataka is 23,000 (Shiksha. com, 2018).

$$
\begin{gathered}
n=\frac{1000}{1+\frac{(1000-1)}{23,000}} \\
n=\frac{1000}{1.04343478} \\
\boldsymbol{n}=\mathbf{9 5 8 . 3 7}=\mathbf{9 5 8} \text { students }
\end{gathered}
$$

However, to be more precise and accurate, a sample of 960 respondents was selected for this study. As far as data analysis tool, data analysis is carried out by using SEM which was run by AMOS 20.0 Program.

\section{Sampling Method}

1. Stratified sampling was used for the study. According to Baker and Cerro (2000), this is a method in which the total population is divided into stratas. The strata are formed based on some common characteristics in the population data. In this case, the strata are divided based on the geographical location After dividing the population into geographical strata, the researcher randomly selects the sample proportionally using simple random sampling. The sample was divided based on the geographical division in Karnataka. There are four administrative divisions in Karnataka. First Division consisting of Bengaluru, Ramanagara, and Davanagere. Second Division consisting of Belagavi, Vijayapura, and Haveri. Third Division consisting of Mysuru, Haasan, and Udupi. Fourth Division consisting of Kalaburgi, Ballari, Bidar, and Koppal (Karnataka Administration, 2016).

2. Simple Random sampling was used in the next stage. There are $456 \mathrm{MBA}$ colleges and 23,000 students in Karnataka (Shiksha.com, 2020). Bangalore has 85 MBA colleges, Belagavi has 8 colleges, Mysore has 6 MBA colleges, while Kalburgi has only 4 MBA colleges. Here all MBA college names were put into a box (division-wise) and based on the lottery method, two colleges' names were drawn. MBA colleges that were eventually selected were CMS Business School (First Division), Christ Institute of Management (First Division), Institute of Management Education and Research 
Table 2. Indicating Pearson's Correlation Coefficients Between Emotional Intelligence and Academic Performance

\begin{tabular}{llc}
\hline Emotional Intelligence Factors & & $\begin{array}{c}\text { Academic } \\
\text { Performance }\end{array}$ \\
\hline Overall emotional intelligence & & $\mathbf{0 . 5 2 0 * *}$ \\
& Self-awareness and impulse control & $0.812^{* *}$ \\
& Response to adversity & $0.708^{* *}$ \\
& Pro-social behavior & $0.564^{* *}$ \\
& Inspirational leadership & $0.427^{* *}$ \\
& Optimism and tolerance to ambiguity & $0.302^{* *}$ \\
& Achievement orientation & $0.302^{* *}$ \\
\hline
\end{tabular}

Source: Survey.

Note: ** Correlation is significant at the 0.0 l level (2-tailed).

(Second Division), Center for PG Studies (Second Division), Cauvery Degree College (Third Division), Anjuman Institute of Technology and Management (Third Division) and Doddappa Appa Institute of Master of Business Administration (Fourth Division).

3. The students were selected based on convenient sampling as it required them to fill up the EI and the study skills questionnaire.

Inclusion Criteria. This study was exclusively conducted for MBA students who have completed their first two semesters and have their SGPA scores with them. Students who have not yet completed their first two semesters or do not have their SGPA scores of the first two semesters have been excluded from the study.

\section{Data Analysis}

\section{Analysis Based on Correlation}

As shown in Table 2, a Pearson product-moment correlation coefficient is computed to assess the relationship between EI and academic performance of MBA students. The consolidated strength of the relationship between EI and academic performance was found to be moderate at 0.520 . Although the relationships between EI and academic performance were found to be significant at 0.01 , however the strongest correlation is between self-awareness and impulse control and academic performance (0.812), and the weakest correlation is between optimism, tolerance to ambiguity, achievement orientation, and academic performance (0.302). The hypothesis exhibits a significant relationship existing between EI and academic performance. The studies conducted so far by Parker (2004), Petrides et al. (2004), Gupta and Huang (2014), Arcari et al. (2014), Sharma (2014), and Asghar et al. (2020) clearly state that EI has a direct impact on academic performance.

\section{Findings and Discussion}

There is a significant relationship between EI and academic performance. The relationship between EI and academic performance was moderate. The studies 
conducted so far by Parker (2004), Petrides et al. (2004), Gupta and Huang (2014), Arcari et al. (2014), Sharma (2014), and Asghar et al. (2020) clearly state that EI has a direct impact on academic performance. It is indicated that students in a random population of MBA students with higher EI perform exceptionally well in academics when compared to students with lower EI (Petrides et al., 2004). Students with higher EI are socially responsible and are focused on achieving the academic rigor set by the higher educational institutions, making them an asset to the institute and society at large.

\section{Implications}

Educational Implications. Educational institutions must create awareness on "EI to all the stakeholders - teachers, students, parents, management through symposiums, seminars, motivational videos and case studies." Annual computation of EI of a student has to be made mandatory at an institutional level. Systematic and Consistent training of EI in institutions is imperative.

Societal Implications. Establishing centers of EI that focus on Training and Coaching of EI has to be widely implemented. These centers should focus on identifying lacunae in individuals and can concentrate on enhancing their EI skills.

Recommendation to the Ministry of Human Resource Development/Education. The Ministry of HRD should create awareness on EI to all the stakeholders. They need to ensure annual EI computation of a student, which has to be made mandatory at an institutional level. They need to ensure EI measurement scales are easily available to facilitate self-assessment. Evaluation of EI for the selection of students in schools and colleges should become mandatory throughout the country. EI should become a parameter of assessment in institutes as a part of their holistic system of education. EI needs to become a paper in UGC NET/SET examination so that academicians will be better equipped to handle students. EI should be added to the high school curriculum as a core subject to help students understand the role of EI from a young age.

Blueprint. UGC can implement the above blueprint in all institutes, schools, and universities across the country to ensure EI is given its due in higher education. The blueprint of MHRD is shown in Figure 4.

\section{Limitations of the Study}

For this study of EI and academic performance, the geographical span was limited to Karnataka state and only the MBA students were considered for the study. There was no equal distribution of gender in the sample. The balance of the government-private university was also not maintained.

Social desirability in the self-report measure can lead to inaccuracy in the data collected. The respondent could be a victim of leniency effect. The limited size of the sample is not adequate to make further conclusions. 


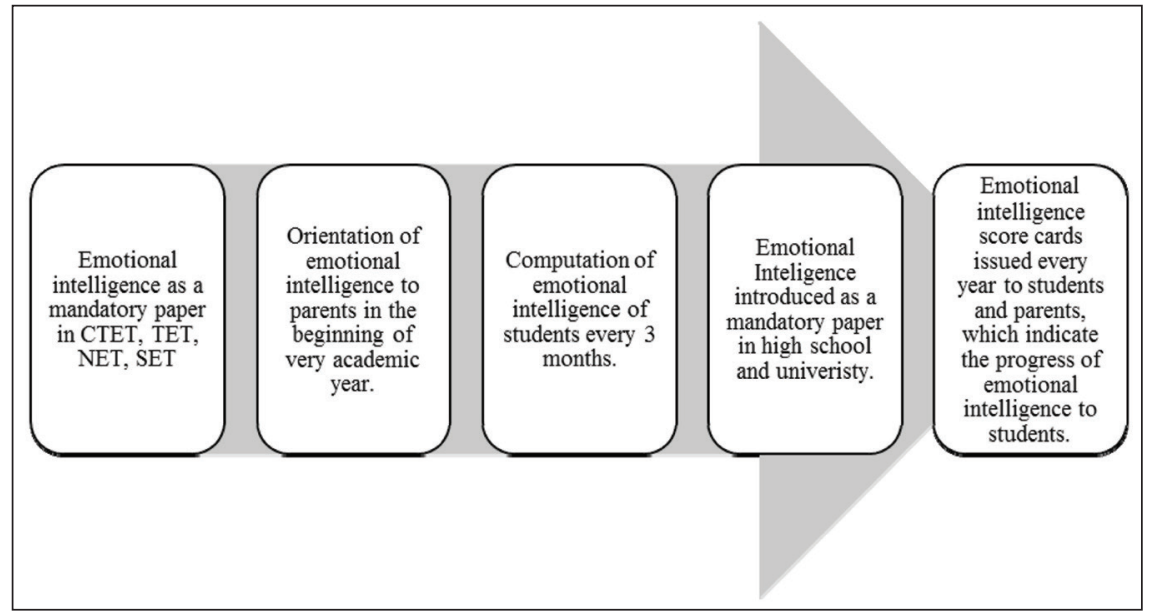

Figure 4. Blueprint for MHRD

Source: Researcher created.

\section{Suggestions for Further Research}

The modern concept of EI is in itself a youthful one. Much work has yet to be done to discover exactly what EI encompasses and how it would be most effectively applied.

The present research was limited only to the students of MBA, but academic administrators such as chancellors, vice-chancellors, directors, deans, and heads of various departments may be taken into account and research could be pursued in that area. So, further research could be done to study the relationship between the academic administrator's leadership style and EI.

Research may be carried out to understand the degree to which EI can be instructed and trained. Evidences exist in favor of and contradicting to the trainability of EI. Subsequent researches must ascertain the degree to which these training sessions are feasible and viable before an organization decides on investing substantial funds for upskilling and reskilling the employees.

\section{Conclusion}

EI has seen a rapid growth in the past decade. It has impacted every aspect of human life. Academic performance is one of the most important indicators in student life. This study identified the relationship between EI and academic performance of MBA students in Karnataka. This empirical study is based on a sample drawn from 960 MBA students in Karnataka. Warrier's EI Tool ( $a=0.887$ ) was used to collect the responses of EI.

This study along with its findings should be viewed as a starting point for more extensive research. The present research reveals that there is a close relationship between EI and academic performance. EI is effective and important 
for the successful performance of any job. Students deal with the emotions of faculty, non-teaching staff, peers, and family, therefore they need emotional management skills to handle situations that make for a healthier, productive, and rewarding life.

\section{Declaration of Conflicting Interests}

The authors declared no potential conflicts of interest with respect to the research, authorship, and/or publication of this article.

\section{Funding}

The authors received no financial support for the research, authorship, and/or publication of this article.

\section{References}

Adeoye, A. O., Oso, B. J., Olaoye, I. F., Tijjani, H., \& Adebayo, A. I. (2020). Repurposing of chloroquine and some clinically approved antiviral drugs as effective therapeutics to prevent cellular entry and replication of coronavirus. Journal of Biomolecular Structure and Dynamics, 1-11.

Adnan, H. (2014). An analysis of the factors affecting online purchasing behavior of Pakistani consumers. International Journal of Marketing Studies, 6(5), 133.

Al-Musa, H. M., Ahmed, R. A., Alsamghan, A. S., Abadi, S., Al-Saleem, M. A. S., Alsabaani, A. A. M., ... \& Alqahtani, H. A. (2017). The prevalence of symptoms experienced during menopause, influence of socio-demographic variables on symptoms and quality of life among women at Abha, Saudi Arabia. Biomedical Research, 28(6), 2587-2595.

Arcari, M., Söllner, I., Javadi, A., Hansen, S. L., Mahmoodian, S., Liu, J., ... \& Lodahl, P. (2014). Near-unity coupling efficiency of a quantum emitter to a photonic crystal waveguide. Physical Review Letters, 113(9), 093603.

Asghar, M. A., Khan, M. J., Rizwan, M., Mehmood, R. M., \& Kim, S. H. (2020). An innovative multi-model neural network approach for feature selection in emotion recognition using deep feature clustering. Sensors, 20(13), 3765.

Baker, L., \& Cerro, L. C. (2000). Assessing metacognition in children and adults.

Bar-On, R. (2004). The Bar-On Emotional Quotient Inventory (EQ-i): Rationale, description and summary of psychometric properties.

Bar-On, R., Handley, R., \& Fund, S. (2006). The impact of emotional intelligence on performance. Linking emotional intelligence and performance at work: Current research evidence with individuals and groups, 3-19.

Boyatzis, R. E., Goleman, D., \& Rhee, K. (2000). Clustering competence in emotional intelligence: Insights from the Emotional Competence Inventory (ECI). Handbook of Emotional Intelligence, 99(6), 343-362.

Chan, J. F. W., Kok, K. H., Zhu, Z., Chu, H., To, K. K. W., Yuan, S., \& Yuen, K. Y. (2020). Genomic characterization of the 2019 novel human-pathogenic coronavirus isolated from a patient with atypical pneumonia after visiting Wuhan. Emerging Microbes \& Infections, 9(1), 221-236.

David, G. C. (2005). Ergonomic methods for assessing exposure to risk factors for workrelated musculoskeletal disorders. Occupational Medicine, 55(3), 190-199.

Dhillon, G. S., Kaur, S., Pulicharla, R., Brar, S. K., Cledón, M., Verma, M., \& Surampalli, R. Y. (2015). Triclosan: Current status, occurrence, environmental risks and bioaccumulation potential. International Journal of Environmental Research and Public Health, 12(5), 5657-5684. 
Festus, C., \& Ekpete, O. A. (2012). Improving students' performance and attitude towards chemistry through problem-based-solving techniques (pbst). International Journal of Academic Research in Progressive Education and Development, 1(1), 167-174.

Goleman, D. (1995). Emotional intelligence. Bantam Books, Inc.

Gupta, B., \& Huang, S. (2014). Mechanism of salinity tolerance in plants: Physiological, biochemical, and molecular characterization. International Journal of Genomics, 2014.

Jafari, N., \& Eftekhari, K. (2020). Novel coronavirus in a 15-day-old neonate with clinical signs of sepsis, a case report. Infectious Diseases, 52(6), 427-429.

Javed, N., \& Nasreen, A. (2013). The role of emotional intelligence in academic performance of male and female students in the University of the Punjab. Methodology, 5(4), $116-122$.

Jenaabadi, H. (2014). Studying the relation between emotional intelligence and selfesteem with academic achievement. Procedia-Social and Behavioral Sciences, 114, 203-206.

Joibari, A., \& Mohammadtaheri, N. (2011). The study of relation between emotional intelligence and students' academic achievement of High Schools in Tehran city. Procedia-Social and Behavioral Sciences, 29, 1334-1341.

Karnataka Administration. (2016, June 31). Karnataka Government. https://www. karnataka.gov.in/english

Kumar, A. (2009). Who gambles in the stock market? The Journal of Finance, 64(4), 1889-1933.

MacCann, C., Jiang, Y., Brown, L. E., Double, K. S., Bucich, M., \& Minbashian, A. (2020). Emotional intelligence predicts academic performance: A meta-analysis. Psychological Bulletin, 146(2), 150.

Mayer, J. D., \& Salovey, P. (2007). Mayer-Salovery-Caruso emotional intelligence test. Multi-Health Systems Incorporated.

Moshahid, M., \& Vadakkayil, S. T. (2017). Role of involvement in activities for enhancing professional capacities (EPC) in developing the teaching ability of prospective teachers of two-year B.Ed. programme. Jamia Journal of Education, 3(2), 136-150.

Muhammad, F., Guo, M., Qi, W., Sun, F., Wang, A., Guo, Y., \& Zhu, G. (2011). pH-triggered controlled drug release from mesoporous silica nanoparticles via intracelluar dissolution of $\mathrm{ZnO}$ nanolids. Journal of the American Chemical Society, 133(23), 8778-8781.

Nwadinigwe, I. P., \& Azuka-Obieke, U. (2012). The impact of emotional intelligence on academic achievement of senior secondary school students in Lagos, Nigeria. Journal of Emerging Trends in Educational Research and Policy Studies, 3(4), 395-401.

Oke, T. R. (2006). Towards better scientific communication in urban climate. Theoretical and Applied Climatology, 84(1), 179-190.

Olatoye, R. A., Akintunde, S. O., \& Yakasi, M. I. (2010). Emotional intelligence, creativity and academic achievement of business administration students. Electronic Journal of Research in Educational Psychology, 8(2), 763-786.

Osho, A., Mabekoje, O. O., \& Bello, O. O. (2010). Comparative study on the microbial load of Gari, Elubo-isu and Iru in Nigeria. African Journal of Food Science, 4(10), 646-649.

Oyerinde, K., Harding, Y., Amara, P., Garbrah-Aidoo, N., Kanu, R., Oulare, M., ... \& Daoh, K. (2013). A qualitative evaluation of the choice of traditional birth attendants for maternity care in 2008 Sierra Leone: implications for universal skilled attendance at delivery. Maternal and Child Health Journal, 17(5), 862-868.

Parker, J. D. (2005). The relevance of emotional intelligence for clinical psychology. International Handbook of Emotional Intelligence, 271-288. 
Parker, S. C. (2004). The economics of self-employment and entrepreneurship. Cambridge University Press.

Petrides, K. V., Frederickson, N., \& Furnham, A. (2004). The role of trait emotional intelligence in academic performance and deviant behavior at school. Personality and individual differences, 36(2), 277-293.

Pinyol, I., \& Sabater-Mir, J. (2013). Computational trust and reputation models for open multi-agent systems: A review. Artificial Intelligence Review, 40(1), 1-25.

Power, R. (2017). 7 qualities of people with high emotional intelligence.

Saleem, H. (2015). The impact of leadership styles on job satisfaction and mediating role of perceived organizational politics. Procedia-Social and Behavioral Sciences, 172, $563-569$.

Sekar, J., \& Lawrence, A. S. (2016). Emotional, social, educational adjustment of higher secondary school students in relation to academic achievement. Journal on Educational Psychology, 10(1), 29-35.

Sharma, A., Gur, R., \& Bhalla, P. (2012). Kuppuswamy's socioeconomic scale: Updating income ranges for the year 2012. Indian Journal of Public Health, 56(1), 103-104.

Sharma, S. (2014). Understanding emotion regulation and child abuse in adolescence. International Journal of Innovation and Applied Studies, 6(3), 580.

Shiksha.com. (2017). Discover colleges, courses \& exams for higher education in India. https://www.shiksha.com/

Shiksha.com. (2018). MBA colleges in Karnataka - Fees, courses, placements, cut off, admission. https://www.shiksha.com/mba/colleges/mba-colleges-karnataka

Shiksha.com. (2020). MBA colleges in Karnataka - Fees, courses, placements, cut off, admission. https://www.shiksha.com/mba/colleges/mba-colleges-karnataka

Umaru, Y., \& Umma, A. (2015). Effect of instruction in emotional intelligence skills on locus of control and academic self-efficacy among junior secondary school students in Niger State, Nigeria. Journal of Education and Practice, 6(18), 164-169.

Venkteshwar, A., \& Warrier, U. (2018). The impact of family type on the emotional intelligence of net generation students. International Journals of Multi-Dimensional Research, 6(7), 247-256.

Warrier, U., John, M., \& Warrier, S. (2021). Leveraging emotional intelligence competencies for sustainable development of higher education institutions in the new normal. FIIB Business Review, 10(1), 62-73. 


\title{
Ace V. Simpson, Leadership Lessons from the Bhagavad Gita, SAGE Publications, New Delhi, 2020, pp. xxiv + 310
}

\author{
Reviewed by: Sanjoy Mukherjee, Sustainability and Liberal Studies, \\ Indian Institute of Management (IIM) Shillong, India
}

Among the wisdom literature the world over, Shrimat Bhagavad Gita has a very unique position and is of immense significance - both spiritual or philosophical and empirical or functional. Illustrious scholars and thinkers across countries, cultures, and time have searched for insights and direction and found their answers and solace in this book. In the West, scientists such as Warner Heisenberg and Robert Oppenheimer, American Transcendentalists such as Henri David Thoreau and Ralph Waldo Emerson, literary masters such as T. S. Eliot and Hermann Hesse, philosophers and psychologists such as Aldous Huxley and Carl Gustav Jung, among many others, have drawn inspiration from this celebrated text and that has been documented in their works. In India, classical philosophers such as Adi Shankaracharya, Ramanuja, and Madhwa handed down to us their own commentaries and interpretations for future studies and research. Among the modern seers and spiritual masters, Swami Vivekananda, and especially Sri Aurobindo, have enlightened us with their profound insights and also practical guidance from the Gita suited to our times.

Beyond the domain of pursuit of knowledge, there have been great Indian leaders such as Gandhi and Tilak, former Indian Presidents such as Dr S. Radhakrishnan and Dr A. P. J. Abdul Kalam who have written and highlighted the significance of the Gita in their writings and discussions. Even in the field of management, leaders of thought and action, academics and practitioners across the world have referred to this scriptural text to draw inspiration and insights into leadership and teamwork, personality development and motivation, counselling and communication, values and ethics, decision-making and conflict resolution, as well 
as stress management in times of crisis. The uniqueness of the Gita as a remarkable exception in the genre of spiritual literature is that here the highest wisdom on life and work has been transmitted by the Divine Master (Shri Bhagavan) to the protagonist disciple (Arjuna) in a moment of acute crisis in a battlefield where a violent drama of death and destruction was waiting to unfold. Just before the beginning of the battle of Kurukshetra, Arjuna was facing the crisis (orchestrated and perpetrated in a planned manner by the Lord) arising out of a conflict of values: rational versus emotional. The universal appeal and relevance of the Gita is that the crisis and the message of resolution thereof are applicable to one and all in the battlefield of life, across time and space, and traditions and cultures.

The discipline of management and leadership is no exception. There had been several veteran management academics such as S. K. Chakraborty, Gouranga P. Chattopadhyay, Subhash Sharma, among many others, who have written extensively on this subject. Of late, a significant contribution in this domain has been made by the Debashis Chatterjee, Director of Indian Institute of Management (IIM) Kozhikode, in his insightful book, Timeless Leadership, highlighting 18 Sutras of the Gita for leadership excellence worldwide.

Ace V. Simpson, the author of the present book under review, who was introduced to the Gita by his father at the age of five, is an eminent Reader in Human Resource Management and Organizational Behavior at Brunel Business School, Brunel University London. In the Preface he has clearly mentioned that the main purpose of this book is to present his 'Linked Leadership Model' derived from the perennial Indian concept of yog (union). Along one dimension, a linked leader is linked or connected with himself/herself through "self-leadership" while with the world or others through "servant leadership." Along the other dimension, he/she is connected with the environment through "holistic systems" while with the Divine through "higher purpose" (p. x) adequately illustrated with a diagram (p. xxi). This model is the author's original contribution to leadership literature and has been discussed in detail in the last chapter (Chapter 19) of the book.

The book has been divided into three sections, following the traditional approach to the text, each comprising six chapters though the theme and focus of these sections as presented in this book are different from the focus in interpretations by other authors or commentators. The author has candidly admitted in the Introduction that his purpose is to present a literal translation of the text and explore the inferences on leadership without trying to delve into the metaphysical claims on the text. His exploration has been prompted by an attempt to search for directions and guiding light at a time of alarming 'crisis of faith in leadership' (p. xiii) of values and ethics, as evident from questionable business practices including stakeholder relationships.

The merit of the book is that it follows a structured approach that suits the modern managerial orientation and leadership imperative. The author deals with a particular theme, covering one particular aspect of leadership, in each of the 18 chapters. There is then a subsequent systematic evolution of the chapter through a number of sub-themes, each comprising a number of verses in that chapter, in a chronological sequence. After completing the translation of the verses under a sub theme, the author engages in 'Reflections' where he presents the leadership 
insights and applications drawn from that sub theme. Finally, he concludes each chapter with a Summary of Leadership Lessons drawn collectively from the Reflections of each of the sub themes. The use of tables to illustrate many aspects of the wisdom and the categories thereof (like the impact of the three gunas on knowledge, action, motivation, food, penance, sacrifice, etc.) across the chapters of the books will be useful for leaders in the present organizational context. The practical and experiential aspect of the wisdom of the Gita, as illustrated in Tables 6.2 and 6.3 (pp. 100, 102), giving details of the processes and benefits of meditation (yog), deserve special mention in this regard.

Another merit of the book is that the author has given a complete and lucid translation of the 700 verses of the original in Sanskrit. While translating the text, the author has also honestly and rightly confessed that many of the classical Indian terms (in Sanskrit) like karma cannot be adequately translated because of a paradigmatic difference between the Western and ancient Indian tradition and thought. This is indeed true because a loose and causal translation in the conventional manner often dilutes the original meaning and lends a millennia old wisdom literature and its messages subject to misinterpretation and instrumental use of such wisdom purely for purely commercial gains losing out entirely on the deeper significance of insights into meaning of work and purpose of life. We hope that Simpson's erudition in Indian philosophy and respect for the ancient wisdom will be a safeguard against any such attempts in dilution or manipulation.

A few observations may be pertinent here. The original Indian word is yog not yoga as abundantly used and grossly misused today and largely commercialized and instrumentalized even in the field of business and management. Use of the original word may help in authentic presentation, proper interpretation, and wholesome application of the wisdom of the Gita. The author had admitted the problem of translation of the spirit of the original Sanskrit terms in the beginning. In the same vein, one may observe that the deeper meaning of the three gunas — sattva, rajas, and tamas - cannot be captured by goodness, passion, and ignorance only. There are more profound and functionally important connotations of these three psychological forces along multiple layers of our understanding or consciousness. The seminal lifelong contribution of the late Professor S. K. Chakraborty, Founder-Convener, Management Centre for Human Values (MCHV), Indian Institute of Management (IIM) Calcutta, has been documented in his prolific writings covered in his several books on this subject. Absence of mention of his monumental and most significant work on this subject in management and leadership has been a glaring omission in the References.

But all this does not demean the merit of the book. Simpson has made a timely and significant contribution to the spectrum of management and leadership literature, adding value particularly to the discipline of Human Resource Management and Organizational Behavior. This book will be useful to thinkers and practitioners in the field of management, both in terms of concepts and applications, committed to grooming ethically enlightened, socially responsible, and ecologically conscious future leaders for organizations worldwide through authentic synthesis of the principles and practices of modern management with the timeless wisdom and pristine messages of the Bhagavad Gita. 
An episode from academic life comes to mind, narrated by Dr Subir Chowdhury, former Director, IIM Calcutta. He was on official trip to UK during which he found some time to visit his former university from where he had completed his $\mathrm{PhD}$ in Operations Research (OR). He also paid a visit to his supervisor, then a retired Professor who was a doyen in the field of OR. When he met him in his residence, Dr Chowdhury found to his utter surprise that the veteran academic was reading the Bhagavad Gita. When asked why, a prompt retort came from the old man: "I fail to understand why you people send your students here to study OR when such an authentic book on decision making is available in your country and culture." Dr Chowdhury was stunned to silence. Later he became the prime force behind the creation of MCHV, IIM Calcutta that was the most comprehensive and globally acclaimed pioneering venture to enrich the field of management with insights from the millennia old Indian ethos and Bhagavad Gita as a primary source of its inspiration.

From the corpses of soldiers killed in the Second World War in Europe were found translations of the Bhagavad Gita; it is not just a Hindu religious text or an Indian spiritual literature but a psychological handbook for mankind in an hour of crisis in the battlefield of life. 


\section{Manuscript submission}

- The preferred format for your manuscript is MS Word.

- The journal does not consider a paper that has been published elsewhere or that is under submission to another publisher. Authors must attest to this at the time of submission. It is also author's responsibility to disclose any potential conflict of interests regarding their submitted papers.

- Authors will be provided with a copyright form once the contribution is accepted for publication. The submission will be considered as final only after the filled-in and signed copyright form is received.

\section{Basic formatting of the manuscripts}

The journal publishes the following article types:

- Research Articles

- Book Reviews

- Case Studies

- Commentaries

- Perspectives

Recommended length of articles is $6000-8000$ words, inclusive of tables, figures and references. All regular/research articles must be accompanied by an abstract of up to 200 words and 4-6 keywords.

Please refer to the Submission Guidelines on the journal website for details on formatting.

\section{Spelling and numerical usages}

- Consistent use of either British or American spelling is advised, but not both at the same time.

- Spell out numbers from one to nine, 10 and above to remain in figures. However, for exact measurements use only figures (e.g. $3 \mathrm{~km}, 9 \%$ ). Please use 'thirteenth' instead of ' 13 th century'; use '1960s' instead of 'nineteen sixties'.

\section{Quotations, notes, tables and figures}

- British English uses single quotation marks to indicate quotations or dialogue, double quotation marks for quotation inside quotation (nested quotation). American English flips that method and uses double quotation marks to indicate quotations or dialogue, and single quotation marks for nested quotations. Either British or American punctuation patterns should be used and it should not be a mix.

- Notes should be numbered serially and presented at the end of the article. Notes must contain more than a mere reference.

- Tables and figures must be cited in the text, and indicated by number separately (Table 1), not by placement (see Table below). Source details for figures and tables should be mentioned irrespective of whether or not they require permissions.

- All photographs and scanned images should have a resolution of minimum $300 \mathrm{dpi}$ and 1500 pixels, and their format should be TIFF or JPEG. Due permissions should be taken for copyright-protected photographs/images.

\section{References and their text citations}

- References and their citations should be given in accordance with APA 7th edition.

- Please ensure that all references mentioned in the reference list are cited in the text and vice versa.

For detailed style guidelines, please visit https://ims.spectrumjps.com 
